Konzeption 5:

Ein Sklavenball / Pompeji - Adaptierungsarbeiten 
Ein Sreaven bale

$R$

mit gesang ind Taws.

I. Alt. 1. Bild. Dic Aliofahrt.

2. Bill. Lemmiselenis mird an den Practor varleafa.

3. Bicle. Der Untergany des Scliltr. Gestrandet:

4. Bied.

1. Bied. Die Acosfohns Lemuinclemis: Heffet mis ind ith will Eich lich!

5. Bied.

2. Bild.

Toxilan: Mid. ham mon

6. Bill.

7Lemuiselenis verfirest lin tries Dicuer maines

7. Bild.

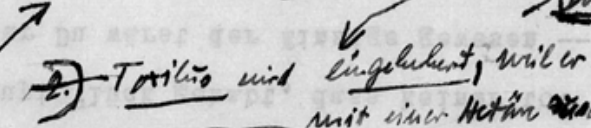

Des Sllencugenida

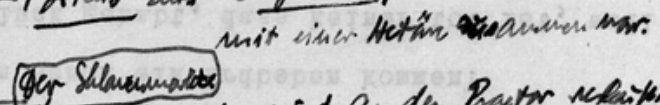

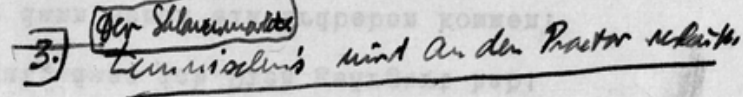

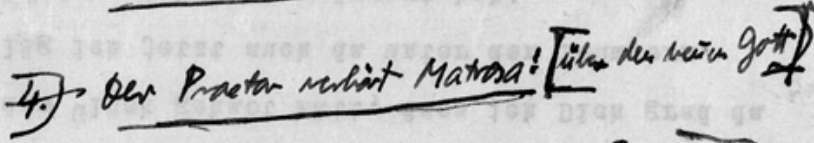

F) Totiliss in Katur trits Bagin's

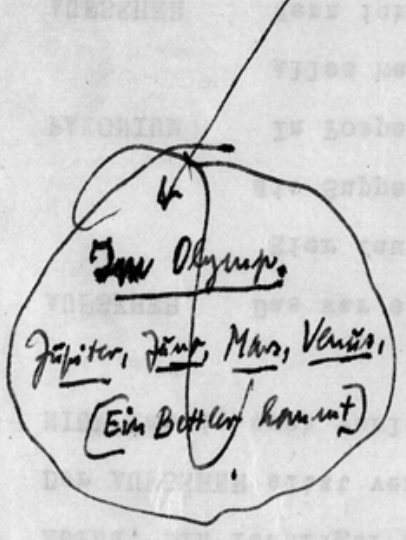

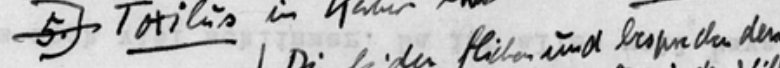

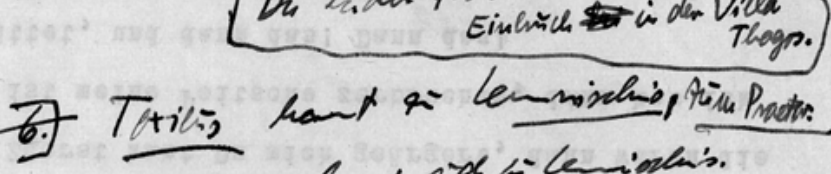

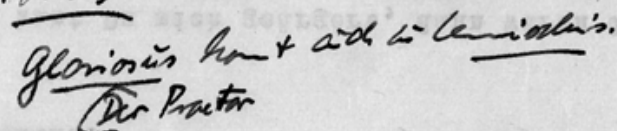

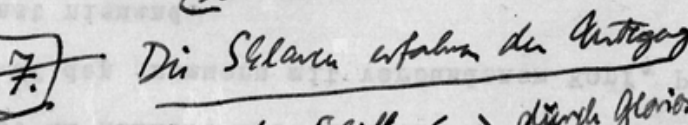

1.) Leunuisdemis unfiest Totilus.

2.) Oas Slearrageicts.

3.) Der Secanvumares.

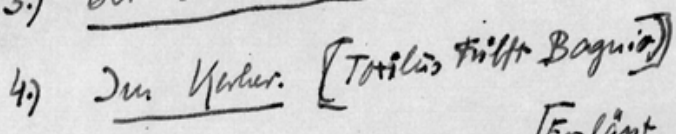

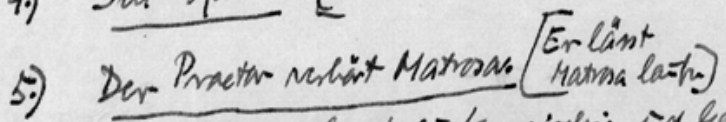
des Schiltens $\longleftrightarrow$ diende Geviosices.

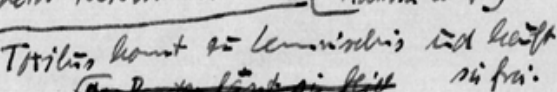

6.) Gestraper.

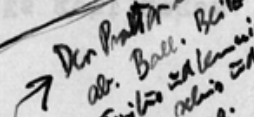
Glaisiso $=$ ad dirtima in der Nähe cinm Withle,

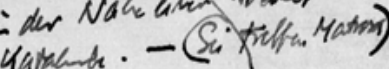

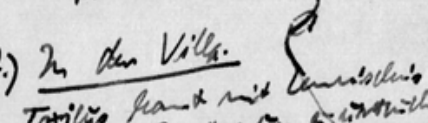

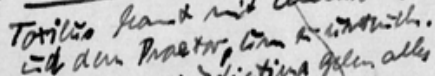

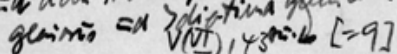




\section{Ein Sklavenball}

mit Gesang und Tanz.

I. Akt. 1. $\underline{\text { Bild. }}$ Die Ausfahrt.

2. Bild. Lemniselenis wird an den Praetor verkauft.

3. Bild. Der Untergang des Schiffes. Gestrandet.

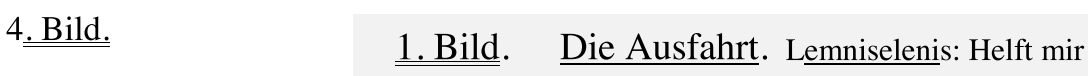

5. Bild.

2. Bild. und ich will Euch lieben!

Toxilus: Mich kann man nicht bestechen! Ich bin ein treuer Diener meines

6. Bild.

1.] Lemniselenis verführt

Herrn!

Toxilus.

7. Bild. $\left|E^{1}\right|$

Z. Toxilus wird eingekerkert, weil er [Das Sklavengericht] mit einer Hetäre zusammen war.

[Der Sklavenmarkte]

3. Lemniselenis wird an den Praetor verkauft.

4.] Der Praetor verhört Matrosa: [über den neuen Gott]

5. Toxilus im Kerker \{mit\} trifft Bagnio Die beiden fliehen und besprechen den

Im Olymp.

Jupiter, J $\underline{\text { uno, }}$ Mars, Venus,

[Ein Bettler kommt]
Einbruch $\{$ bei\} in der Villa
Thagos.

6. Toxilus kommt zu Lemniselenis, zum Praetor.

Gloriosus kommt auch zu Lemniselenis.

[Der Praetor

7. Die Sklaven erfahren den Untergang

des Schiffes $\longleftrightarrow$ durch Gloriosus.

$\mid E^{3} \backslash$
1.) Lemniselenis verführt Toxilus.

2.) Das Sklavengericht.

3.) Der Sklavenmarkt.

4.) Im Kerker. [Toxilus trifft Bagnio]

5.) Der Praetor verhört Matrosa. Er lässt Toxilus kommt zu Lemniselenis und kauft $\mid E^{4} \backslash$ [Der Praetor lässt sie flieh sie frei.
6.) Gestrandet.

Der Praetor erstaunt und

ab. Ball. Blitz.

Toxilus und Lemniselenis und

Gloriosus und Idiotima in der Nähe einer Höhle, Katakombe. - (Sie treffen Matrosa.)

7.) In der Villa.

Toxilus kommt mit Lemniselenis und dem Praetor, um sie zu untersuchen. Gloriosus und Idiotima geben alles 
Strukturplan in sieben Bildern

ÖLA 3/W 89 - BS 57 [1], Bl. 1

Eim Shavenball

Toriliss sdiclet den Azifeher fart.

1. Bied. Villa. An̆ofolert. Lemniselen is heschnät

Totiliss, iler zì helfen.

2. Bild Villa. As prees he n't Dadalis,

Totilins: Lemen ist Gefection -

Alpelen: Was?!

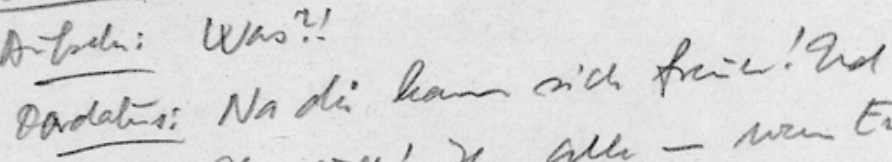

Xor aich! Xur alle - wan Enien

thar zivelhow'! (al)

Tatiliss - Lemsisuis:

Toticisi En is fort! Fide!

Atpen: Holt: Das Gehx ade off

$$
\text { inmarn Böced ains! Deine }
$$

Oas fheavingeidt.

Enchence ess jitht dis

Maslem ab

Totilis usid mitrill.

3. Bild. Shlaren malt. Leminixlemis Matrosa als Zunwag!

378 


\section{Ein Sklavenball}

Toxilus schickt den Aufseher fort.

1. Bild. Villa. Ausfahrt. Lemniselenis beschwört

Toxilus, ihr zu helfen.

2. Bild. Villa. Aufseher kommt mit Dordalus.

Toxilus: Lemni ist geflohen -

Aufseher: Was?!

Dordalus: Na die kann sich freuen! Und

Ihr auch! Ihr alle - wenn Euer

Herr zurückkommt! (ab)

Toxilus - Lemniselenis:

Toxilus: Er ist fort! Freude!

Aufseher: Halt! Das geht auch auf

unseren Buckel aus! Deine

Liebe!

Das Sklavengericht.

[nehmen erst jetzt die

Masken ab]

Toxilus wird verurteilt.

3. Bild. Sklavenmarkt. Lemniselenis wird an den Praetor verkauft Matrosa als Zuwag! 
Strukturplan in sieben Bildern (Fortsetzung)

ÖLA 3/W 89 - BS 57 [1], Bl. 2

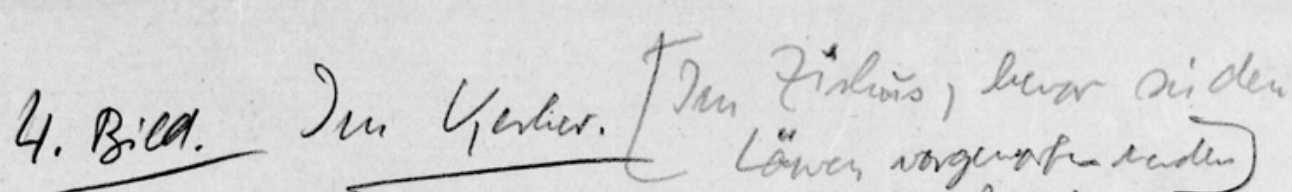

$$
\text { Tribis trilt Boguio - hide }
$$

haschiemon go fieles. Sir tirnes

Id lnder in der Villa lin, Lder

das Geed, wit den eil Len iackis fulhat lion.

5. Bild. Beim Practar.

Oer Ractar noläs Martosa wegen des veñen Gottes. - Er behtert si ale vicat lin, sandem lisist si laif. Si von areg. Alschicd risch Lenidelis od Matrosa.

Taxilio Lut wit Bagria id hult le wishis fri. Practar hut das levisd nor - er welelest Tribis Ed gets - it ith Div Vilen.

380 


\section{Bild. Im Kerker. Im Zirkus, bevor sie den}

Toxilus trifft Bagnio - beide

beschliessen zu fliehen. Sie tun es

und brechen in der Villa ein, holen

das Geld, mit dem sie Lemniselenis

freikaufen können.

\section{Bild. Beim Praetor.}

Der Praetor verhört Matrosa

wegen des neuen Gottes. - Er

kerkert sie aber nicht ein, sondern

lässt sie laufen. Sie muss weg.

Abschied zwischen Lemniselenis und

\{Praetor\} Matrosa.

Toxilus kommt mit Bagnio und

kauft Lemniselenis frei. Praetor

kommt das komisch vor - er

verhaftet Toxilus und geht mit ihm zur Villa. 
Strukturplan in sieben Bildern (Fortsetzung)

ÖLA 3/W 89 - BS 57 [1], Bl. 3

6.) Gestrandet a Meenent.

3

Glaimis $\mathrm{Ed}$ Jdiatima sid gerottct.

(Thagos bewt ach woch). In der Nähe line tyoble. Katahera. Glacans Ed

Odiatima waden lchehrit dierch Matrosa.

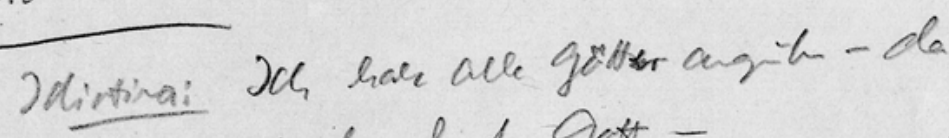
will ith den fish Gott -

Telya: Sin or gill.

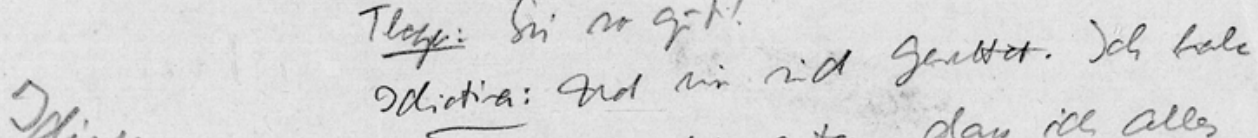
des Guloble Gitar, daw ich alles mach min Genth tain tade. Deh hals with fir Encl Geton.

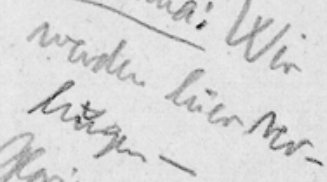


6.) Gestrandet am Meeresufer.

Gloriosus und Idiotima sind gerettet.

(Thago lebt auch noch). In der Nähe eine Höhle. Katakomben. Gloriosus und

Idiotima werden bekehrt durch Matrosa.

Idiotima: Ich hab alle Götter angerufen - da

rief ich den fremden Gott -

Thago: Sei so gut!

Idiotima: Und wir sind gerettet. Ich habe das Gelübde getan, dass ich alles

Idiotima: Wir nach seinen Gesetzen tun werde.-

werden hier verhungern -

Gloriosus: Mars, höre mich! Ich habs auch für Euch getan.

Gloriosus: Für mich? Wie kommst Du dazu? Idiotima: Du bist doch mein Mann Thago: Einen Menschen, (sie lächelt) Und ich liebe Dich wenn wir treffen halt, so wie Du bist dem schenke ich alles Siehst Du Dich noch im Schild? hier - Gloriosus: $\{\mathrm{We}\} \mathrm{Ja}$.

Idiotima: Alles? Das ist Idiotima: Was siehst Du? doch dieser neue Gott - Gloriosus: Einen dummen Jungen.

Thago: Dann bet ich zu

dem neuen Gott! Einen Menschen, wenn er uns nur schickt! Einen Menschen!

Matresa: (Singen aus der Höhle) einen, der über die Wasser gehen kann - 
Strukturplan in sieben Bildern (Fortsetzung)

ÖLA 3/W 126 - BS 58 f [2], Bl. 1v

7. Sild h Aler Vibla

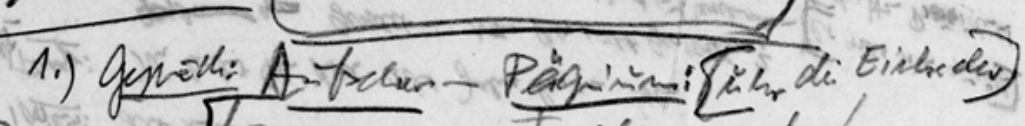

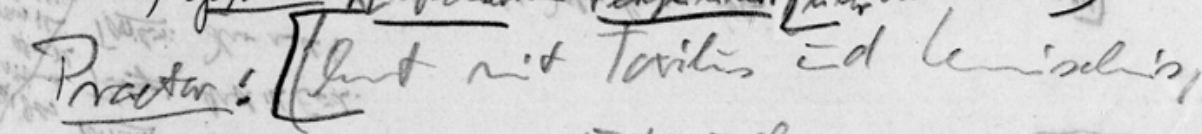
them the interizchan

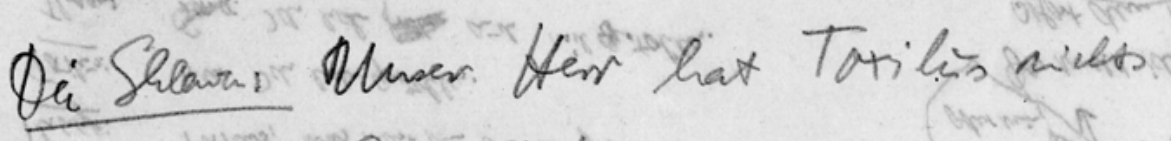
Praetar Na also!

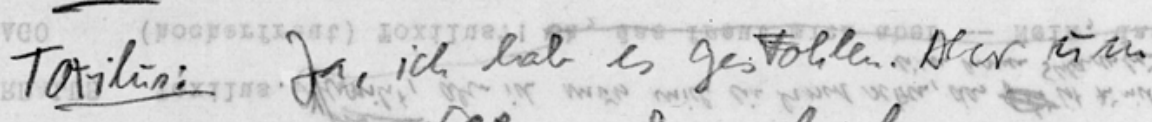

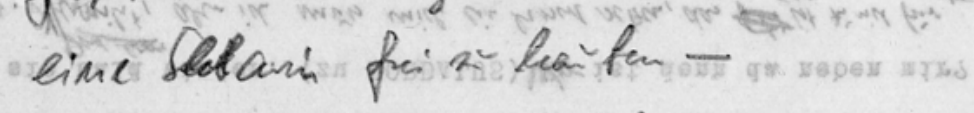

Shavin Kof line ani fi, der he Reide!

$$
\text { Bogniv: (ht - das Sclith sit }
$$

10 


\section{Bild. In der Villa.}

1.) Gespräch: Aufseher - Pägnium: [über die Einbrecher]

Praetor: [kommt mit Toxilus und Lemniselenis, um zu untersuchen -

Die Sklaven: Unser Herr hat Toxilus nichts geschenkt!

Praetor: $\quad \mathrm{Na}$ also!

Toxilus: Ja, ich hab es gestohlen. Aber um eine Sklavin frei zu kaufen -

Sklavin: Kauf eine schë arme frei, aber keine Reiche!

\{Glerio\} Bagnio: [kommt - das Schiff ist

$$
\begin{aligned}
& \text { untergegangen - grad hats mir } \\
& \text { einer erzählt] }
\end{aligned}
$$

Praetor: Das Schiff?!

$$
\text { [und Thago] }
$$

Gloriosus und Idiotima und Matrosa: [kommen]

Thago: Ich schenke alles her. Ja, es ist wahr - - Alles geb ich h \{die Hetär\} ich gab ihr das Geld.

Idiotima: Und nun gehen wir fort als

$$
\text { Bettler - fort! }
$$

Thago: Ich hab noch ein kleines Konto - (ab) 
\| Zweites Bild.

Das Sklavengericht.

$\ulcorner$ AUfSEHER Um folgendes dreht es sich: Toxilus hat egoistisch etwas begangen, was auf unser aller Buckel ausgeht -

10 Alter Natürlich! Es gibt nur einen Buckel, und das ist der unsere!

$\ulcorner$ ToxiLus Jedem und jeder von Euch habe ich geholfen - erinnert Ihr Euch?! Nun will ich heute ein Danke haben -

Aufseher Passt auf, er wickelt Euch ein!

ToxiLus Ich $\ulcorner$ wickle $\urcorner$ weder ein noch aus!

15

Aufseher Hört, Ihn Euren Wortführer, Euren Toxilus! .... (usw)

Toxilus Es geht um einen Menschen! Um einen Sklaven, wie Euch! Den liess ich fliehen!

(Die $\ulcorner$ Waagschale $\urcorner)$

20 SkLavin Lass arme fliehen, keine reichen!

$\ulcorner$ Matrosa (tritt vor) Oh Schwester! Was weisst Du von der reichen Sklaven Leid? (usw) $)^{\urcorner}$

Alter $\ulcorner$ Das Urteil: $\urcorner$ Wir alle -

Alle Ein Jeder und jede von uns -

25 (Sprechchor)

Heil! Heil! Heil!

Ein Wort ist ein Pfeil!

Alter Was soll das sinnlos Reden? Denkt doch, denkt!

Alle (denken)

30 Toxilus Nun?

Alle Es kommt nichts heraus. (Rollen unter der Erde)

Alter Was war das?

Toxilus Ein Erdbeben.

Alle Erdbeben?!

${ }_{35}\ulcorner$ (Stille $\left.)\right\urcorner$

ToxiLus Wahrscheinlich hängts mit dem Vesuv zusammen.

Alle (schauen auf den $\ulcorner$ Vesuv) $\urcorner$

AufseHer Vielleicht bricht er bald aus.

SKLAVIN Hoffentlich! Hoffentlich geht bald alles unter!

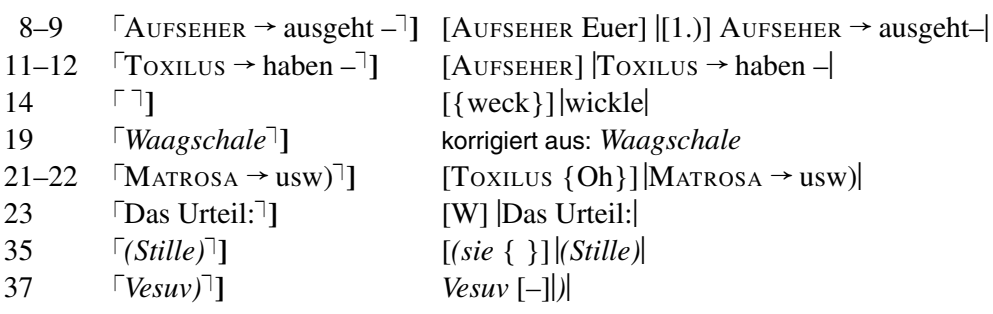


$\ulcorner\operatorname{AlteR}\urcorner$ (der Schluss) Der neue Gott -

$\ulcorner$ AUfSEHER Wer hat dir das erzählt?

Matrosa Ich.

Toxilus Es gibt $\ulcorner$ so viele $\urcorner$ neue Götter. Man weiss schon garnicht, was man glauben soll. $\ulcorner$ Ach, Lemniselenis! $`($ Rollen $\{$ unter der Erde\})

(Vorhang)

$1\lceil$ Alter $\urcorner] \quad$ [Matrosa] $\mid$ Alter $\mid$

$2 \quad\ulcorner$ AUfSEHER $\rightarrow$ erzählt? $\urcorner$ [TOXI] |Aufseher $\rightarrow$ erzählt?|

$4\lceil$ so viele $\urcorner$ korrigiert aus: soviele

$5 \quad\ulcorner$ Ach, Lemniselenis! $\urcorner \quad \backslash$ Ach, Lemniselenis!/ 
Dialogskizze zum vierten Bild

ÖLA 3/W 125 - BS 58 f [1], Bl. 4V

1 Zmits Bild.

$4 v$

$$
\text { - 3٪4-R | Virrts Bild. }
$$

Das Shlavengericht.

Totilins-Bagnia

Totilin: Th hal gemeinx, dan man

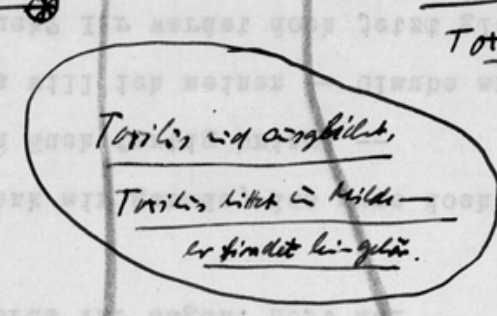

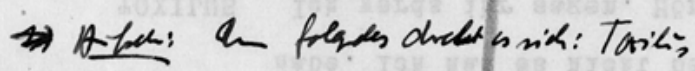
hat egaisinch etros leger, en

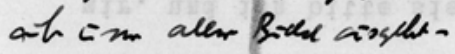

Hed: Natilix! Eo gilt ain sinen Revell, ad der it du =m!

Jeh ad jide in Gock hak ich gelolk - Sinent $x$ Eich

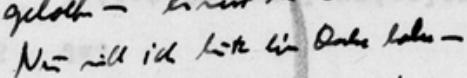

Ab: Pant arih, en wichet $E=c$ cin!

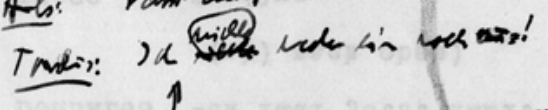

1

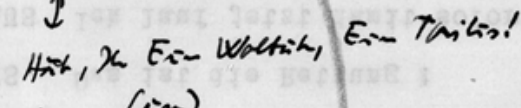
-...(in)

Tribin En quat lin ain Mand Ih ain

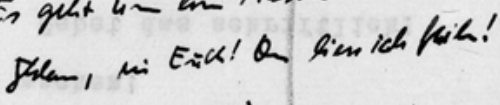

(Oii Waguded)

Selen: Lan ane feire, hin saikl

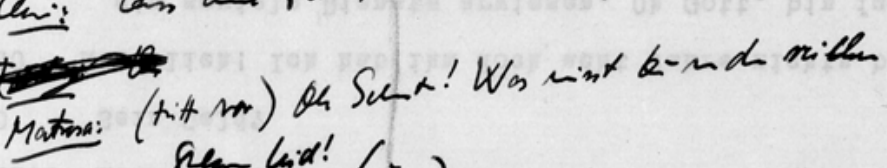
frem lind! (inm)

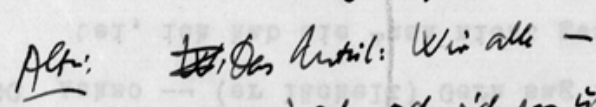

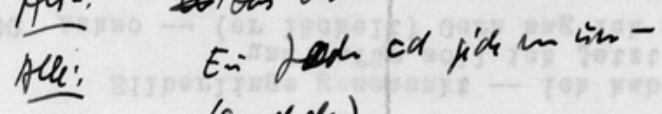
(spedder)

Hail! Hol! Kel!

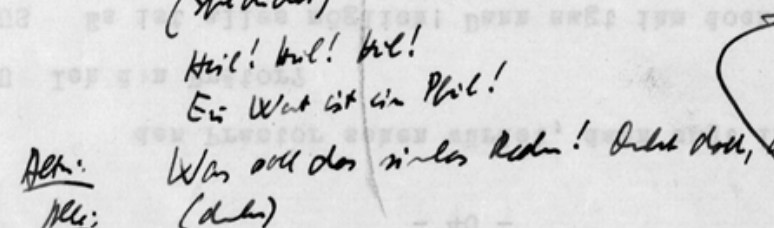
Tonilas: Now?

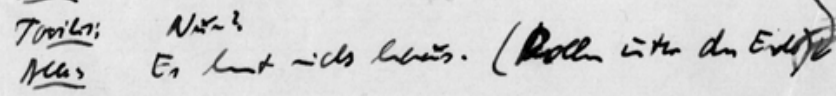

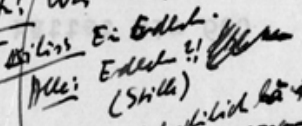

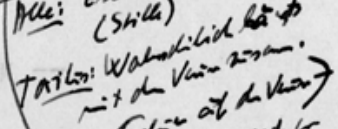

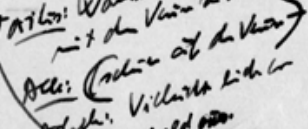

$V$ [II, $40[-6]$

388 
Zweites Bild.

\section{Das Sklavengericht.}

$$
-3 \circledast 4-
$$<smiles>C1CC2CC12</smiles>
Toxilus bittet um Milde

Aufseher: Euer er findet kein Gehör.
Viertes Bild.

\section{Toxilus $-\underline{\text { Bagnio }}$}

Toxilus: Ich hab gemeint, dass man sich wenigstens auf seine Mitsklaven verlassen kann! Aber das ist auch nichts! - Oh, wenn ich wenigstens nur wüsst, wo Lemniselenis ist!

Bagnio: Was ist das? Ein Weib?

Das klingt so Doch nicht ein Weib?

1.) Aufseher: Um folgendes dreht es sich: Toxilus hat egoistisch etwas begangen, was auf unser aller Buckel ausgeht -

Alter: Natürlich! Es geht um einen Buckel, und der ist der unsere!

Aufseher:

Toxilus: Jedem und jede von Euch habe ich geholfen - erinnert Ihr Euch?! Nun will ich heute ein Danke haben -

Aufs: Passt auf, er wickelt Euch ein! Toxilus: Ich [wickle] 1

Aufseher: Hört, Ihn Euren Wohltäter, Euren Toxilus! ... (usw)

Toxilus: Es geht um einen Menschen! Um einen Sklaven, wie Euch! Den liess ich fliehen! (Die Wagschale)

Sklavin: Lass arme fliehen, keine reichen! Foxilus: $\{\mathrm{Oh}\}$

Matrosa: (tritt vor) Oh Schwester! Was weisst Du von der reichen
Toxi Aufseher: Wer

hat Dir das erzählt? Matrosa: Ich.
Toxilus: Es gibt soviele neue

Götter. Man weiss schon garnicht, was man glauben sell. [Ach, Lemniselenis! ${ }^{\text {(Rollen }} \begin{gathered}\text { unter der Erde }\}) \\ \text { (Vorhang) }\end{gathered}$
Alter:

Matrosa: (der Schluss) Der neue Gott -
Sklaven Leid?

$$
\text { (usw) }
$$

Alter: $\quad$ WW Das Urteil: Wir alle -

Alle: $\quad$ Ein Jeder und jede von uns -

(Sprechchor)

Heil! Heil! Heil!

Ein Wort ist ein Pfeil

Alter: Was soll das sinnlos Reden! Denkt doch, denkt!

Alle: (denken)

Toxilus: Nun?

Alle: Es kommt nichts heraus. (Rollen unter der Erde)
Sklavin: Hoffentlich! Hoffentlich geht bald alles unter! (Stille)

Toxilus: Ein Erdbeben.

Alle: Erdbeben?! (sie \{ \} (Stille)

Toxilus: Wahrscheinlich hängts mit dem Vesuv zusammen.

Alle: (schauen auf den Vesuv $+\mid) \mid$ Aufseher: Vielleicht bricht er bald aus. $\mid T S^{1} \backslash$
Alter: Was war das? 
$\|$ Zweites Bild.

Am nächsten Tag. Die Luxusgaleere ist ausgefahren, $\ulcorner$ im Hafen $\urcorner$ liegt nichts.

ÖLA 3/W $112-$ BS 58 b [1], BI. 1

LEMNISELENIS (sitzt und $\ulcorner$ hat das Gesicht in den Händen verborgen) $\urcorner$

Matrosa (sitzt neben ihr; sie hat die Maske noch auf)

5 Toxilus ( $\ulcorner$ kommt, $\urcorner$ erblickt Lemniselenis und stutzt; $z u$ Matrosa) Was hat sie denn? \ulcorner\urcorner

\|Matrosa Sie weint.

ÖLA 3/W 109 BS 30 a, BI. 12

Toxilus Warum?

Matrosa Es ist ihr hier so gut gegangen und jetzt hat sie Angst vor der Zukunft.

Toxilus Aber-aber! Einen solchen schiechen alten Kracher, wie meinen gnädigen Herrn, den wird doch solch \ulcorner\urcorner liebliches $\ulcorner$ Ding $\urcorner$ immer wieder leicht finden! Direkt über Nacht!

Matrosa Unberufen!

Toxilus Sie kriegt auch junge fesche stramme --

LEMNISELENIS (unterbricht ihn) Also nur das nicht!

Toxilus (perplex) Was hör ich?

$\|$ Matrosa ( $z u$ Toxilus) Sie möcht von der männlichen Jugend nichts wissen. Wenns nach ihr ging, tät sie sich einen Herrn Gebieter aus dem Greisenasyl holen.

Toxilus Aha! Capisco! Einen gichtigen Greis, wacklig, zittrig, hirnrissig, der mit dem einem Haxen bereits durch die Unterwelt hatscht und von dem sich gar federleicht allerhand erben lässt -- schau-schau! Mit himmelblauen Pupillen blickt die Unschuld geschäftstüchtig in die $\ulcorner$ Welt. Jaja $\urcorner$, im Kontor der Tugend wird mit der Jugend gar häufig gewuchert!

LEMNISELENIS Ihr versteht mich nur halb.

Toxilus Möglich. Denn die eine Hälfte, dass Ihr nämlich von der männlichen Jugend überhaupt nichts wissen wollt -- diese Hälfte kapier ich überhaupt nicht!

$\|\ulcorner\urcorner$ LEM Diese Hälfte kann ich mir nicht leisten. Aber Ihr dürft nicht annehmen, dass ich mit unerlaubten Mitteln -\ulcorner\urcorner$\|$ als da sind: böse Kräuter, Schlangengift, etcetera -- das Ableben eines gebrechlichen Gebieters beschleunigen wollte. Ich würde auch nimmer ein massgebliches Wort in seinem Testament fälschen, aber ich tät ihm die Schrecken der Unterwelt ausmalen, und das fiele mir leicht, denn ich müsst ihm doch nur vom Schicksal der Sklaven auf der Oberwelt berichten. Die Haare würden ihm alle gen Himmel stehen und er würd mich vor lauter Grauen garantiert freikaufen, um nicht in der Unterwelt als Sklave verhandelt zu werden, als ein Ding mit menschlichen Allüren -- Oh Götter, es fällt mir immer schwerer an Euere Güte zu glauben! Sagt mir: gibt es Euch denn überhaupt? Und wenn es Euch gibt, warum seid Ihr denn so böse zu mir? Wie gern würde ich gut sein --

ToxiLus Das ist ein Traum.

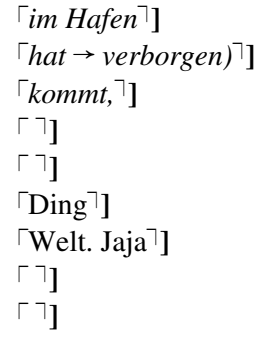

[der] |im Hafen $\mid$

[weint [)$] \mid$ still vor sich hin; $] \mid$ hat $\mid \rightarrow$ verborgen $) \mid$

kommt [und] |,|

gestrichen: (S. 9[)] |- 10)|

[ein junges]

$[\mathrm{K}]|\mathrm{D}| \mathrm{in}[\mathrm{d}]|\mathrm{g}|$

Welt./ [--] [j]|J|aja

gestrichen: bis:

gestrichen: $\overline{\overline{(\mathrm{S} .}}$ 11)
ÖLA 3/W 109 BS $30 \mathrm{a}, \mathrm{Bl} .13$ BS 30 a, Bl. 14 
Matrosa ( $z u$ Toxilus) Sie hat eine zarte Seele.

Toxilus ( $z u$ Matrosa) Was verstehst Du unter Seele?

$\|$ LEMNISELENIS Was sich aus einem fortsehnt.

ÖLA 3/W 112 -

$\ulcorner$ (Amor-Szene $)$

5 PäGNIUM $\ulcorner$ (läuft $\urcorner$ rasch $\ulcorner$ von links herbei und hinter die Villa $\urcorner$, verfolgt vom $\ulcorner$ Aufseher, der ${ }^{\urcorner}$ihn mit der Peitsche verfolgt)

Aufsener Lausbub, elender! \ulcorner\urcorner$\left\ulcorner\right.$ Ich $^{\urcorner}$soll ein Aff sein?! $\ulcorner$Beim Jupiter, das halt ich nicht aus! Na wart! (er will ihm nach)

Toxilus Halt! \ulcorner\urcorner$\|$ Du wirst doch da nicht herumprügeln, wo wir Sklaven jetzt sozusagen untereinander sind?!

AufseHer Das ist mir wurscht!

$\ulcorner$ ToxiLus $\urcorner$ Mir aber nicht!

AUfSEHER Das ist mir erst recht wurscht!

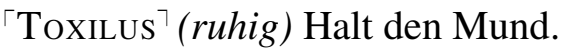

15 Aufseher (braust auf) Was erlaubst Du Dir --

$\left\ulcorner\right.$ ToxiLus ${ }^{\urcorner}$(unterbricht ihn) Kannst Du lesen?

Aufseher (perplex) Nein.

Toxilus Dann schau her -- (er zeigt ihm ein Dokument) Während der Abwesenheit unserer Herrschaft wurde ich, ich Toxilus, zum obersten Verwalter dieser Villa eingesetzt, \ulcorner\urcorner$\ulcorner$ verstanden?! $\urcorner$ Denn ich geniesse das restlose Vertrauen meines Herrn, verstanden?! Und hier hat mir nun jeder zu gehorchen, $\ulcorner$ denn $\urcorner$ ich bin die höchste Instanz, bitt ich mir aus!

$\|\ulcorner$

LEM (horcht auf)

$25 \|\left\ulcorner\right.$ Toxilus ${ }^{\urcorner}$Also los-los, an die Arbeit! Rastet nicht, damit ${ }^{\ulcorner}$Ihr nicht ${ }^{\top}$ rostet! TempoTempo! ‘Und ${ }^{\urcorner}$geprügelt wird $\ulcorner$jetzt da $\urcorner$nichtmehr, Du mazedonischer Büffel! Gib BS 30 a, BI. 11 mir Dein Werkzeug, auf der Stell, von heut ab prügel nur ich! Los, her damit! Vorwärts!

ÖLA 3/W 112 BS 58 b [1], BI. 1

ÖLA 3/W $109-$ BS 30 a, BI. 11

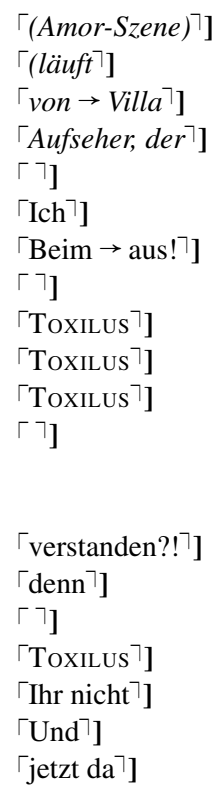

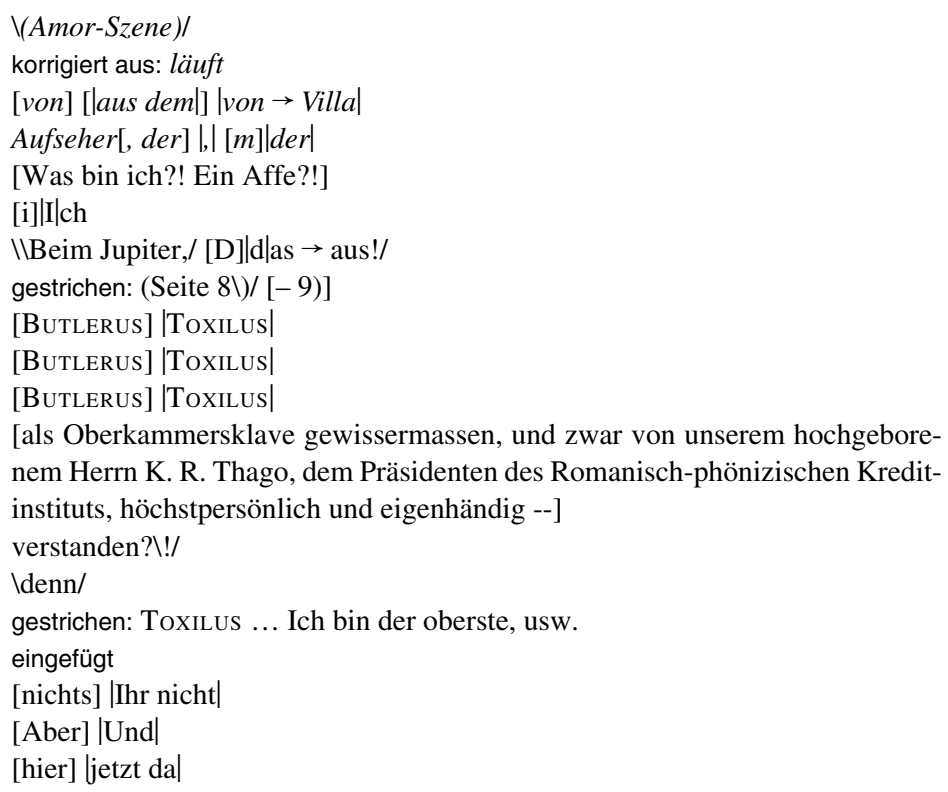


AufseHer (gibt ihm widerwillig seine Peitsche) Werd glücklich. Jetzt möcht ich nur wissen, zuwas ich noch leb -- ich kann doch nur strafen, sonst hab ich ja nichts gelernt! \ulcorner\urcorner$\|\ulcorner\urcorner$ Ohne Arbeit kann ich nicht leben!

Matrosa (deutet plötzlich nach links) Dort kommt Dordalus!

ÖLA 3/W 112 BS 58 b [1], BI. 1

5 Alle (blicken nach links)

LEMNISELENIS (zuckt erschrocken zusammen und zittert)

ToxiLus (nach links) Dordalus, unser aller Händler -

$\ulcorner$ Matrosa $\urcorner$ ( $\{$ gering $\})$ Ich war auch mal seine Ware!

ToxıLus Ein`schäbiger ${ }^{\top}$ Geizhals!

10 Aufseher Wenn ich kein Sklave wär, sondern ein freier Mann, dann tät ich dem Kerl was erzählen!

LEM $\ulcorner\text { (leise })^{\urcorner}$Er naht, er naht - wer hilft? Oh Amor, Amor, Du bist der einzige, der helfen kann, wenn alles versagt - Hilf Amor, hilf! Hilf oh, Amor! Amor!

15

ToxiLus (plötzlich zum AufseHER) Kannst Du reiten?

\| AUfSEHER (perplex) Reiten?

Toxilus Ja.

ÖLA 3/W $109-$ BS 30 a, BI. 11

AufseHER Natürlich kann ich reiten! Ich bin $\left\ulcorner\operatorname{sogar}{ }^{\urcorner}\right.$gewissermassen auf dem Pferd geboren --

20 || Toxilus Sattel das schnellste Pferd!

Aurs Zu was!

Toxilus Frag nicht! Sattel oder $-\ulcorner$ (er hebt die Peitsche $)\ulcorner\urcorner\ulcorner\urcorner$

\| Aufsener Ich sollt ein Tier misshandeln? Für was hältst Du mich?! (rasch ab)

Toxilus ( $z u$ LEM) Kannst Du reiten?

ÖLA 3/W 112 BS 58 b [1], BI. 2

25 LEM Ich?

Toxilus Ja, Du. Schnell, schnell! ‘Du kannst doch!?

LEM Nein.

Toxilus Du kannst nicht reiten?

LEM Nein. Woher?

30 Toxilus Dann ist auch das vorbei - ich wollt Du sollst fliehen -

3

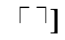

3

8

9

12

15

18

22-393, 11

\ulcorner\urcorner$]$
$\ulcorner$ MAtrosA $\urcorner]$
$\ulcorner$ schäbiger $\urcorner]$
$\ulcorner($ leise $)\urcorner]$
\ulcorner\urcorner$]$
$\ulcorner$ sogar $\urcorner$
$\ulcorner($ er $\rightarrow$ Haus $)\urcorner]$

22

22

26

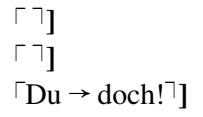

[Toxilus Ich weiss-ich weiss! Du hast die Peitschenvolksschul mit lauter Einser bestanden, hast die Prügelmatura summa cum laudis absolviert und hast sogar auf der Folterhochschul einige Semester studiert -- ich weiss-ich weiss! Aufseher Jaja, ich hatte eine goldene Jugend! Toxilus Noch ist kein triftiger Grund zur Melancholie vorhanden -AufSEHER (unterbricht ihn)]

gestrichen: Aufs .... (S. 8)

(1) Aufseher

(2) IMatrosa/

korrigiert aus: schäbbiger

(leise)/

gestrichen: Aufs Ja..... (usw.)

[ja] |sogar|

(1) (er $\rightarrow$ Haus)

(2) LEM (ihr Auge leuchtet auf, sie rennt [\{rasch\}] [|rasch|] zu Toxilus, küsst ihn hastig und ab in den Hintergrund)

Matrosa (besorgt) Wohin? \(sie sieht Toxilus an)/ Wohin?/

gestrichen: (S. 9)

[\AuFs/]

[Kannst] |Du $\rightarrow$ doch!| 
LEM Fliehen?! Ja, dann kann ich reiten! Lieber brech ich mir den Hals, nur nicht wieder auf den Sklavenmarkt!

Toxilus Sei so gut! Und an mich denkst Du garnicht?

Matrosa Was soll sie an Dich denken? Was hat sie schon von Dir?

5 Toxilus Ich kaufe sie frei.

LEM Frei?!

Toxilus Ja.

Matrosa Verdreh dem Mädel nicht den Kopf! Woher willst Du denn das Geld nehmen?! Sechshundert Silberlinge?!

10 Toxilus Ich klaue sie - Rasch, weg mit Euch, ins Haus hinein!

Matrosa und Lem ( $a b$ ins Haus)

Dordalus (kommt mit Schergen) Ist das nicht Toxilus?

Toxilus $\ulcorner\text { (imitiert ihn })^{\urcorner}$Ist das nicht Dordalus?

Dordalus Natürlich ist das Toxilus! Toxilus, Toxilus - Dich hab ich nicht zu billig verkauft! Du bereitest mir immer Kummer - mies wirds mir, wenn ich Dich seh. Also, wo ist die Hetär, Lemniselenis, die Schönste von Lemnos -

Toxilus Wie sag ichs meinem Händler? Ich weiss nicht, wo sie ist. Das heisst: ich weiss es, wo sie ist, und weiss es doch nicht.

$\ulcorner$ AufseHer (kommt und $\{$ horcht $\})\urcorner$

20 Dordalus Was sollen die ${ }^{\ulcorner}$schlechten ${ }^{\urcorner}\ulcorner\urcorner$Witze?

Toxilus Das heisst: $\left.{ }^{\ulcorner}\right\urcorner$sie ist fort und ich weiss nicht, wohin -

Dordalus Na und die Pointe?

Toxilus Sie ist geflohen.

Dordalus Geflohen?! - Na das 「sind ja nette Sachen, die Ihr da treibt!

25 Aufs Wir?!

DORDALus Ihr Sklaven seid immer nur ,wir“! Wenn einer flieht, so haftet Ihr alle! Alle alle!? In Kommission hat er sie mir gegeben zum Verkauf, und jetzt ist es fort - ein kleines Kapital durch die Finger hindurch geflossen - Na, das werden Eure Buckel spüren, wenn Ihr sie nicht herbeischafft! $(a b)$

30 || AufseHER Du hast sie fliehen lassen?

Toxilus Ja.

AufseHER Warum?

Toxilus Das geht Dich nichts an.

AufseHER Mich vielleicht nicht, aber meinen Buckel - und noch andere Buckel! (er schreit) He, herbei, ‘alle’! Herbei, Ihr Sklaven! `Tempo-tempo!` Herbei-herbei!

Alle Sklaven (kommen)

Aufseher $\ulcorner$ Ich klage an! Ich klage Toxilus an -

\begin{tabular}{|c|c|c|}
\hline 13 & $\ulcorner($ imitiert ihn $)\rceil]$ & $\backslash$ (imitiert ihn)/ \\
\hline 19 & $\ulcorner$ AUFSEHER $\rightarrow\{$ horcht $\})\urcorner]$ & $\backslash$ AUFSEHER $\rightarrow\{$ horcht $\}) /$ \\
\hline 20 & $\lceil$ schlechten $\rceil]$ & korrigiert aus: schlechten $\backslash /$ \\
\hline 20 & \ulcorner\urcorner$]$ & [\alten/] \\
\hline 21 & \ulcorner\urcorner$]$ & [ich weiss, ] \\
\hline $24-27$ & $\ulcorner$ sind $\rightarrow$ alle! $\urcorner]$ & $\begin{array}{l}\text { (1) werdet Ihr aber alle büssen hier, wenn Euer Herr kommt! } \\
\text { (2) Isind } \rightarrow \text { alle!/ }\end{array}$ \\
\hline 35 & $\lceil$ alle $\rceil]$ & [I] $]$ allle \\
\hline 35 & $\lceil$ Tempo-tempo! $]$ & [Los-los!] |Tempo-tempo!| \\
\hline 37 & $\ulcorner$ Ich $\rightarrow$ an -$\urcorner]$ & [Ich klage an! Es ist] $\mid$ Ich $\rightarrow$ an $-\mid$ \\
\hline
\end{tabular}


$\ulcorner$ ERSTER $\ulcorner$ (unterbricht ihn $)\urcorner$ Halt! $!\ulcorner$ Plärr nicht so penetrant! $!\urcorner$

AufseHER Wie redest Du mit mir?

PäGNIUM Kusch selber! \ulcorner

AufseHER (ausser sich) Unglaublich!

$5 \quad$ Alter $\ulcorner$ (er nimmt die Maske $a b)\urcorner$ Wir sind unter uns!

$\ulcorner$ AlLE (nehmen die Masken ab) $\urcorner$

$\ulcorner$ Alter $\urcorner$ Und da ist es Sitte, dass ein Jeder gehört wird! Der Kläger und der Angeklagte! Es muss eine Ordnung herrschen - wir wollen nicht in den Fehler unserer Herrschaft verfallen und die Willkür regieren lassen. $\ulcorner$ Wir sind Sklaven und haben unseren Stolz. $\urcorner\ulcorner\ulcorner\urcorner$ Als der Älteste unter uns nehme ich den Vorsitz - $\ulcorner$ Dich $\urcorner$, Dich und Dich wähle ich zu meinen `Beisitzern?! Nun los, um was dreht es sich! AufseHer Um folgendes dreht es $\ulcorner$ sich mit schlichten Worten: $\urcorner$ Toxilus liess Lemniselenis $\ulcorner$ fliehen $\urcorner$, damit sie nicht wieder verkauft wird - und das geht jetzt auf unseren Buckel aus!

15 Alter Natürlich! Es $\ulcorner$ kann $\urcorner$ nur einen $\ulcorner$ Buckel geben?

$\ulcorner$ (es rollt unter der Erde)

EINER Was war das? Ein Erdbeben?

Alter Das Urteil: Toxilus wird ausgeliefert. `Ruft den Praetor! Den Praetor von Pompeji!

20 Matrosa - Toxilus

Matrosa $\ulcorner$ Du tust mir leid. $\urcorner$ Hast Du gehört, dass es einen neuen Gott geben soll?

Toxılus Man hört ${ }^{\ulcorner}$so viel ${ }^{\urcorner}$von neuen Göttern. Man weiss schon garnichtmehr, was man glauben soll.

(Vorhang) $)^{\urcorner}$

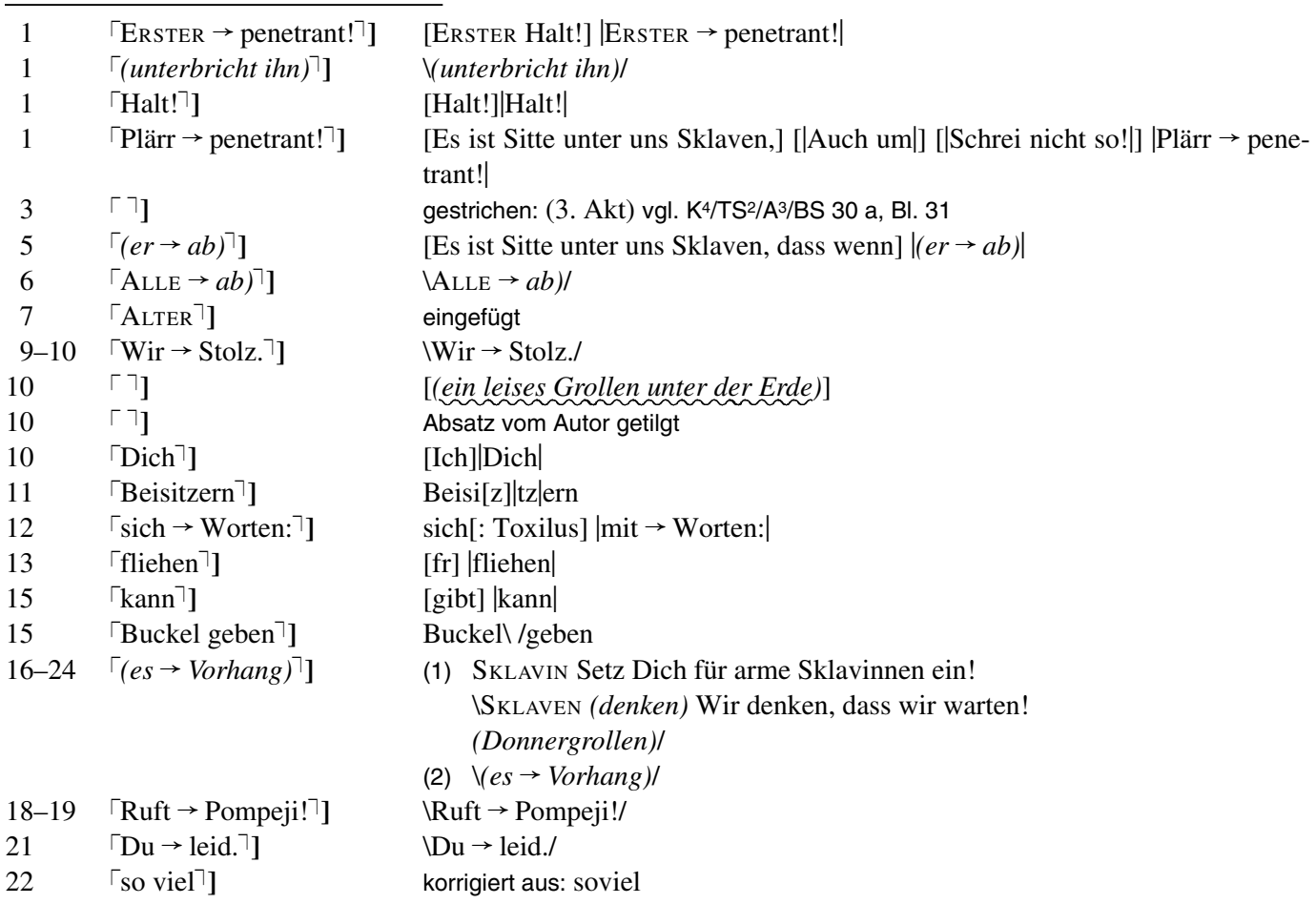





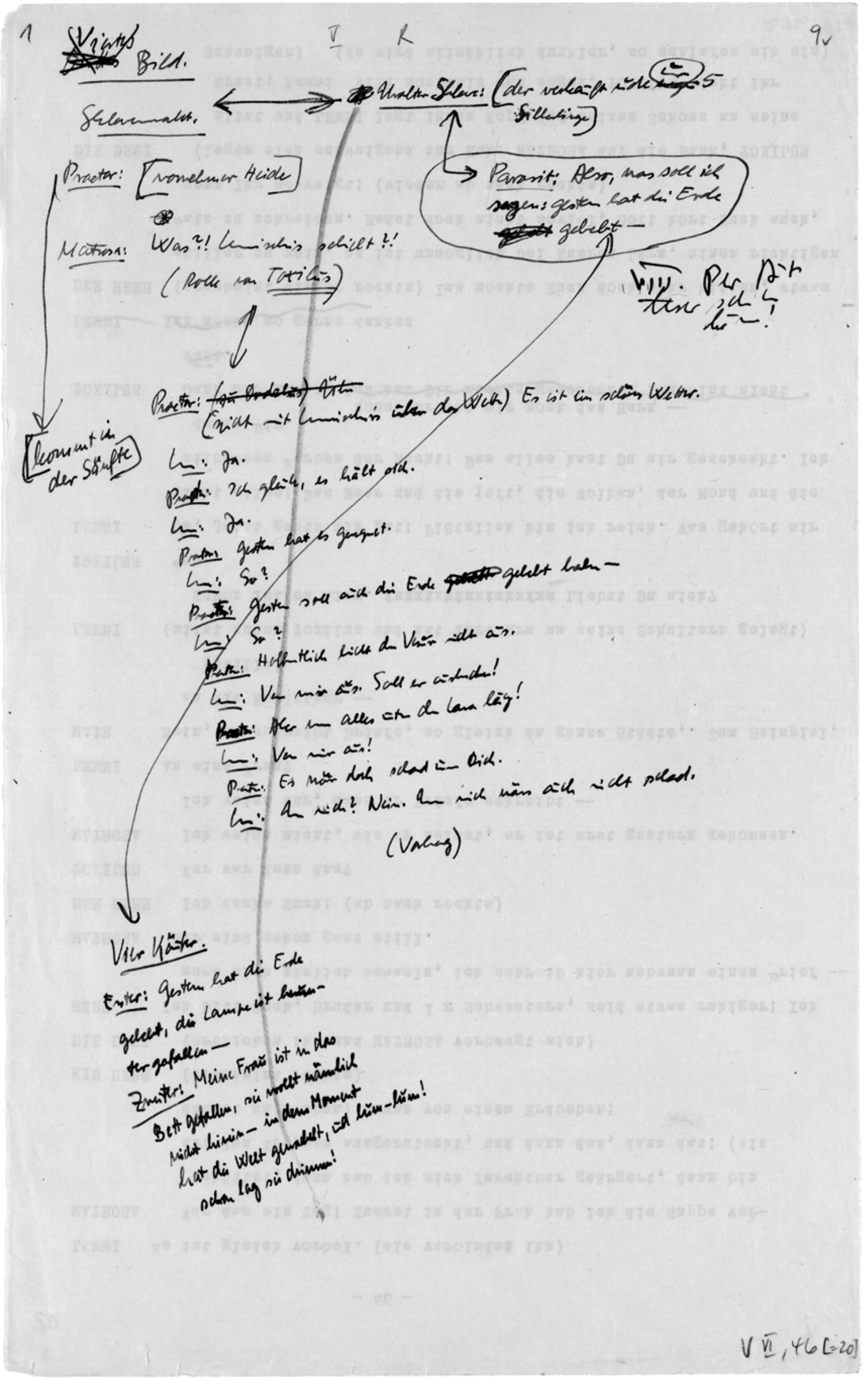




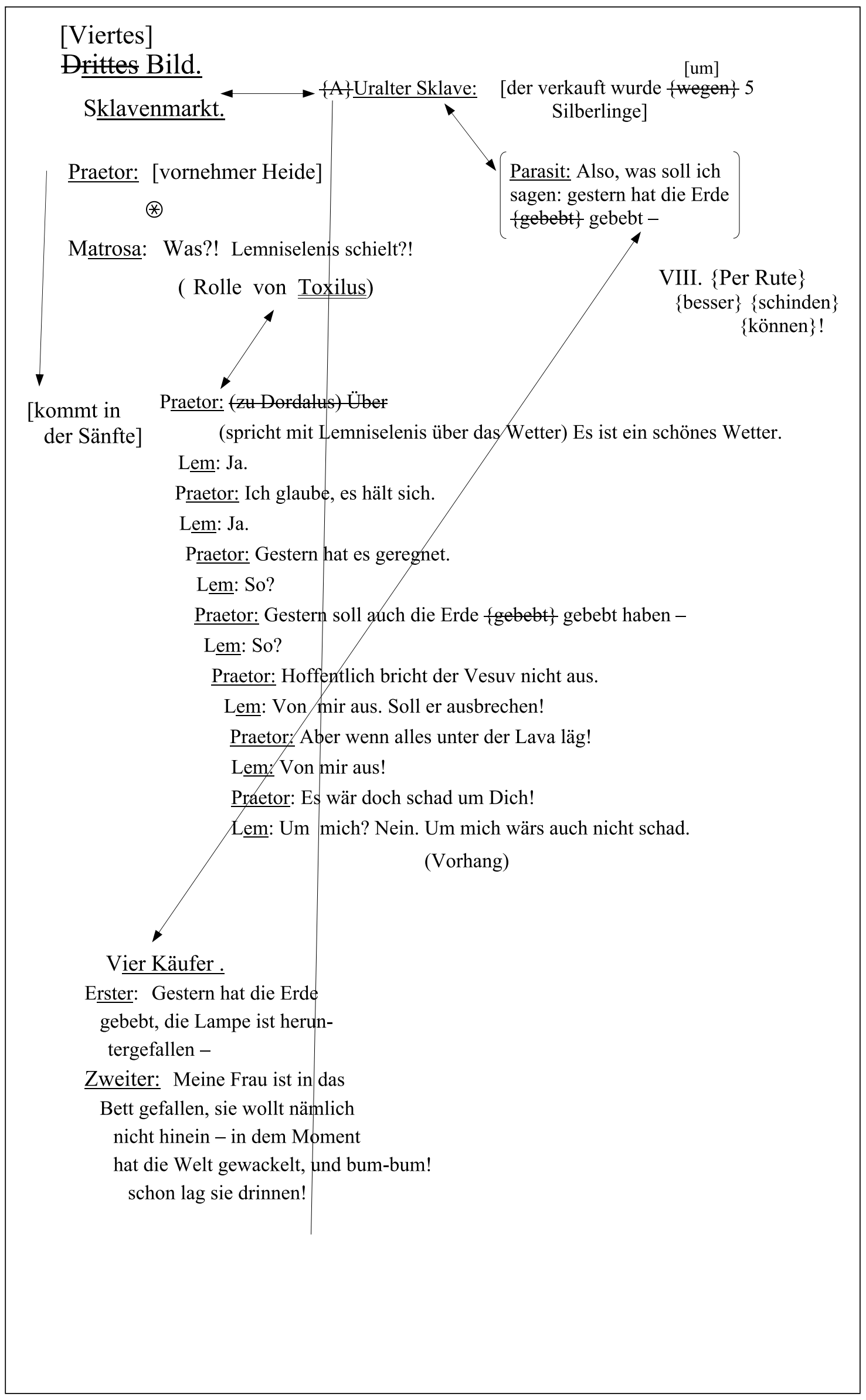


$\|$ 5. Bild.

\section{Beim Praetor.}

ÖLA 3/W $110-$ BS 57 [2], BI. 3

Praetor $\left\ulcorner 8\right.$ Tage bist Du nun bei mir und immer $\left\ulcorner\right.$ bist ${ }^{\urcorner}$Du traurig. Du lächelst wohl, wenn Du mich siehst, aber Deine Umarmung ist kalt. Was hab ich Dir denn getan? Benehme ich mich schlecht? Fehlt Dir etwas?

LEM Nein. Ihr seid sehr gut zu mir. Aber ich bin einsam. Ich liebe einen anderen, wenn der hier wäre -

$\ulcorner$ Praetor Du solltest mich erheitern, denn es gibt kein Recht. Ich spreche Recht und werde die Gespenster nicht los -7$\urcorner$

LEM Ich liebe einen, und ich weiss es garnicht, ob es ihn noch gibt. Ich weiss nicht, wo er ist. Ich kannte ihn so kurz, ich weiss garnicht, wie er aussieht.

Praetor Das ist verdächtig. Mir scheint, Du willst einen lieben, $\ulcorner$ um enttäuscht zu werden. $\urcorner$ Du suchst die $\ulcorner$ Enttäuschung $\urcorner$, das Nichts -

LEM $\ulcorner$ Es $\urcorner$ ist die erste Liebe meines Lebens.

Praetor Mir scheint, Du suchst das Nichts -

LEM Ich lebe nicht lang.

Aabbruch der Bearbeitungl

\footnotetext{
$4-10 \quad\ulcorner 8 \rightarrow$ los -$\urcorner]$

$4 \quad\lceil$ bist $\urcorner]$

9-10 $\ulcorner$ PRAETOR $\rightarrow$ los -7$]$

13-14 「um $\rightarrow$ werden. $\urcorner]$

14 「Enttäuschung \]

$15\lceil E s\urcorner]$

(1) Ich weiss nicht, was Du hast: ich habe Dich gekauft, Du hast alles, was Dein Herz begehrt, und bist nicht glücklich - ich möchte Dich so gerne glücklich sehen -

LEM Ich liebe einen anderen.

Praetor So? Wie [kommst] |kommst| Du [dazu?] |dazu?|

(2) $18 \rightarrow \operatorname{los}-1$

[lächelst] |bist|

(1) Praetor Also das wär zuviel verlangt.

(2) PPRAetor $\rightarrow$ los $-/$

[den es nicht g] lum $\rightarrow$ werden.|

[Entscheidung] |Enttäuschung|

$\mathrm{E}[\mathrm{r}]|\mathrm{s}|$
} 
Das Stück beginnt mit einem le be ndem Bild:

Im Hafen, links im Hintergrunde, ankert die Luxusgaleere des Bankiers. ZAHLREICHE

5 Sklaven und Sklavinnen schleppen vom Ufer Gepäckstücke auf das Schiff, Kisten, Truhen, Fässer, Schläuche, Geschirr. Sie werden von einem AufseHER mit Nilpferdpeitsche in drohender Pose beaufsichtigt. Im Vordergrunde stehen von links nach rechts: GloRIOSUS, stolz auf den Knauf seines Schwertes gestützt; neben ihm kniet der Sklavenlausbub PAEGNIUM und putzt einen Schild; dann IDIOTIMA, umgeben von DREI KAMMERSKLAVINNEN, die noch etwas am Saum ihres Kleides zu nähen haben und ihr mit einer $\ulcorner$ Brennschere $\urcorner$ auch noch Löckchen ins Haar brennen; dann K.R. THAGO persönlich mit der achtzehnjährigen Hetäre LEMNISELENIS und deren Dienerin Matrosa, einer Person im gefährlichsten Alter, die sich nun etwas im Hintergrund hält, denn der Bankier tätschelt gerade der Hetäre Wange. Ganz im Vordergrunde steht Toxilus als Prologus, in $\ulcorner$ einen $\urcorner$ feierlichen $\urcorner$ weissen Radmantel gehüllt, eine Pergamentrolle in der Hand. Es ist ein herrlicher Tag, ohne Wellen und Wolken.

Alle Personen tragen griechische Masken, die die wesentlichen Züge ihrer Charaktere, so wie man sich selbe landläufig vorstellt, darstellen sollen. So steht nun ToxILus mit der typischen Prologmaske vor dem Publikum. K.R. THAGO, ein gütiger Börsianer, Lemniselenis, ein freches Dirnchen, Matrosa, eine alte Dirnchenmutter, IDIOTIMA, gepflegt, $\ulcorner$ versnobt $\urcorner$, mit dem leerem Lächeln der $\left.{ }^{\ulcorner}\right\urcorner$Gesellschaftsdame, Gloriosus, ei-||tel, dumm und aufgeblasen, PAEgnium, ein pfiffiger Spitzbub, der Aufsener roh und niederträchtig, die SKLAVEN und SKLAVINnEN, niedergedrückt, bemitleidenswert armselig, so wie es sich eben gehört.

$\ulcorner$ Es ist ein herrlicher Tag, ohne Wellen und Wolken.

$\ulcorner$ Toxilus (zum Publikum)

Als Prologus

Beginne ich mit einem Zitat aus Plautus:

„Oh Publikum!

Lasst Euch behaglich auf Euere Sitze nieder

Bezahlt oder unbezahlt -- das ist nicht die Frage

Die Frage ist vielmehr:

Ob Ihr satt oder hungerig $\left\ulcorner\right.$ hierher ${ }^{\urcorner}$gekommen seid.

Wer bereits genachtmahlt hat, der hat das bessere Teil erwählt

Doch wer hungert, esse sich an unseren Witzen satt --

Aber wem zu Hause das Nachtmahl steht

Der ist ein Narr

Ein grosser Narr

40 Dass er uns zulieb nüchtern hergekommen ist! ${ }^{67}$

(er nimmt seine Maske ab und entledigt sich seines Mantels)

\begin{tabular}{|c|c|c|}
\hline 11 & $\ulcorner$ Brennschere $\rceil]$ & korrigiert aus: Brennscheere \\
\hline 15 & $\lceil$ einen $\rceil]$ & eine $[m]|n|$ \\
\hline 15 & $\ulcorner$ feierlichen $\rceil$ & feierliche $[m]|n|$ \\
\hline & $\lceil$ versnobt $\rceil$ & korrigiert aus: versnobbt \\
\hline & \ulcorner\urcorner$]$ & [grossen] \\
\hline & $\ulcorner E s \rightarrow$ Wolken. $\urcorner]$ & Es $\rightarrow$ Wolken./ \\
\hline-40 & $\lceil$ Toxilus $\rightarrow$ ist!“"ך] & Textentlehnung Plautus, $\mathrm{POE}^{1}$ \\
\hline & $\ulcorner$ hierher $\urcorner]$ & hierlher/ \\
\hline
\end{tabular}


Huh, ist mir heiss!

Verzeiht, dass ich mich demaskiere

Doch hoffe ich, dass Ihr mich auch ohne Maske goutieren werdet --

Erlaubt, dass ich mich vorstelle:

$5 \quad$ Ich heisse Toxilus und bin hier der Oberkammersklave.

Eigentlich bin ich zwar eine Herrennatur

Die $\ulcorner$ eben $\urcorner$ nur im $\ulcorner$ Sklavenstande $\urcorner$ lebt

Ein Mann voll geistiger Kraft und Gewandtheit

Voll Witz und Gesundheit

Dem sich seine Umgebung willig unterordnet ${ }^{\top}\ulcorner\urcorner$

Die Sklaven nämlich, deren Oberster ich bin --

Jedoch auch -- (leise) -- meine Herrschaft!

Ich sag es leise, denn sie steht hier hinter mir und soll es nicht hören! Sonst setzt es was ab auf meinen Buckel und das wollt ${ }^{\top} \mathrm{Ihr}$ mir doch nicht ${ }^{\urcorner}$gönnen! (laut) Erlaubt nun, dass ich Euch die Szenerie erläutere: Ihr seht hier ein lebendes Bild. Rechts die Villa meiner Herrschaft und links im Hintergrunde das Meer -- dort ankert die Luxusgaleere meines Herrn, des Präsidenten des Romanisch-phönizischen Kreditinstitutes, K.R. Thago -- (er deutet auf K.R. THAGO) -- er ist ein gebürtiger Punier, hat sich aber in Rom naturalisieren lassen und allerhand Geld gemacht. Er verabschiedet sich soeben von seiner Fräulein Hetäre, namens Lemniselenis -- die Alte dahinter ist ihre Dienerin Matrosa, ein treuer Schatten! Jawohl, mein Herr verabschiedet sich, denn er $\left\ulcorner^{\ulcorner}\right.$segelt ${ }^{\top}$ mit seiner Tochter Idiotima und derem Gatten Gloriosus nach Kreta in die $\ulcorner$ Sommerfrisch $\urcorner$, denn Kreta ist zur Zeit der letzte Schrei. $\ulcorner$ Die Herrschaften $\urcorner$ segeln noch heute, sie warten nur noch, bis die Sklaven das viele Gepäck auf die Luxusgaleere gebracht haben. Der $\ulcorner$ Rüpel $\urcorner$ dort hinten mit der Peitsche, das ist der Aufseher, ein $\ulcorner$ roher, $\urcorner$ niederträchtiger $\ulcorner$ Mensch $\urcorner$-.

AufseHer (fällt ihm ins Wort) Was bin ich?!

Toxilus Hast es nicht gehört? Zweimal sag ichs nicht.

30 AufseHER Ich bin ein roher, niederträchtiger Mensch?!

|| Toxilus Hab ich das gesagt?

AufseHer \ulcorner\urcorner Jawohl!

Toxilus Dann wirds schon stimmen --

AufSEHER Es stimmt aber nicht! Da, schau her -- (er reisst seine Maske herunter, ein rundes, gutmütiges Gesicht wird sichtbar) Ist das das Antlitz eines Peitschenkulis?!

$\begin{array}{ll}6-10 & \ulcorner\text { Eigentlich } \rightarrow \text { unterordnet }\urcorner \\ 7 & \ulcorner\text { eben }\urcorner] \\ 7 & \ulcorner\text { Sklavenstande }\urcorner] \\ 10 & \ulcorner\urcorner] \\ 14 & \ulcorner\text { Ihr } \rightarrow \text { nicht }\urcorner] \\ 22 & \ulcorner\text { segelt }\urcorner] \\ 23 & \ulcorner\text { Sommerfrisch }\urcorner] \\ 24 & \ulcorner\text { Die Herrschaften }\urcorner] \\ 26 & \ulcorner\text { Rüpel }\urcorner] \\ 26 & \ulcorner\text { roher, }\urcorner] \\ 27 & \ulcorner\text { Mensch }\urcorner \\ 32 & \ulcorner\urcorner]\end{array}$

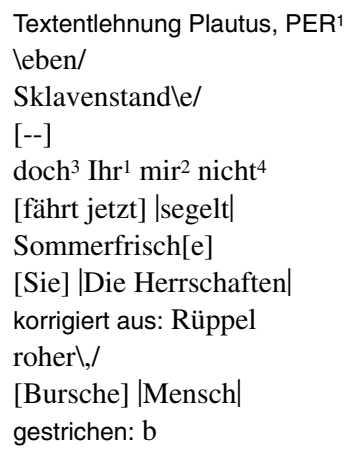


Toxilus (perplex) Sieh da! $\ulcorner$ Komisch, dass $\urcorner$ ich \ulcorner\urcorner Dein Gesicht noch nie gesehen $\mathrm{hab}^{\urcorner}$-- hm. Nein, roh und niederträchtig sieht es nicht aus, eher ein bisserl blöd --

AufSEHER (braust jähzornig auf) Ein solches Wort noch und -- (er hebt drohend seine Peitsche)

5 Toxilus (herrscht ihn an) Schäm Dich, immer nur die Peitsche, die Peitsche, die Peitsche! Bist doch selber nur ein Sklav!

Aufsener $\ulcorner$ Sklave $\urcorner$ her, Peitsche hin! Ich erfüll ja nur meine Pflicht! (er knallt mit der Peitsche und brüllt die SKLAVEN, die die Gepäckstücke tragen, an) Vorwärts-vorwärts! Nur nicht getrödelt, gewurstelt, geschlafen, sonst weck ich Euch auf, Skla-

$10 \quad$ venpack!

Die Sklaven (tragen ihre Lasten auf das Schiff)

AUFSEHER (zählt die an ihm vorbeigeschleppten Gepäckstücke) -- 84, 85, 86, 87 -los-los! Wir haben noch 164 Stück! (er knallt wieder mit der Peitsche)

IDIOTIMA (zuckt etwas zusammen)

15 Toxilus (zum Publikum) Nachdem ich Euch alles erklärt habe, darf ich nun wohl gehen -- ich muss nämlich auf das Schiff, um nachzusehen, ob auch alles richtig verstaut wird. Ich komme wieder, wenn ich muss! (rasch ab auf das Schiff)

Aufseher (brüllt einen ALTEN SKLAVEn grimmig an) Tempo-tempo! 107, 108, 109 -hast nicht gehört, altes Stück Elend?! (er knallt abermals mit der Peitsche)

20 || IDIOTIMA $\ulcorner$ (zuckt abermals zusammen $)\urcorner$

Oh saget ihm, er knalle nicht so mit der Peitsche!

Er schlage lieber, dann gibts nicht diesen schrillen Ton!

Meine Nerven vertragen keine Disharmonien

Ich bin geschwächt --

25 Gloriosus Paegnium! Wo bleibt mein Schild?

Paegnium (reicht ihm den Schild) Aufzuwarten, gnädiger Herr!

$\ulcorner$ Gloriosus (blickt auf seinen Schild, wie in einen Spiegel) Ich kann mich in meinem Schild nicht sehen. Wo bin ich? Du sollst meinen Schild so putzen, dass ich ihn als Spiegel benützen kann -- begreifs doch endlich, dass ich mit Mars verwandt bin! (er reicht ihm wieder seinen Schild) Putz ihn, sonst erledig ich Dich, wie jene fünfhundert in Kappadozien im vorigen Herbst -- fünfhundert mit einem Streich, obwohl mein Schwert abgestumpft war!?

Paegnium (putzt eifrig den Schild)

IDiotima (nimmt langsam ihre Maske ab: eine verhärmte, frühgealterte Frau wird sichtbar)

DiE KAMMERSKLAVINNEN (stürzen sich sofort eifrigst auf die Maske, schminken und pudern sie)

IDIOTIMA (blickt zum Himmel empor)

Ach, Wölklein in der Höh

$40 \quad$ Nur du erkennst mein Weh:

Mein Gatte ist ein Berufsmensch.

$\begin{array}{cll}1 & \ulcorner\text { Komisch, dass }\urcorner] & {[\text { Eigentlich hab] } \mid \text { Komisch, dass } \mid} \\ 1 & \ulcorner\urcorner] & {[\mathrm{ja}]} \\ 2 & \ulcorner\text { hab }\urcorner] & \mid \text { hab/ } \\ 7 & \ulcorner\text { Sklave }\urcorner] & {[\text { Peitsche }] \mid \text { Sklave } \mid} \\ 20 & \ulcorner(\text { zuckt } \rightarrow \text { zusammen })\urcorner] & \backslash[\text { zuck }] \mid \text { zuckt } \rightarrow \text { zusammen } \mid / \\ 27-32 & \ulcorner\text { GLORIOSUS } \rightarrow \text { war }\urcorner]] & \text { Textentlehnung Plautus, MG1 und MG² }\end{array}$


Er liebt nur sein Schwert, seinen Schild, seinen Panzer --

Was gilt ihm der Venusberg neben einem befestigten Hügel?

Nichts, oh nichts!

Er fürchtet nur immer, ob seine Rüstung auch richtig $\ulcorner$ glänzt.

Heut zieht er sich schon seit gestern an

Er legte sich garnicht zu Bett in der Nacht

Er zog sich nur an --

Ich frag mich oft:

Warum kennt mein Gatte keine Gemütlichkeit?

\section{Gloriosus Ein böses Wort!}

Viel lieber als in die Sommerfrische zög ich in einen flotten Krieg

Viel lieber würd ich blutige ${ }^{\top}$ Dinge $\urcorner$ vollbringen

Als friedlich meine Brust in der Sonne bräunen --

Denn $\ulcorner$ meine Brust $\urcorner$ sehnt sich nach $\ulcorner\text { der }\urcorner^{\urcorner}\ulcorner$befreienden $\urcorner$Tat!

Idiotima ( $\ulcorner$ einfach $\urcorner$ ) Ich hasse den Krieg.

Gloriosus Versündig Dich nicht! Wenn das \ulcorner\urcorner Mars hört!

IDIOTIMA Lass mich aus mit Deinem Gott!

Wenn mein Vater kein Krösus wär

Wäre mein Gatte ein friedlicher Hirte

20 Aber das Geld meines Vaters lässt ihn nicht arbeiten --

So langweilt er sich auf dem Felde der Ehre zu Tode.

|| GloRiosus (reisst sich wïtend die Maske herab: ein feminines Gesicht wird sichtbar mit ängstlichen Augen; er fixiert unsicher IDIотІмA; plötzlich herrscht er sie an)

Du nimmst den Mund voll, als hättest Du mir einen Sohn geschenkt!

IDIOTIMA (will schreien, doch die KAMMERSKLAVINNEN binden ihr rasch, fast $\ulcorner$ ge-

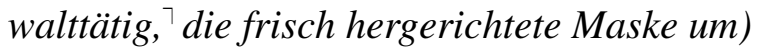

K.R. Thago ( $z u$ LEMniselenis)

Wohl begreif ich Deine Trauer, mein süsses, teuerstes Geschöpf!

Du kostspieliges, Du --

Denn ich fahr nun fort und lass Dich da.

Doch sei beruhigt:

Ich lass auch mein Geschäft da, Handel und Wandel, die Börs, das Kontor --

Mögen die Papiere fallen oder sich heben

Ich muss ruhen!

Der Arzt hats mir verordnet, der Weise

Er kennt mein Leiden.

Es ist nicht der Ausfluss des üppigen Lebens

Sondern der Erregung über das Leben in Geschäften.

\begin{tabular}{|c|c|c|}
\hline 4 & 「glänzt. $\urcorner]$ & glänztl./ \\
\hline 12 & $\ulcorner$ Dinge $\urcorner]$ & [Taten] |Dinge| \\
\hline 14 & $\ulcorner$ meine Brust $\urcorner]$ & meinle/ [Herz] |Brust| \\
\hline 14 & $\ulcorner$ der $\urcorner]$ & \der/ \\
\hline 14 & $\lceil$ befreienden $\rceil$ & befreiende $[\mathrm{r}]|\mathrm{n}|$ \\
\hline 15 & $\ulcorner$ einfach $]$ & [so nebenbei] |einfach $\mid$ \\
\hline 16 & \ulcorner\urcorner$]$ & [der] [|mein|] \\
\hline $25-26$ & $\lceil$ gewalttätig, $\urcorner]$ & gewalttätig \,/ \\
\hline 35 & \ulcorner\urcorner$]$ & [Ja, ruhen --] \\
\hline
\end{tabular}


Verlieren regt auf

Aber verdienen noch mehr --

Und viel verdienen, das legt sich aufs Herz

Denn viel verdienen ist Schmerz

5

Teuer erkaufter Schmerz, Du Kind --

Lemniselenis Der Sommer mag kommen, der Herbst vergehen

Meine Lieb zu Euch wird immer bestehen

Denn Ihr habt mich gekauft.

$\left\ulcorner\right.$ K.R. THAGO ${ }^{\urcorner}$Lieb, sehr lieb -- (er tätschelt wieder ihre Wange)

Toxilus (erscheint rasch an Bord des Schiffes und springt auf den Kai) Euere Hochwohlgeborenen! Die Segel sind gesattelt, der Anker gelichtet, das Gepäck verpackt und die Ruder sind ruderbereit -- es schwimmt alles in Butter, schiffet Euch ein!

IDIOTIMA Endlich! (ab auf das Schiff)

Gloriosus ( $z u$ PAegnium) Her damit! (er nimmt ihm seinen Schild ab und $\|$ betrachtet sich in ihm; entsetzt, denn er sieht sich ohne Maske) Was?! Das soll ich sein?! (er herrscht PAEGNIUM an) Ich seh mich noch immer nicht! Wart nur, Bube, wenn ich heimkehr, lass ich Dich blenden! (rasch ab auf das Schiff)

PAEGNIUM (sieht ihm nach; leise) Idiot! (er nimmt seine Maske ab, ein mageres, trotziges Knabengesicht wird sichtbar; er fächelt sich mit der Maske und wischt sich mit dem Arm den Schweiss von der Stirne)

K.R. Thago ( $z u$ Lemniselenis) Kurz und gut, mit einem Wort: es wird höchste Zeit, dass ich einsteig und Du -- Du kehrst morgen wieder zu Dordalus zurück.

LEMniselenis (entsetzt) Was sagt Ihr?! Wohin?! Zu Dordalus?!

K.R. Thago Ja. Nach Pompeji.

LEMNISELENIS (wie zuvor) Ich soll wieder zum Sklavenhändler?! Ihr wollt mich abermals wieder weiterverkaufen?! ( sie reisst sich die Maske ab: ein schönes Kind mit traurigen Augen und einem frühverbittertem Zug starrt K.R. THAGO verzweifelt an)

30 K.R. Thago (stutzt unwillkürlich etwas) Warum so verzweifelt? Vielleicht kauft Dich ein Besserer, Schönerer, Reicherer --

LEMNISELENIS (unterbricht ihn) Es gibt keinen Reicheren als Euch!

Oh, bringt mich nicht wieder auf den Sklavenmarkt!

Es folget so selten was Besseres nach!

K.R. Thago Aber-aber, grosses Kind! Was hast Du Dir denn $\ulcorner$ ᄀ vorgestellt? Und ausserdem möcht man doch nur Dein Gutes --

LEMNISELENIS Wollet lieber das Schlechte, mein Herr!

Gewährt mir weiter Euere Huld

Ich bleib Euch nichts schuld.

$40 \quad$ Wenn Ihr heimkehrt von Euerer Sommerfahrt

Wird von mir alles in bar bezahlt.

Jeder Groschen ein Kuss

Wenn ich nicht wieder auf den Sklavenmarkt muss --

K.R. Thago Wer weiss, ob ich zurückkehr? Ob das Schiff nicht versinkt? Wer befiehlt dem Meer, dem Sturm -- Neptun oder ich? Bin ich dem Neptun sein Ver-

\footnotetext{
$9\lceil$ K.R. THAGO $] \quad$ korrigiert aus: K. R. THAGO

35\lceil\urcorner$]$ [nur]
} 
trauter? Na also! Abgesehen davon, dass ich Dich jetzt ein halbes Jahr umsonst ernähren müsst! Vorsicht ist die Mutter der Weisheit und Sparsamkeit ist eine Weltanschauung. Verkenne mich nicht, mein Kind! (Stille)

5 Lemniselenis Jetzt weiss ich nichtmehr, was ich glauben soll, Herr Präsident. $\|\ulcorner$

K.R. ThaGo $\left\ulcorner\right.$ Glaub, was Du willst, aber ${ }^{\urcorner}\left\ulcorner\right.$verkauf ${ }^{\urcorner}$Dich nur ja nicht zu billig -- \ulcorner\urcorner

$\ulcorner$ THAGo Danke! (er hält $\ulcorner$ und $\urcorner$ wendet sich nochmals Lemniselenis zu; \{mit erhobenem

\begin{tabular}{|c|c|c|}
\hline 6 & \ulcorner\urcorner$]$ & $\begin{array}{l}\text { [K.R. THAgo (nimmt langsam die Maske ab: er hat überhaupt kein Gesicht) } \\
\text { LEMNISELENIS (start ihn ausser sich an[,]|)|[voll Grauen und Eckel)]] }\end{array}$ \\
\hline 7 & $\ulcorner$ Glaub $\rightarrow$ aber $\urcorner$ & $\begin{array}{l}\text { (1) (feierlich) } \\
\text { Glaub nicht der Gosse } \\
\text { Glaube mir } \\
\text { Glaub nicht den Geldlosen } \\
\text { Ohnehosen } \\
\text { Glaube den Reichen } \\
\text { Sie haben Recht! } \\
\text { Das Armselige } \\
\text { Wird immer vertan } \\
\text { Das Ewig-Geldliche } \\
\text { Zieht uns hinan! } \\
\text { LEMNISELENIS (schreit auf) Nein!! (sie verbirgt ihr Gesicht in den Händen) } \\
\text { K.R. THAGO (setzt sich langsam wieder seine Maske auf und streicht LEM- } \\
\text { NISELENIS über die Haare) [Du bist unter Brüdern sechshundert Silberlinge } \\
\text { wert.] } \rightarrow \\
\text { (2) [(feierlich)] Glaub } \rightarrow \text { aber] }\end{array}$ \\
\hline 7 & $\ulcorner$ verkauf $\rceil]$ & [V]|v|erkauf \\
\hline 7 & \ulcorner\urcorner$]$ & gestrichen: (ab auf das Schiff) \\
\hline $9-13$ & $\lceil$ THAGO $\rightarrow$ ist -$\urcorner]$ & $\begin{array}{l}\text { (1) (ins Orchester) Darf man bitten, Herr Kapellmeister! } \\
\text { (Musik erklingt) } \\
\text { ALLE SKLAVEN (ausser LEMNISELENIS, singen und winken dem verschwin- } \\
\text { dendem Schiffe nach) } \\
\text { Keine Well auf der See } \\
\text { Und der Himmel blau } \\
\text { Frohe Fahrt! } \\
\text { Keine Wolk in der Höh } \\
\text { Und die Luft so lau } \\
\text { Frohe Fahrt! } \\
\text { Keine Sorg in der Brust } \\
\text { Und im Herz nur Lust } \\
\text { Frohe Fahrt! } \\
\text { Vgl. für den weiteren Textverlauf von (1) K/TS } 2 / \mathrm{A}^{3} / \mathrm{BS} 30 \text { a, BI. 11-16 } \\
\text { (2) [(ins Orchester) Darf man bitten, Herr Kapellmeister!] |THAGO } \rightarrow \text { ist }-\mid\end{array}$ \\
\hline 9 & $\ulcorner$ und $\urcorner]$ & [nochmals; $][z u] \mid$ und $\mid$ \\
\hline 10 & $\ulcorner\mathrm{Du} \rightarrow$ wert. $\urcorner]$ & - Du $\rightarrow$ wert. \\
\hline
\end{tabular}


|Textverlust|

|| Villa ist der ländliche Lustsitz des reichen punischen Bankiers K.R. Thago, eines naturalisierten Römers. Hier wohnt er im Frühling mit seiner Tochter Idiotima und derem $\ulcorner$ Gatten $\urcorner$ Gloriosus.

5 Rechts im Vordergrunde sieht man einige Säulen der Villa, links im Hintergrunde liegt das Meer. Dort ankert die Luxusgaleere des Bankiers. Und in der Ferne raucht der Vesuv.

Das Stück beginnt mit einem le bendem Bild:

ZahlReiche Sklaven und SKLAVInNen schleppen vom Ufer Gepäckstücke auf das Schiff, Kisten, Truhen, Fässer, Schläuche, Geschirr. Sie werden von einem AUfSEHER mit Nilpferdpeitsche in drohender Pose beaufsichtigt. Im Vordergrunde stehen von links nach rechts: GLORIOSUS, stolz auf den Knauf seines Schwertes gestützt; neben ihm kauert der Sklavenlausbub PAEGNIUM auf dem Boden und putzt seinen Schild; dann IDIOTIMA, umgeben von DREI KAMMERSKLAVINNEN, die noch etwas am Saum ihres Kleides zu nähen haben und ihr mit einer $\ulcorner$ Brennschere $\urcorner$ auch noch Löckchen ins Haar brennen; dann K.R. THAGO persönlich mit der achtzehnjährigen Hetäre LEMNiselenis und deren Dienerin Matrosa, einer Person im gefährlichsten Alter, die sich etwas abseits hält, denn der Bankier tätschelt gerade der Hetäre Wange. Ganz im Vordergrunde steht ToxiLus als Prologus, in einen weissen weiten Radmantel gehüllt, eine Pergamentrolle in der Hand.

Alle Personen tragen griechische Masken, die die wesentlichen Züge ihrer Charaktere, sowie man sich selbe eben landläufig vorstellt, darstellen sollen. In diesem Sinne steht Toxilus mit der typischen Prologmaske vor dem Publikum. K.R. THAGO ist ein gütiger Börsianer, Lemniselenis ein freches Dirnchen, Matrosa eine alte Dirnchenmutter, IDIOTIMA gepflegt, $\ulcorner$ versnobt $\urcorner$, mit $\ulcorner$ dem leerem $\urcorner$ Lächeln der Gesellschaftsdame, $\ulcorner$ GLORIOSUs $\urcorner$ eitel $\ulcorner$ und $\urcorner$ aufgeblasen, $\ulcorner$ PAEGNIUM $\urcorner$ ein pfiffiger Spitzbub, der Aufseher roh $\ulcorner$ und niederträchtig , die SKLAVen und SKLAVINnen niedergedrückt, geschunden, bemitlei-\|denswert armselig, so wie es sich eben gehört.

Es ist ein herrlicher Tag, ohne Wellen und Wolken.

$\left\ulcorner\right.$ Toxilus (zum Publikum) Als Prologus beginne ich mit einem Zitat aus Plautus: $\left.{ }^{\circ}, \mathrm{Oh}\right\urcorner$ Publikum! Lasst Euch behaglich auf Euere Sitze nieder, bezahlt oder unbezahlt -das ist nicht die Frage. Die Frage ist vielmehr: ob Ihr satt oder hungerig hierher gekommen seid? Denn wer bereits genachtmahlt hat, der hat das bessere Teil erwählt, doch wer hungert, esse sich an unseren Witzen satt -- aber wem zu Hause das Nachtmahl steht, der ist ein Narr, ein grosser Narr, dass er uns zulieb nüchtern hergekommen $\ulcorner$ ist!‘ㄱ (er nimmt seine Maske ab) Erlaubt, dass ich mich vorstelle:

\begin{tabular}{|c|c|c|}
\hline 4 & $\ulcorner$ Gatten $]$ & Gatt $[\grave{e}]|e| n$ \\
\hline 15 & $\ulcorner$ Brennschere $\rceil]$ & korrigiert aus: Brennscheere \\
\hline & $\ulcorner$ versnobt $\rceil]$ & korrigiert aus: versnobbt \\
\hline & $\lceil$ dem leerem $]$ & Blatt beschädigt, ergänzt aus K7/TS5/ÖLA 27/W 36, BI. 4 \\
\hline & $\lceil$ GLORIOSUS $\urcorner$ & GLORIOSUS[,] \\
\hline & $\ulcorner$ und $\rceil$ & Blatt beschädigt, ergänzt aus K/TS5/ÖLA 27/W 36, BI. 4 \\
\hline & $\ulcorner$ PAEGNIUM $\urcorner]$ & PAEGNiUm[,] \\
\hline & $\ulcorner$ und niederträchtig $\rceil$ & Blatt beschädigt, ergänzt aus K/TS5/ÖLA 27/W 36, BI. 4 \\
\hline-38 & $\lceil$ Toxilus $\rightarrow$ ist!‘`] & Textentlehnung Plautus, $\mathrm{POE}^{1}$ \\
\hline & $\ulcorner, \mathrm{Oh}\rceil]$ & $\backslash, / \mathrm{Oh}$ \\
\hline & $\lceil$ ist! $" `\rceil]$ & ist!!"/ \\
\hline
\end{tabular}


ich heisse Toxilus und bin hier der Oberkammersklave. Jawohl: Sklave! `Denn $\|$ durch der Götter Fügung hab ich das Pech, dem Sklavenstande anzugehören, obwohl ich eigentlich von Natur aus eine Herrennatur bin -- ein Mann voll geistiger BS 58 a, BI. 2 Kraft und Gewandtheit, voll Witz und Gesundheit, dem sich seine Umgebung willig unterordnet, ${ }^{\urcorner}$meine Mitsklaven nämlich, jedoch auch -- (leise) meine Herrschaft! Ich sag es leise, denn sie steht da hinter mir und soll es nicht hören, sonst setzt es was $\ulcorner$ ab, $\urcorner$ und das wollt Ihr $\left.{ }^{\ulcorner}\right\urcorner$doch $\ulcorner$meinem Buckel $\urcorner$nicht gönnen! (laut, indem er sich seines Radmantels entledigt) Und nun erlaubt, dass ich Euch die Szenerie erläutere: Ihr seht hier ein lebendes Bild. Rechts die Villa meiner Herrschaft und links im Hintergrunde das $\ulcorner$ Meer: $\urcorner\ulcorner$ Im Hafen $\urcorner$ ankert die Luxusgaleere meines $\left\ulcorner\right.$ Herrn: ${ }^{\urcorner}\ulcorner$(er deutet auf K.R. THAGO $\left.)\right\urcorner\left\ulcorner\right.$Präsident ${ }^{\urcorner}$des Romanisch-phönizi-

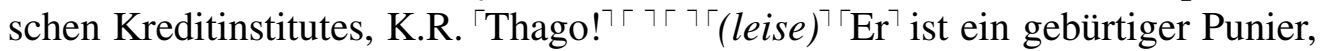
$\ulcorner$ liess $\urcorner$ sich $\ulcorner$ jedoch $\urcorner$ in Rom $\ulcorner$ naturalisieren, $\urcorner\ulcorner\urcorner\ulcorner$ opferte dortselbst $\ulcorner$ unseren $\urcorner$ Göttern und hat dabei ${ }^{\urcorner}$allerhand Geld $\ulcorner$gemacht -$\urcorner\left\ulcorner\right.$jetzt ${ }^{\urcorner}$tätschelt $\left\ulcorner\right.$er $^{\urcorner}$gerade die Wange seines Fräulein Hetäre, namens $\ulcorner$ Lemniselenis $\urcorner\ulcorner\urcorner,\ulcorner\urcorner$ die Alte $\ulcorner$ daneben $\urcorner$ ist $\ulcorner$ des Kindleins $\urcorner$ Dienerin ${ }^{\ulcorner}$Matrosa $\urcorner\ulcorner$- ich vertrag mich mit ihr recht gut. $\urcorner$Jaja, mein Herr tätschelt gern, wenn er sich verabschiedet -- er möcht nämlich mit seiner Tochter Idiotima und derem Gatten Gloriosus nach Kreta in die Sommerfrische segeln, denn Kreta ist zur Zeit der letzte Schrei. Die Herrschaften warten nur noch, bis die Sklaven und Sklavinnen das viele Gepäck auf die Galeere gebracht $\left\ulcorner\right.$ haben, ${ }^{\urcorner}$der ${ }^{\ulcorner}$Rüpel $\urcorner$dort hinten mit der Nilpferdpeitsche ist der Aufseher, ein roher, niederträchtiger Mensch --

\begin{tabular}{|c|c|c|}
\hline $1-5$ & $\ulcorner$ Denn $\rightarrow$ unterordnet, $\urcorner]$ & Textentlehnung Plautus, PER ${ }^{1}$ \\
\hline 7 & $\ulcorner\mathrm{ab}\urcorner]$, & $\mathrm{ab} \backslash, /$ [auf meinen Buckel,] \\
\hline 7 & \ulcorner\urcorner$]$ & [mir] \\
\hline 7 & $\ulcorner$ meinem Buckel $\rceil$ & Imeinem Buckel/ \\
\hline 10 & $\ulcorner$ Meer: $\urcorner]$ & Meerl:/ [--] \\
\hline 10 & $\ulcorner$ Im Hafen $\rceil]$ & {$[[\mathrm{d}]|\mathrm{D}|$ ort $] \backslash[\mathrm{i}]|\mathrm{I}| \mathrm{m}$ Hafen/ } \\
\hline 11 & $\ulcorner$ Herrn: $\urcorner]$ & Herrn[,]::| \\
\hline 11 & $\ulcorner(e r \rightarrow$ THAGO $)\rceil]$ & $\bullet(e r \rightarrow$ THAGO $)$ \\
\hline 11 & $\lceil$ Präsident $\urcorner]$ & [des] [|[Er ist] [d]|D|er|] [|der|] Präsident[en] \\
\hline 12 & $\lceil$ Thago! $]$ & Thagol!/ [--] \\
\hline 12 & \ulcorner\urcorner$]$ & {$[(e r \rightarrow$ THAGO $)] \rightarrow \bullet$} \\
\hline 12 & \ulcorner\urcorner$]$ & {$[--]$} \\
\hline 12 & $\ulcorner($ leise $)\rceil]$ & $\backslash($ leise $) /$ \\
\hline 12 & $\ulcorner\mathrm{Er}\urcorner]$ & {$[\mathrm{e}]|\mathrm{E}| \mathrm{r}$} \\
\hline 13 & $\lceil$ liess $\rceil]$ & [hat] |liess \\
\hline 13 & $\ulcorner$ jedoch $\rceil]$ & [aber] |jedoch| \\
\hline 13 & $\lceil$ naturalisieren, $\urcorner\rceil$ & naturalisieren $\backslash, /$ \\
\hline 13 & \ulcorner\urcorner$]$ & [lassen] \\
\hline $13-14$ & $\ulcorner$ opferte $\rightarrow$ dabei $\urcorner]$ & [und] [|hat dortselbst]] [lopferte dortselbst fremden|] |opferte $\rightarrow$ dabei $\mid$ \\
\hline 13 & 「unseren $\urcorner]$ & [fremden] |unseren| \\
\hline 14 & $\lceil$ gemacht -$\urcorner]$ & gemacht $[!]|-|$ \\
\hline 14 & $\ulcorner$ jetzt $\urcorner]$ & {$[\mathrm{Er}]$ |jetzt| } \\
\hline 14 & $\ulcorner\mathrm{er}\urcorner]$ & ler/ \\
\hline 15 & $\ulcorner$ Lemniselenis $\urcorner]$ & Lemniselenis[,] \\
\hline 15 & \ulcorner\urcorner$]$ & [ein liebliches Kind] \\
\hline 15 & \ulcorner\urcorner$]$ & [und] \\
\hline 15 & $\ulcorner$ daneben $\urcorner]$ & da[hinter] |neben| \\
\hline $15-16$ & $\ulcorner$ des Kindleins $\urcorner]$ & [ihre] |des Kindleins| \\
\hline 16 & $\ulcorner$ Matrosa $\rceil]$ & Matrosa[,] \\
\hline 16 & $\ulcorner-$ ich $\rightarrow$ gut. $\urcorner]$ & [ein treuer, jedoch boshafter Schatten!] $\mid-$ ich $\rightarrow$ gut.| \\
\hline 21 & $\lceil$ haben, $\urcorner]$ & haben $\backslash, /[--]$ \\
\hline 21 & $\ulcorner$ Rüpel $\urcorner]$ & korrigiert aus: Rüppel \\
\hline
\end{tabular}


|| AufseHer (fällt ihm ins Wort) Was bin ich?!

ToxiLus Hast es nicht gehört? Zweimal sag ichs nicht.

ÖLA 3/W 129 BS 59, BI. 4

AuFseHER Ich $\ulcorner$ wäre $\urcorner$ ein roher, niederträchtiger Mensch?!

Toxilus Hab ich das gesagt?

5 || Aufseher Jawohl!

Toxilus Dann wirds schon stimmen --

ÖLA 3/W 129 BS 59, BI. 5

AufseHer Es stimmt aber nicht! Da, schau her! (er reisst seine Maske herunter, ein rundes, gutmütiges Gesicht wird sichtbar) Ist das das Antlitz eines `Prügelwarts?

Toxilus (perplex) Komisch, dass ich Dein Gesicht noch nie gesehen hab -- hm. Nein, roh und niederträchtig sieht es nicht aus, eher ein bisserl blöd --

AUfSEHER (braust jähzornig auf) Ein solches Wort noch und -- (er hebt drohend seine Peitsche)

Toxilus (herrscht ihn an) Schäm Dich, immer nur die Peitsche, \ulcorner\urcorner die Peitsche! \ulcorner\urcorner

Aufseher $\left\ulcorner\right.$ Scham ${ }^{\top}$ her, Peitsche hin! Ich erfüll ja nur meine Pflicht! (er knallt mit der Peitsche und brüllt die SKLAVEn und SKLAVInnen, die die Gepäckstücke tragen, an) Vorwärts-vorwärts! Nur nicht getrödelt, gewurstelt, geschlafen, sonst weck ich Euch auf, Sklavenpack!

Alle Sklaven (tragen hurtig ihre Lasten auf die Galeere)

AUFSEHER (zählt die an ihm vorbeigeschleppten Gepäckstücke) -- 84, 85, 86, 87 -los-los! Wir haben noch 164 Stück! (er knallt wieder mit der Peitsche)

IDIOTIMA (zuckt etwas zusammen)

Toxilus (zum Publikum) Nachdem ich Euch alles erklärt habe, darf ich nun wohl gehen -- ich muss nämlich rasch auf das Schiff, um nachzusehen, ob auch alles richtig verstaut wird. Ich komme wieder, wenn ich muss! (rasch ab auf die Galeere)

Aufseher (brüllt einen ALTEN SkLAVEn grimmig an) Tempo-tempo! 107, 108, 109 -hast nicht gehört, altes Stück Elend?! (er knallt abermals mit der Peitsche)

IDiotima (zuckt abermals zusammen) Oh saget ihm, er knalle nicht so mit der Peitsche! Er schlage lieber, dann gibts nicht diesen schrillen Ton! Meine Nerven vertragen keine Disharmonien, ich bin geschwächt --

30 Gloriosus Paegnium! Wo bleibt mein Schild?

Paegnium (reicht ihm den Schild) Aufzuwarten, gnädiger Herr!

$\|\ulcorner$ GLoriosus (blickt auf seinen Schild, wie in einen Spiegel) Ich kann mich in meinem Schild nicht sehen. Wo bin ich? Du sollst meinen Schild so putzen, dass ich ihn ÖLA 3/W 129 BS 59 , BI. 6 als Spiegel benützen kann -- begreifs doch endlich, dass ich mit Mars verwandt bin! (er reicht ihm wieder seinen Schild) Putz ihn, sonst erledig ich Dich, wie jene fünfhundert in Kappadozien im vorigen Herbst -- fünfhundert mit einem Streich, obwohl mein Schwert abgestumpft war!

Paegnium (putzt eifrig den Schild)

IDiotima (nimmt langsam ihre Maske ab: eine verhärmte, frühgealterte Frau wird sichtbar)

DiE KAMMERSKLAVINNEN (stürzen sich sofort eifrigst auf die Maske, schminken und pudern sie)

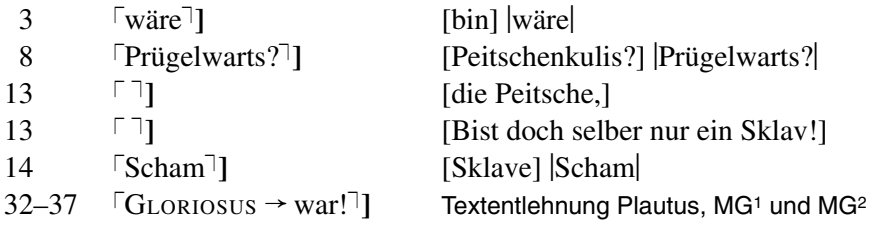


IDiotima (blickt zum Himmel empor) Ach, Wölklein in der Höh, nur Du erkennst mein Weh: mein Gatte ist ein Berufsmensch. Er liebt nur sein Schwert, seinen Schild, seinen Panzer -- was gilt ihm der Venusberg neben einem befestigtem Hügel? Nichts, oh nichts! Er fürchtet nur immer, ob seine Rüstung auch richtig glänzt. Heut zieht er sich schon seit gestern an, er legte sich garnicht zu Bett in der Nacht, er zog sich nur an -- Ich frage mich oft: warum kennt mein Gatte keine Gemütlichkeit?

GLORIOSUS Ein böses Wort! Viel lieber als in die Sommerfrische zög ich in einen flotten Krieg, viel lieber würd ich blutige Dinge vollbringen, als friedlich meine Brust in der Sonne bräunen -- denn meine Brust sehnt sich nach der befreienden Tat!

Idiotima (einfach) Ich hasse den Krieg.

Gloriosus Versündig Dich nicht! Wenn das Mars hört!

IDIOTIma Lass mich aus mit Deinem Gott! Wenn mein Vater kein Krösus wär, wäre mein Gatte ein friedlicher Hirte, aber das Geld meines Vaters lässt ihn nicht arbeiten -- so langweilt er sich auf dem Felde der Ehre zu Tode.

GLORIOSUs (reisst sich wütend die Maske herab: ein feminines Gesicht mit ängstlichen Augen wird sichtbar; er fixiert unsicher IDIOтІмА; plötzlich herrscht er sie an) Du nimmst den Mund \| voll, als hättest Du mir einen Sohn geschenkt!

IDIOTIMA (will schreien, doch die KAMMERSKLAVINNEN binden ihr rasch, fast gewalttätig, die frischhergerichtete Maske um)

K.R. Thago ( $z u$ Lemniselenis) Wohl begreif ich Deine Trauer, mein süsses, teuerstes Gschöpf, Du kostspieliges, Du -- denn ich fahr nun fort und lass Dich da. Doch sei beruhigt: ich lass auch mein Geschäft da, Handel und Wandel, die Börs, das Kontor -- mögen die Papiere fallen oder sich heben: ich muss ruhen! Der Arzt hats mir verordnet, es $\ulcorner$ wird $\urcorner$ Zeit, er kennt mein Leiden --

Lemniselenis Was fehlt Euch denn, Herr Präsident?

K.R. Thago Mein Leiden, Kind, ist nicht der Ausfluss des üppigen Lebens, sondern der Erregung über das Leben in Geschäften. Verlieren regt auf, aber verdienen noch mehr -- und viel verdienen, das legt sich aufs Herz, denn viel verdienen ist Schmerz, teuer erkaufter Schmerz.

LemNiselenis Der Sommer mag kommen, der Herbst vergehen, meine Lieb zu Euch wird auch dann noch bestehen. Denn Ihr habt mich gekauft.

ToxiLus (erscheint rasch auf der Galeere und springt auf den Kai) Euere Hochwohlgeborenen! Die Segel sind gesattelt, der Anker gelichtet, das Gepäck verpackt und die Ruder sind ruderbereit -- es schwimmt alles in Butter, schiffet Euch ein!

IDiotima Endlich! (ab auf die Galeere)

Gloriosus ( $z u$ PAEgNiUm) Her damit! (er nimmt ihm seinen Schild ab und betrachtet sich in ihm; entsetzt, denn er sieht sich ohne Maske) Was?! Das soll ich sein?! (er herrscht PAEgNIUM an) Ich seh mich noch immer nicht! Wart nur, Bube, wenn ich heimkehr, lass ich Dich blenden! (rasch ab auf die Galeere)

PAEGNIUM (nimmt seine Maske ab: ein mageres, trotziges Knabengesicht wird sichtbar; er wischt sich mit dem Arme den Schweiss von der Stirne und fächelt sich mit der Maske) 
K.R. Thago ( $z u$ Lemniselenis) Kurz und gut, mit einem Wort: $\ulcorner$ jetzt wirds aber $\urcorner$ höchste Zeit, dass ich mich einschiff, und Du -- Du kehrst morgen wieder zu Dordalus zurück.

LEMNiSELENIS (entsetzt) Was sagt Ihr?! Wohin?! Zu Dordalus?!

5 K.R. Thago Ja. Nach Pompeji.

LEMNISELENIS (wie zuvor) Ich soll wieder zum Sklavenhändler?! Ihr wollt mich abermals wieder weiterverkaufen?! (sie reisst sich die Maske ab: ein schönes Kind mit traurigen Augen und einem frühverbittertem Zug starrt K.R. THAGO verzweifelt an)

K.R. Thago (stutzt unwillkürlich etwas) Warum so verzweifelt? Vielleicht erwirbt Dich ein Besserer, Schönerer, Reicherer --

LEMNISELENIS (unterbricht ihn) Es gibt keinen Reicheren als Euch! Oh, bringt mich nicht wieder auf den Sklavenmarkt! Es folget so selten was Besseres nach!

K.R. Thago Aber-aber, grosses Kind! Was hast Du Dir denn vorgestellt? Und ausserdem möchte man doch nur Dein Gutes --

Lemniselenis Wollet lieber das Schlechte, mein Herr! Gewährt mir weiter Euere Huld, ich bleib Euch nichts schuld! Wenn Ihr heimkehrt von Euerer Sommerfahrt, wird von mir alles in bar bezahlt -- jeder Groschen ein Kuss, wenn ich nur nicht wieder auf den Sklavenmarkt muss!

K.R. Thago Wer weiss, ob ich zurückkehr? Ob das Schiff nicht versinkt? Wer befiehlt $\ulcorner$ dem Sturm, dem Meer $\urcorner$-- Neptun oder ich? Bin ich dem Neptun sein Vertrauter? Na also! Abgesehen davon, dass ich Dich jetzt ein halbes Jahr umsonst ernähren müsst! Vorsicht ist die Mutter der Weisheit und Sparsamkeit ist eine Weltanschauung. Verkenne mich nicht, mein Kind!

Lemniselenis Jetzt weiss ich $\ulcorner$ bald $\urcorner$ nichtmehr, was ich glauben soll, Herr Präsident.

K.R. Thago Glaub, was Du willst, aber ${ }^{\ulcorner}$verschleuder ${ }^{\urcorner}$Dich nur $\left.{ }^{\ulcorner}\right\urcorner$nicht zu $\ulcorner$preiswert ${ }^{-}$-- (er geht auf die Galeere zu)

Toxilus ( $z u$ K.R. Thago) Gute Erholung, frohe Fahrt!

30 K.R. Thago ( $z u$ Toxilus) Danke. (er hält und wendet sich nochmals LeM-||NISELENIS $z u$; mit erhobenem Zeigefinger) Du bist unter Brüdern sechshundert Silberlinge wert -- (ab auf die Galeere)

LEMNISELENIS (schreit plötzlich auf) Nein!! (sie verbirgt ihr Gesicht in den Händen) Matrosa (legt ihren Arm um Lemniselenis Schultern und tröstet sie) Gebe dem Kaiser, was des Kaisers ist -- --

\begin{tabular}{|c|c|c|}
\hline 1 & $\ulcorner$ jetzt $\rightarrow$ aber $\urcorner]$ & [es] |jetzt| wird\s/ \aber/ \\
\hline 21 & $\ulcorner$ dem $\rightarrow$ Meer $\urcorner]$ & $\operatorname{dem}^{1}$ Meer $[,]^{4} \operatorname{dem}^{3}$ Sturm $\backslash, / 2$ \\
\hline 26 & $\lceil$ bald $]$ & Ibald/ \\
\hline 27 & $\lceil$ verschleuder $\urcorner]$ & [verkauf] |verschleuder[e]| \\
\hline 27 & \ulcorner\urcorner$]$ & [ja] \\
\hline $27-28$ & $\lceil$ preiswert $\urcorner]$ & [billig] |preiswert| \\
\hline
\end{tabular}


4

NISELENIS zu; mit erhobenem Zeigefinger) Du bist unter Brüdern sechshundert Silberlinge wert -- (ab auf die Galeere)

LEMNISELENIS (schreit plötzlich auf) Nein!! (sie verbirgt ihr Gesicht in den Händen)

MATROSA

(legt ihren Arm um LBMNISELENIS schultern und tröstet sie) Gebe dem Kaiser, was des Kaisers ist -- --

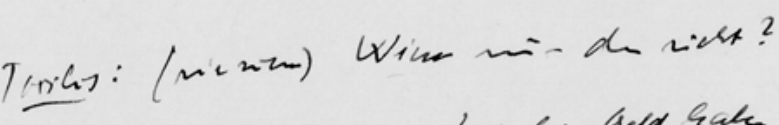

Matra: Whil dis jiese hix hir Geld Gaken -

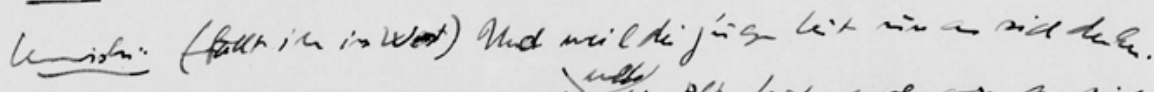

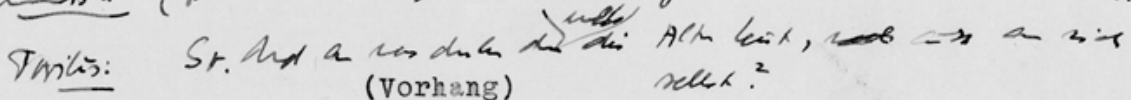

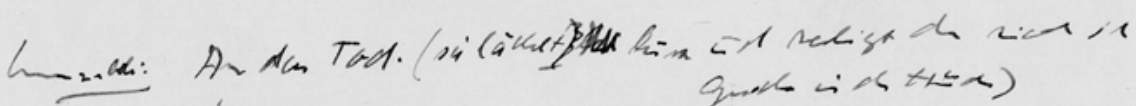
(Sh)

quats ind thex)

Thila: (other 2ica)

(Sn.te)

)

Matress:
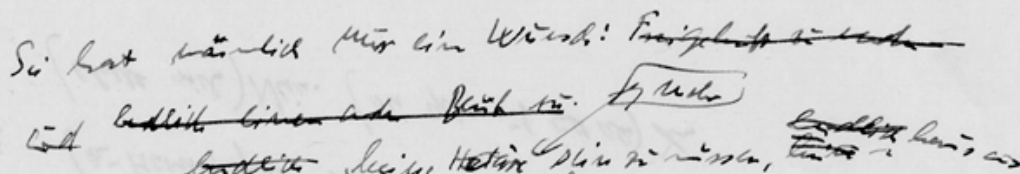

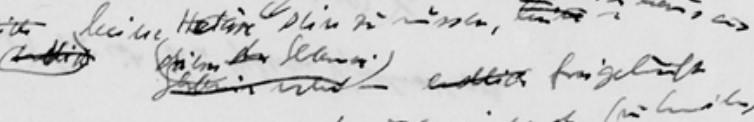

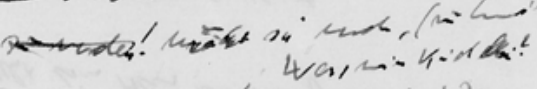

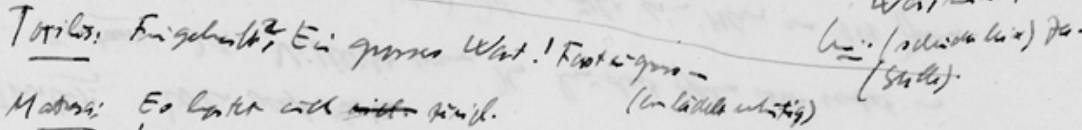

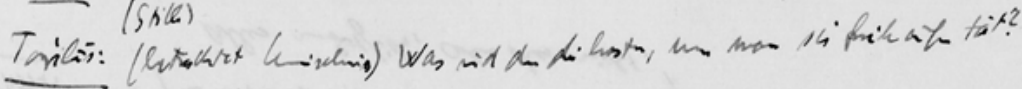

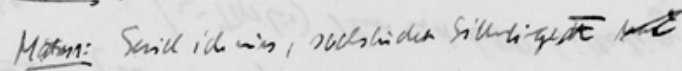

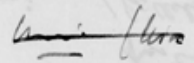

Torili: Prollata! for is ein Vuaqu!

Matons: Selet $x_{\text {no }}$ ! Warle 


\section{$-7-$}

NISELENIS zu; mit erhobenem Zeigefinger) Du bist unter

Brüdern sechshundert Silberlinge wert -- (ab auf die Galeere)

LEMNISELENIS (schreit plötzlich auf) Nein!! (sie verbirgt ihr Gesicht in den Händen)

MATROSA (legt ihren Arm um LEMNISELENIS Schultern und tröstet sie) Gebe dem Kaiser, was des Kaisers ist -- --

Toxilus: (wie zuvor) Wieso nur das nicht?

Matrosa: Weil die jungen Leut kein Geld haben -

Lemniselenis: (fällt ihr ins Wort) Und weil die jungen Leut nur an sich denken. [wohl]

Toxilus: $\quad$ So. Und an was denken denn die Alten Leut, \{sond\} ausser an sich

$$
\text { (Vorhang) selbst? }
$$

Lemniselenis: An den Tod. (sie lächelt) \{beił kurz und verbirgt dann wieder ihr

\section{(Stille)}

Gesicht in den Händen)

Toxilus: (starrt sie an)

(Stille)

Matrosa: $\quad$ Sie hat nämlich nur einen Wunsch: Freigekauft zuwerdenund endlich einen anderen Beruf zu $\nabla^{[\mathrm{mehr}]}$ endlich heraus aus [endlich] [dieser der Sklaverei]

Sklavin mehr - endlich freigekauft zu werden! möchte sie werden (zu Lemniselenis) Was, mein Kindleinlchenl?

Toxilus: Freigekauft? Ein grosses Wort! Fast zu gross Lem: ( $\{$ schluchzt $\}$ leise): Ja.

Matrosa: Es kostet auch viel. zuviel.

$$
\text { (er lächelt wehmütig) (Stille) }
$$

(Stille)

Toxilus: (betrachtet Lemniselenis) Was wird denn die kosten, wenn man sie freikaufen tät?

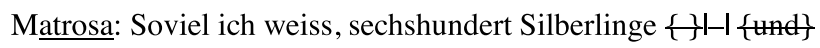

Lemni: (leise

Toxilus: Potz Pluto! Das ist ein Vermögen!

Matrosa: Seht Ihrs! \{Welcher\} 
Am nächsten Tage, wieder vor der Villa am Meer. Die Luxusgaleere ist ausgefahren, 5 nun liegt der Hafen still. Lemniselenis sitzt am Fusse der einen Säule und hält das Gesicht in den Händen verborgen. Matrosa sitzt neben ihr und strickt. Das Wetter ist noch immer schön.

Toxilus (kommt aus dem Hintergrunde, erblickt LeMniselenis, hält und betrachtet sie; $z u$ Matrosa) Was hat sie denn?

Matrosa Sie weint.

Toxilus Warum?

Matrosa Es ist ihr hier so gut gegangen und jetzt hat sie Angst vor der Zukunft.

Toxilus Aber-aber! Einen solchen schiechen alten Kracher, wie meinen gnädigen Herrn, den wird doch solch liebliches Kind immer wieder leicht finden! Die kriegt auch elegante, junge --

LEMNISELENIS (unterbricht ihn) Also nur das nicht!

Toxilus (perplex) Was hör ich?

Matrosa ( $z u$ Toxilus) Sie möcht von der männlichen Jugend nichts wissen.

ToXILUs (wie zuvor) Wieso warum denn nicht?

Matrosa Weil die jungen Leut kein Geld haben --

LEMNiselenis (fällt ihr ins Wort) Und weil die jungen Leut nur an sich denken.

ToxiLus So? Und an was denken denn noch die alten Leut, ausser an sich selbst?

LEMNISELENIS An den Tod. (sie lächelt kurz und verbirgt dann wieder ihr Gesicht in den Händen)

Toxilus (starrt sie an) $\|\ulcorner\urcorner$

Matrosa ( $z u$ Toxilus) Sie hat nämlich nur einen Wunsch: keine Hetäre mehr sein zu müssen, heraus aus dieser Sklaverei -- endlich freigekauft zu werden! (sie streichelt Lemniselenis) $\left\ulcorner\right.$ Nicht, ${ }^{\urcorner}$Kindchen?

LEMNISELENIS (schluchzt leise) Ja.

ToxiLus Freigekauft? Ein grosses Wort! Fast zu gross -- (er lächelt wehmütig)

Matrosa Es kostet auch eh zuviel. \ulcorner\urcorner

Toxilus (betrachtet aufmerksam $\ulcorner$ Lemniselenis, $z u$ MATrosa $\urcorner$ ) Was ${ }^{\ulcorner}$würds ${ }^{\urcorner} \operatorname{denn}\ulcorner\urcorner$ kosten, wenn man $\ulcorner$ die $\urcorner$ freikaufen tät?

Matrosa Soviel ich weiss, zirka sechshundert Silberlinge --

Toxilus Potz Pluto! Ein Vermögen!

Matrosa Wenns nach ihr ging, würde sie sich einen Herrn Gebieter aus dem Greisenasyl holen.

[(Stille $)]$

[Was, mein] |Nicht,|

[(Stille $)]$

Lemniselenis $\backslash z u$ Matrosa/

würd \s/

[die]

[s]|d|ie 
Toxilus Aha! Jetzt begreif ich allmählich! Ein gichtiger Greis, \ulcorner\urcorner$\ulcorner$ wacklig, zittrig, hirnrissig, der mit dem einem Haxen bereits durch die Unterwelt hatscht und von dem sich gar federleicht allerhand erben lässt -- schau-schau! Mit himmelblauen Pupillen blickt die Unschuld geschäftstïchtig in die $\ulcorner$ Welt. Jaja $\urcorner$, im Kontor der Tugend wird $\urcorner$ mit der Jugend gar häufig gewuchert!

LEMNISELENIS (blickt ihn plötzlich gross an) Ihr versteht mich nur halb.

\ulcorner\urcorner Toxilus Möglich. Denn die eine Hälfte, dass Ihr nämlich von der männlichen Jugend überhaupt nichts wissen wollt -- diese Hälfte kapier ich überhaupt nicht!

Lemniselenis (erhebt sich) Diese Hälfte kann ich mir nicht leisten. Aber Ihr dürft nicht annehmen, dass ich mit unerlaubten ${ }^{\top}$ Mitteln, als da sind: böse Kräuter, Schlangengift, etcetera -- das Ableben eines gebrechlichen Gebieters beschleunigen wollte. Ich würde auch nimmer ein massgebliches Wort in seinem Testament fälschen, aber ich tät ihm die Schrecken der Unterwelt ausmalen, und das fiele mir leicht, denn ich müsst ihm doch nur vom Schicksal der Sklaven auf der Oberwelt berichten. Die Haare würden ihm alle gen Himmel stehen und er würd mich vor lauter Grauen garantiert freikaufen, um nicht in der Unterwelt als Sklave verhandelt zu werden, als ein Ding mit menschlichen Allüren -- Oh Götter, es fällt mir immer schwerer an Euere Güte zu glauben! Sagt mir: gibt es Euch denn überhaupt? Und wenn es Euch gibt, warum seid Ihr denn so böse zu mir? Wie gern würde ich gut sein --

Toxilus Das ist ein Traum.

Matrosa ( $z u$ Toxilus) Sie hat eine zarte Seele.

Toxilus ( $z u$ Matrosa) Was verstehst Du unter Seele?

\ulcorner\urcorner

LEMNISELENIS Was sich aus einem fortsehnt.

(Stille)

Toxilus Ich weiss nicht, ob Ihr gut sein wollt, ich seh nur, dass Ihr schön seid. Sehr schön. $\ulcorner$ Komisch, ich $\urcorner$ sehs erst jetzt.

$\left\ulcorner\right.$ LEMNISELENis (lächelt) Schad, dass Ihr keine hundert Jahr alt seid $\ulcorner$ und $\urcorner$ dass $\operatorname{Ihr}\left\ulcorner\right.$ nie $^{\urcorner}$ sechshundert Silberlinge haben werdet -

Toxilus (unterbricht sie) Nie? $\left.{ }^{\ulcorner}\right\urcorner$Warum soll ich niemals in meinem Leben 600 Silberlinge besitzen?!

Matrosa Es ist alles möglich, aber das nicht.

Toxilus Wer sagt das?

35 Matrosa Ich.

LEM ( $z u$ ToxiLus) Würdet Ihr mich freikaufen, wenn ihr $\ulcorner$ es könntet??

\begin{tabular}{|c|c|c|}
\hline 1 & \ulcorner\urcorner$]$ & Leerzeile getilgt \\
\hline $1-5$ & $\ulcorner$ wacklig $\rightarrow$ wird $\urcorner]$ & ergänzt aus $\mathrm{K}^{4} / \mathrm{TS}^{2} / \mathrm{A}^{3} / \mathrm{BS} 30 \mathrm{a}, \mathrm{BI} .13$ \\
\hline 4 & $\ulcorner$ Welt. Jaja $\rceil]$ & Welt $\backslash . /[--][j]|J| a j a$ \\
\hline 7 & \ulcorner\urcorner$]$ & Leerzeile getilgt \\
\hline $7-8$ & $\lceil$ Toxilus $\rightarrow$ nicht! $\rceil$ & ergänzt aus $\mathrm{K}^{4} / \mathrm{TS}^{2} / \mathrm{A}^{3} / \mathrm{BS} 30 \mathrm{a}, \mathrm{BI} .13$ \\
\hline $10-23$ & $\ulcorner$ Mitteln $\rightarrow$ Seele? $\urcorner]$ & ergänzt aus $\mathrm{K}^{4} / \mathrm{TS}^{2} / \mathrm{A}^{3} / \mathrm{BS} 30 \mathrm{a}, \mathrm{BI} .14$ \\
\hline 24 & \ulcorner\urcorner$]$ & Leerzeile getilgt \\
\hline 28 & $\ulcorner$ Komisch, ich $\urcorner]$ & $\backslash$ Komisch,/[I] $|\mathrm{i}| \mathrm{ch}$ \\
\hline $29-414,8$ & $\ulcorner$ LEMNISELENIS $\rightarrow a u f)\urcorner]$ & $($ LEMNISELENIS $\rightarrow$ auf)/ \\
\hline 29 & $\ulcorner$ und $\urcorner]$ & und[,] \\
\hline 29 & $\ulcorner$ nie $\urcorner]$ & nie[mals] \\
\hline 31 & \ulcorner\urcorner$]$ & [Wer sagt das?] \\
\hline 36 & 「es könntet?ך] & [600 hättet?] les könntet? \\
\hline
\end{tabular}


Toxilus \ulcorner\urcorner Sofort!

Matrosa (lacht) $\ulcorner$ Gerede Gerede!

LEM ( $z u$ Toxilus) Hört nicht auf sie!

Toxilus Ich hör nur auf Euch.

5 LEM (lächelt) Fein! Und warum würdet Ihr mich freikaufen?

Toxilus Weil Ihr mir gefällt.

LEM (erschrickt etwas, lächelt \{nochmals\} und sieht ihn an)

MATRosa (horcht besorgt auf) ${ }^{\urcorner}$

Aabbruch der Bearbeitungl 
$\| \quad\ulcorner$ LEM Ich würde nur einen Menschen lieben - nur den, der mich freikauft. Toxilus Also nur einen Reichen? LEM Nein. Ich würde auch den lieben, der mir zur Flucht verhilft!?

\section{ZWEITES BILD}

Am nächsten Tage, wieder vor der Villa am Meer. Die Luxusgaleere ist ausgefahren, nun liegt der Hafen still. LemNiselenis sitzt am Fusse der einen Säule und hält das

Gesicht in den Händen verborgen. Matrosa sitzt neben ihr und strickt. Das Wetter ist noch immer schön.

Toxilus (kommt aus dem Hintergrunde, erblickt LEMNISELENIS, hält und betrachtet sie; zu MAtrosa) Was hat sie denn?

Matrosa Sie weint.

Toxilus Warum?

Matrosa Es ist ihr hier so gut gegangen und jetzt hat sie Angst vor der Zukunft. `Der Dordalus müsste ja $\ulcorner$ schon hiersein. $\urcorner$

$\left\ulcorner\right.$ Toxilus $\left\ulcorner\right.$ Jaja, er ${ }^{\urcorner}$ist zwar ein widerlicher Bursche, aber es gibt noch schlimmere Sklavenhändler - da könnt ich erzählen!

Matrosa Ich auch.

$\ulcorner$ LEMNISELENIS Ich gäb was drum, wenn ich nur nicht wieder auf den Sklavenmarkt müsst!

Toxilus $\ulcorner$ Aber-aber! $\urcorner$ Ist alles nur halb so schlimm. Wie oft seid Ihr denn schon verkauft worden?

LEMNISELENIS $\ulcorner$ Dreimal.

ToxiLus Nur?

$\left\ulcorner\right.$ Matrosa ${ }^{\urcorner}\ulcorner(z u$ Lemniselenis $)\urcorner$ Uns genügts. Was, Kindchen? ( $z u$ Toxilus) Sie regt sich dabei immer so furchtbar auf.

Toxilus $\urcorner\ulcorner$ Also $\urcorner\ulcorner$ einen $\urcorner\ulcorner$ derart $\urcorner\ulcorner$ geizigen $\urcorner$ alten Kracher, wie meinen gnädigen Herrn, den wird doch solch liebliches Ding immer wieder leicht finden! Die kriegt auch elegante, junge --

LEMNISELENIS (unterbricht ihn) $\left\ulcorner\mathrm{Nur}^{\urcorner}\right.$das nicht!

Toxilus (perplex) Was hör ich?

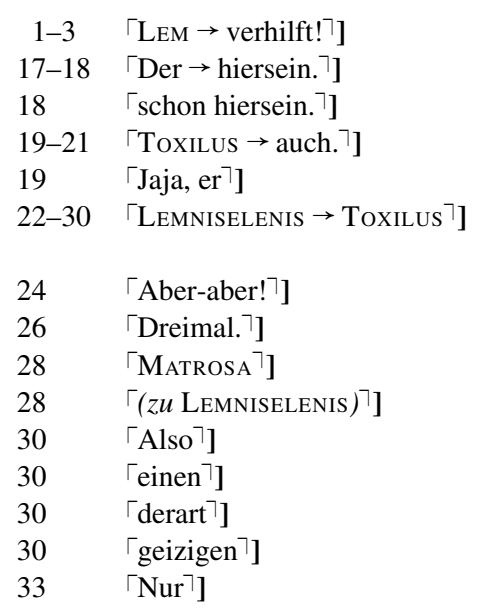

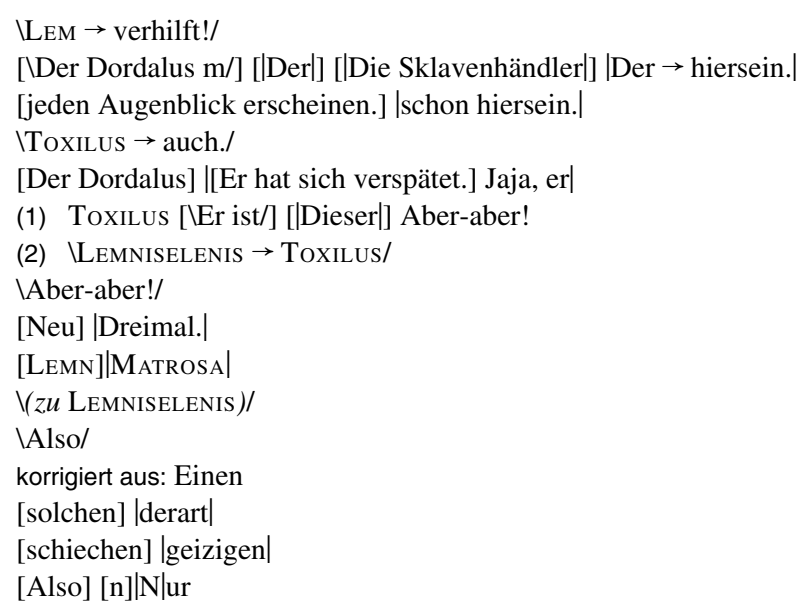


Matrosa ( $z u$ Toxilus) Sie möcht von der männlichen Jugend nichts wissen.

Toxilus (wie zuvor) Wieso warum denn nicht?

-

\urcorner LEMNISELENIS $\urcorner\ulcorner$ Weil $\urcorner$ die $\ulcorner$ Jungen $\urcorner$ nur an sich denken.

5 Toxilus So? Und an was denken denn noch die $\ulcorner$ Alten $\urcorner$, ausser an sich selbst?

LEMNISELENIS An den Tod. (sie lächelt kurz und verbirgt dann wieder ihr Gesicht in den Händen)

Toxilus (starrt sie an)

\|Matrosa ( $z u$ Toxilus) Wenns nach ihr ging, würde sie sich einen Herrn Gebieter aus dem Greisenasyl holen.

Toxilus Aha! Jetzt begreif ich allmählich! Ein gichtiger Greis, wacklig, zittrig, hirnrissig, der mit dem einem Haxen bereits durch die Unterwelt hatscht und von dem sich gar federleicht allerhand erben lässt -- schau-schau! Mit himmelblauen $\mathrm{Pu}-$ pillen blickt die Unschuld geschäftstïchtig in die Welt. Jaja, im Kontor der Tugend wird mit der Jugend gar häufig gewuchert!

LEMNISELENIS (ohne ihn anzusehen) Ihr versteht mich nur halb.

Toxilus Kein Wunder! Denn jene Hälfte, dass Ihr nämlich von der männlichen Jugend überhaupt nichts wissen wollt -- diese Hälfte kapier ich überhaupt nicht!

LEMNISELENIS (sieht ihn plötzlich gross an) Diese Hälfte kann ich mir nicht leisten. (sie verbirgt ihr Gesicht wieder in den Händen)

Matrosa ( $z u$ Toxilus) Sie hat nämlich nur einen Wunsch: keine Hetäre mehr sein zu müssen, heraus aus dieser Sklaverei -- endlich freigekauft zu werden! $\left\ulcorner\left(\left\ulcorner u u^{\urcorner}\right.\right.\right.$LEMNISELENIS ${ }^{\urcorner}$) Nicht, Kindchen?

$\ulcorner$ LEMNISELENIS $\ulcorner$ (leise $)\urcorner \mathrm{Ja}$.

Toxilus Freigekauft? Ein grosses Wort!

Matrosa Fast zu gross -- $\ulcorner\text { (sie lächelt })^{\urcorner}$

Toxilus (betrachtet schätzend Lemniselenis; zu Matrosa) Was würds denn kosten, wenn man die freikaufen tät?

Matrosa Soviel ich weiss, zirka sechshundert Silberlinge --

30 Toxilus Potz Pluto! Ein Vermögen!

$\|$ LEMNISELENIS $\ulcorner$ (horcht auf $)\urcorner$ Bin ichs nicht wert?

Toxilus \ulcorner\urcorner$\left\ulcorner\right.$ Woher soll ich das wissen $-(\text { er grinst })^{\urcorner}$

LeMniselenis (kurz) Danke.

(Stille)

ÖLA 3/W $113-$ BS 58 b [2], BI. 11

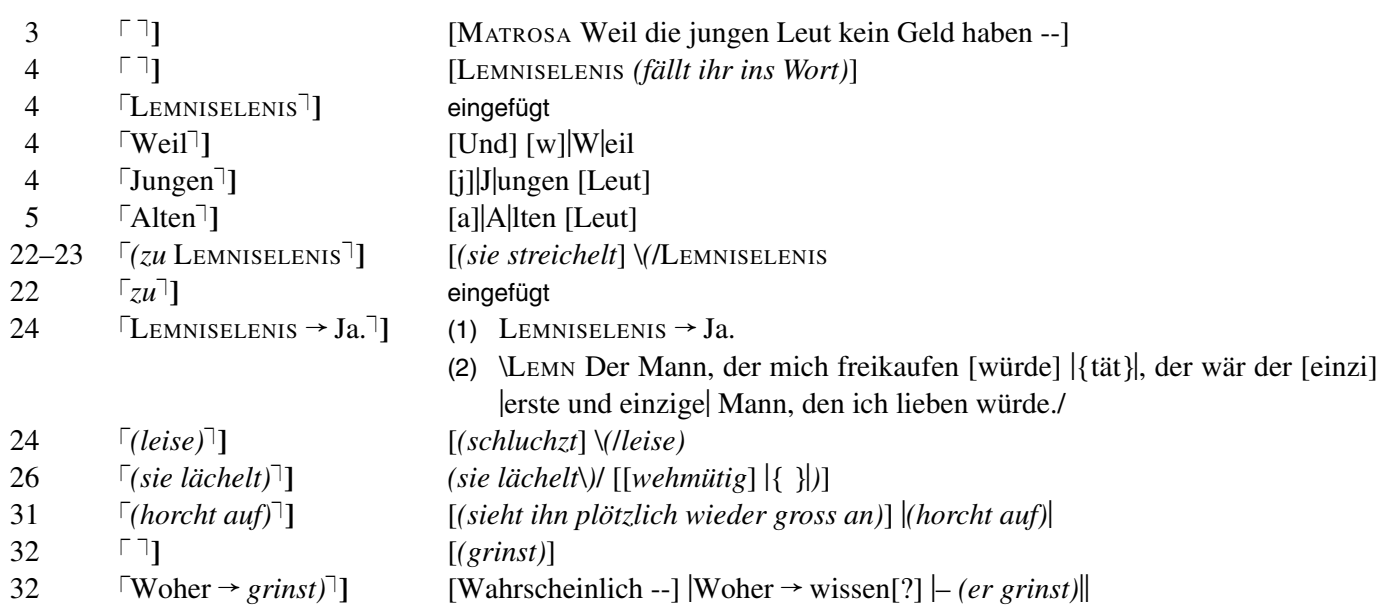


Toxilus ( $z u$ Lemniselenis) Seid mir nicht böse, es war nicht böse gemeint -- $\ulcorner$ Ich bin überzeugt, Ihr seid sogar sechstausend wert.

$\|\ulcorner$ Matrosa Hoffentlich! Denn das wär nicht schön von Euch.

Toxilus $(z u$ LEMNISELENIS $)\ulcorner\urcorner\ulcorner$ Ihr seid sogar so schön, dass $\ulcorner$ ich Euch freikaufen tät,

LEM (lächelt kalt) Lieb von Euch.

Matrosa (zu Toxilus) Ihr und 600 Silberling? $\ulcorner($ sie lacht $)\urcorner$ Es ist alles möglich, aber das nicht!

Toxilus Wer sagt das?

10 Matrosa Ich. Vielleicht wenn Ihr hundert Jahr alt werdet -

LEM (fällt ihr ins Wort) Ich möcht einen Mann von 100 Jahren.

$\ulcorner$ Toxilus ( $\ulcorner$ grinst; $z u$ MatrosA $\urcorner$ ) Sie ist die geborene $\ulcorner$ Krankenschwester. $\urcorner\urcorner$

LEM (erhebt sich) Nein. (sie geht auf und $a b$ ) Ihr ${ }^{\urcorner}$Aabbruch der Bearbeitungl

\begin{tabular}{ll}
\hline 1-2 & $\ulcorner$ Ich $\rightarrow$ wert. $\urcorner$ \\
$3-13$ & $\ulcorner$ MatrosA $\rightarrow$ Ihr $\urcorner]$ \\
& \\
4 & \ulcorner\urcorner$]$ \\
$4-5$ & $\ulcorner$ Ihr $\rightarrow$ hätt! $\urcorner$ \\
& \\
$4-5$ & $\ulcorner$ ich $\rightarrow$ hätt! $\urcorner]$ \\
7 & $\ulcorner($ sie lacht $)\urcorner]$ \\
12 & $\ulcorner$ ToxiLus $\rightarrow$ Krankenschwester. $\urcorner]$ \\
12 & $\ulcorner$ grinst $\rightarrow$ MATROSA $\urcorner]$ \\
12 & $\ulcorner$ Krankenschwester. $\urcorner$
\end{tabular}

[UIhr seid sicherli/] |Ich $\rightarrow$ wert.|

\|[LEMNISELENIS (erhebt sich und geht auf und ab) Ihr dürft nicht annehmen, dass ich mit unerlaubten Mitteln, als da sind: böse] [MATrosa $\rightarrow$ Ihr|

[Ich sehe ja, dass Ihr schön seid - sehr schön sogar.]

(1) Und [wenn ich] les tut mir [\{leid $\}]$ leid, dass ich keine\| 600 Silberlinge [hätt] |hab, dann würd ich Euch freikaufen.|

(2) \Ihr $\rightarrow$ hätt!/ [wenn ich 600 Silberlinge] |ich $\rightarrow$ hätt!|

$\backslash($ sie lacht $) /$

[( sie erhebt] |ToxıLus $\rightarrow$ Krankenschwester.|

$z$ u Matrosa ${ }^{2}$; grinst $^{1}$

korrigiert aus: Krankenschwester
ÖLA 3/W $113-$ BS 58 b [2], BI. 6 
Am nächsten Tage, wieder vor der Villa am Meer. Die Luxusgaleere ist fortgefahren, 5 nun liegt der Hafen still. Lemniselenis sitzt am Fusse der einen Säule und hält das Gesicht in den Händen verborgen. Matrosa sitzt neben ihr und strickt. Das Wetter ist noch immer schön.

Toxilus (kommt aus der Villa, erblickt Lemniselenis, hält und betrachtet sie; zu Matrosa) Was hat sie denn?

Matrosa Sie weint.

Toxilus Warum?

Matrosa Es ist ihr hier so gut gegangen und jetzt hat sie Angst $\|$ vor der Zukunft. Der Dordalus müsst ja schon hier sein.

Toxilus Jaja, er ist zwar ein widerlicher Bursche, aber es gibt noch schlimmere Sklavenhändler -- da könnt ich erzählen!

Matrosa (lächelt) Ich auch.

LEMNISELENIS Ich gäb was drum, wenn ich nicht wieder auf den Sklavenmarkt müsst!

Toxilus Aber-aber! Ist alles nur halb so schrecklich! Wie oft seid Ihr denn schon verkauft worden?

LEMNISELENIS Dreimal.

Toxilus Nur?

Matros a (lächelt wieder) Uns genügts. Nicht, Kindchen? ( $z u$ Toxilus) Sie regt sich dabei immer so furchtbar auf.

Toxilus Also einen derart geizigen alten Kracher, wie meinen gnädigen Herrn, den sollt doch solch liebliches Ding immer wieder leicht finden! Die kriegt auch elegante, junge --

LEMNISELENIS (unterbricht ihn) Nur das nicht!

30 Toxilus (perplex) Was hör ich?

Matrosa ( $z u$ Toxilus) Sie möcht von der männlichen Jugend nichts \Textverlust।

|| Toxilus (wie zuvor) Wieso warum denn nicht?

$\|$ LEMNiselenis Weil die jungen Herren nur an sich denken.

Toxilus So? Und an was denken denn noch die alten Herren, ausser an sich selbst?

Lemniselenis An den Tod. (sie lächelt kurz und verbirgt dann wieder ihr Gesicht in den Händen)

ToxiLus (starrt sie an)

Matrosa ( $z u$ Toxilus) Wenns nach ihr ging, würde sie sich einen Herrn Gebieter aus dem Greisenasyl holen.

Toxilus Aha! Jetzt begreif ich allmählich: ein gichtiger Greis, wacklig, zittrig, hirnrissig, der mit dem einem Haxen bereits durch die Unterwelt hatscht und von dem sich gar federleicht allerhand erben lässt -- schau-schau! Eine geborene Krankenschwester!

LEMNISELENIS (sieht ihn plötzlich gross an) Ihr versteht mich nur halb.

Toxılus Kein Wunder! Denn jene Hälfte, dass Ihr nämlich von der männlichen Jugend überhaupt nichts wissen wollt -- diese Hälfte kapier ich allerdings überhaupt nicht! 
LEMNISELENIS (erhebt sich) Diese Hälfte kann ich mir nicht leisten. (sie geht auf und ab) Ihr dürft nicht annehmen, dass ich mit unerlaubten Mitteln, als da sind: böse Kräuter, Schlangengift, etcetera, das Ableben eines gebrechlichen Gebieters beschleunigen wollte. Ich würde auch nimmer ein massgebliches Wort in seinem Testament fälschen, aber ich tät ihm die Schrecken der Unterwelt ausmalen, und das fiele mir leicht, denn ich müsst ihm doch nur vom Schicksal der Sklaven auf der Oberwelt berichten. Die Haare würden ihm alle gen Himmel stehen und er würd mich vor lauter Grauen garantiert freikaufen, um nicht in der Unterwelt als Sklave verhandelt zu werden, als ein Ding mit menschlichen $\|$ Allüren -- Oh Götter, es fällt mir immer schwerer an Euere Güte zu glauben! Sagt mir: gibt es Euch denn überhaupt? Und wenn es Euch gibt, warum seid Ihr denn so böse zu mir? Wie gern würde ich gut sein --

Toxilus Das ist ein Traum.

Matrosa ( $z u$ Toxilus) Sie hat eine zarte Seele.

Toxilus ( $z u$ Matrosa) Was verstehst Du unter Seele?

LEMNISELENIS Was sich aus einem fortsehnt.

(Stille)

\|Matrosa ( $z u$ Toxilus) Sie hat nämlich nur einen Wunsch: keine Hetäre mehr sein zu müssen, heraus aus dieser Sklaverei -- endlich freigekauft zu werden! ( $z u$ LEMNISELENIS) Nicht, Kindchen?

LEMNISELENIS (blickt vor sich hin; leise) Ja.

Toxilus Freigekauft? Ein grosses Wort!

Matrosa Fast zu gross -- (sie lächelt)

|| Toxilus (betrachtet schätzend Lemniselenis; $z u$ Matrosa) Was würds denn ko-

25 sten, wenn man sie freikaufen tät?

Matrosa Soviel ich weiss, zirka sechshundert Silberlinge --

Toxilus Potz Pluto! Ein Vermögen!

LEMNISELENIS (horcht auf) Bin ichs nicht wert?

Toxilus (grinst) Wahrscheinlich --

30 Lemniselenis (kurz) Danke.

(Stille)

Matrosa ( $z u$ Toxilus) Jetzt habt Ihr sie beleidigt. Macht es wieder gut.

$\|$ Toxilus ( $z u$ Lemniselenis) Es war nur ein Witz.

LEMNISELENIS (lächelt kalt) Lieb von Euch.

ÖLA 3/W $113-$

35 Toxilus (grinst) Ich tät Euch sogar freikaufen, wenn ich sechshundert Silberlinge hätt --

$\|$ LEm (lacht kurz hellauf)

Toxilus Wer lacht da?

LEM Ich.

40 Matrosa ( $z u$ Toxilus) Ihr und sechshundert?! Es ist alles möglich, aber das nicht!? Toxilus Wer sagt das?

Matrosa Ich.

37-40 「LEM $\rightarrow$ nicht! $\rceil$

14.)/ Matrosa [(fällt ihm ins Wort)] |(zu ToxiLus)| Ihr und sechshundert?! [(sie] $[\mid$ LEM|] $\backslash($ /lacht $[$ )] $\mid k u r z$ hellauf $) \mid \backslash 1$.$) LEM$

2.) Toxilus Wer lacht da?

3.) LeM Ich./

[MMATrosa/] Es $\rightarrow$ nicht! 
Toxilus Und ich sage: wenn ich will, leiht mir jederzeit $\lceil$ jedermann $\urcorner$ sechshundert -und auch noch mehr!

$\ulcorner$ LEM (horcht auf)

$\ulcorner$ Matrosa Was Ihr nicht sagt!

5 Toxilus Warum nicht? Einem Toxilus leiht man gern!

Matrosa Grössenwahn!

Toxilus ( $z u$ Matrosa) Vergesst nur nicht, wer ich bin!

$\ulcorner$ LEM Ein Sklave.

Toxilus Gewiss! Jedoch $\urcorner\ulcorner$ während $\urcorner$ der Abwesenheit unserer Herrschaft wurde $\ulcorner$ der Sklave Toxilus ${ }^{\urcorner\urcorner\urcorner}$zum obersten Verwalter dieser Villa eingesetzt -- verstanden? Denn ich geniesse das restlose Vertrauen meines Herrn, $\ulcorner$ und ich könnt mir jederzeit auch 6000 Silberlinge beschaffen, ich müsst nur was verkaufen, was nicht mir gehört oder irgendetwas unterschlagen, einen Wechsel fälschen oder dergleichen!

15 Matros A $\ulcorner$ Würdet Ihr das tun?

Toxilus Nein!

Matrosa Na also!

LEM Schade. ${ }^{7}$

\| Lemniselenis $\left\ulcorner\right.$ Denn der ${ }^{\urcorner}$Mann, der mich freikaufen würde, der wäre der erste und einzige Mann, den ich lieben könnte.

ÖLA 3/W $113-$

$\ulcorner$ Toxilus (horcht auf)

Matrosa Alles Unsinn!

LEM Oho!

(Stille)

Toxilus ( $z$ u LEM) Wo kommt Ihr denn her?

LEM Mein Papa ist ein Parasit. $\urcorner$ Aber er müsste für mich da sein, grad oder krumm, auf jede Art, mit allen Mitteln, gesetzlich oder ungesetzlich --

Matrosa (unterbricht sie) Hört auf! (sie sieht sich ängstlich um) „Ungesetzlich“, wenn das einer hört -- (sie herrscht ToxiLus an) Was starrt Ihr denn das Mädel so $30 \quad$ an?!

$\begin{array}{ll}1 & \ulcorner\text { jedermann }\urcorner \\ 3 & \ulcorner\text { LEM } \rightarrow \text { auf })\urcorner] \\ 4 & \ulcorner\text { MATROSA } \rightarrow \text { sagt! }\urcorner] \\ 8-9 & \ulcorner\text { LEM } \rightarrow \text { Jedoch }\urcorner \\ 9 & \ulcorner\text { während }\urcorner \\ 9-10 & \ulcorner\text { der } \rightarrow \text { Toxilus }\urcorner \\ 10 & \ulcorner\urcorner] \\ 11-18 & \ulcorner\text { und } \rightarrow \text { Schade. }\urcorner\end{array}$

$15\ulcorner$ Würdet $\rightarrow$ tun? $\rceil$

$19\ulcorner$ Denn $\operatorname{der}\urcorner]$

21-26 「ToxiLus $\rightarrow$ Parasit. $\urcorner]$

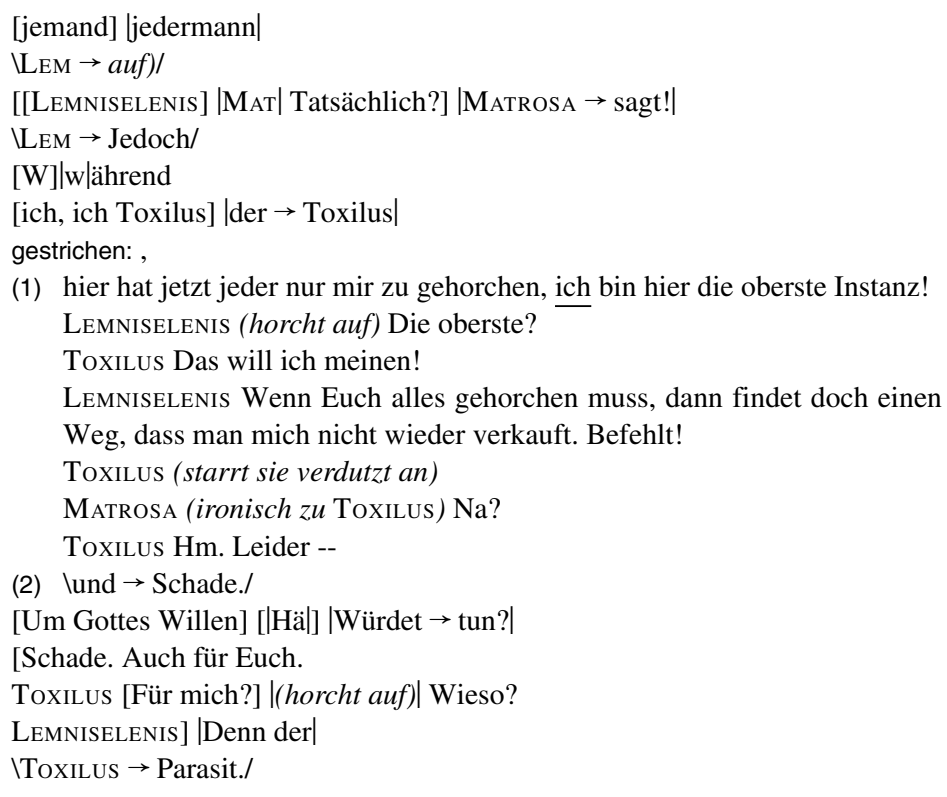


Toxilus (einfach) Weil sie mir gefällt. Zu dumm, sie ist wirklich schön. Komisch, dass ich das erst jetzt bemerk --

Matrosa (aufgeregt zu Lemniselenis) Kommt, Herrin, ziehen wir uns zurück! Das fängt immer so an -- ich bitt Euch, macht keine Dummheiten, Ihr seid eine brave

$5 \quad$ Hetär und jener ist ein Sklave! Das schickt sich nicht, der Kaiser hats verboten!

LEMNISELENIS (hört nicht auf sie, sondern sieht nur in Toxilus Augen) Wer hilft mir?

Toxilus (zuckt plötzlich zusammen) Au! (er fasst sich ans Herz und windet sich etwas)

LEMNISELENIS (erschrickt) Was ist? Was habt Ihr?

10 Toxilus (leise) Mir scheint, ich bin verwundet -- so ein stechender Schmerz --

Lemniselenis Tuts weh?

Toxilus (lächelt) Nein.

(Die Luft klingt)

LEMNiSELENis (blickt empor und ruft) Amor, Amor! -- Dort fliegt er, dort!

15 Matrosa (blickt auch empor) Na servus!

LEMNISELENIS (glücklich) Oh, jetzt fürcht ich nichtsmehr! $\ulcorner$ Amor hat geholfen!

TOXILUs (eilt plötzlich auf LEMNISELENIS zu und hält dicht vor ihr; rasch und leise) Geh rasch in das Haus, versteck Dich im Keller links, ganz hinten rechts, und alles übrige überlass nur mir!

LEMNISELENIS (gibt ihm einen flüchtigen Kuss auf die Wange; leise) Wiedersehen -(rasch ab in die Villa)

$\|$ Matrosa Wo ist die jetzt hin?

Toxilus Fort -- (mit Pathos) um nie wieder verkauft zu werden! Nie wieder!

Matrosa Seid Ihr wahnsinnig geworden?! Wo `habt Ihr die Ärmste versteckt wo?!

25 Toxilus Sag ich nicht.

Matrosa $\left\ulcorner\right.$ Wenn sie entdeckt wird, habt Ihr $\left\ulcorner\right.$ sie $\operatorname{am}^{\urcorner}$Gewissen! $\urcorner$

Toxilus Gerne, sehr gerne!

(Man hört Peitschenknallen von links)

DIE BEIDEN (zucken etwas zusammen und starren hin)

30 Paegnium (lauft rasch von links herbei, verfolgt vom AufSeHer, der mit seiner Peitsche knallt)

$\ulcorner$ AufseHER (ausser Atem) Lausbub, elender! Ich soll ein $\ulcorner$ Peitschenkuli $\urcorner$ sein? Das $\left\ulcorner\right.$ wagst ${ }^{\ulcorner}$Du? Mir, dem $\urcorner$älteren Mann?!

$\ulcorner$ PaEgnium (frech) Du bist ein Sklav, genau, wie ich!

35 Aufseher So? Na pass nur auf, was ich Dir geben werde!

PAEG Nichts! Du hast ja nichts!

Aufseher Mich sollen doch alle Götter strafen --

PAEG $\ulcorner\text { (fällt ihm ins Wort })^{\urcorner}$Das wünsch ich Dir auch als guter Freund!

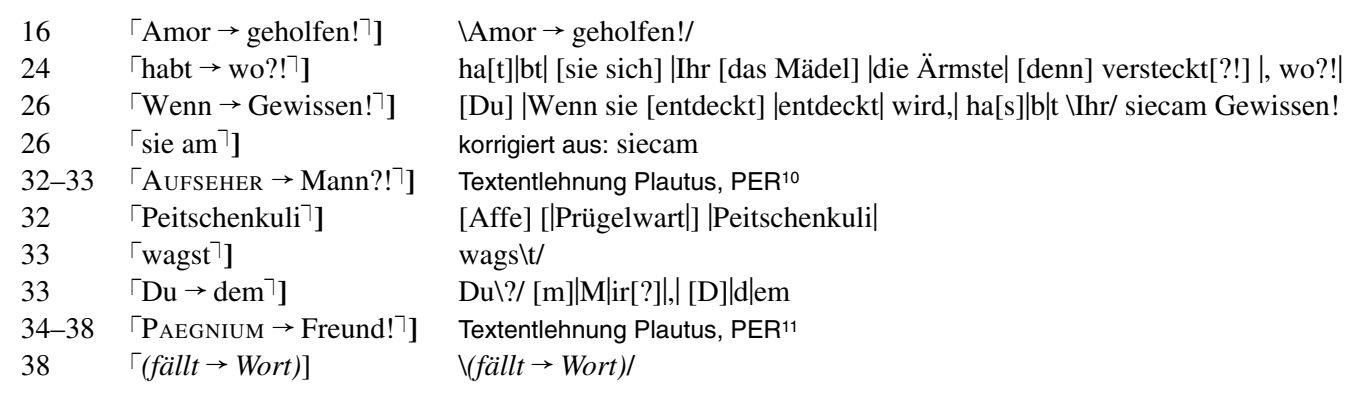


$\left\ulcorner\right.$ AUfSEH ${ }^{\urcorner}$Jetzt steht die Welt nimmer lang -- (er will sich auf $\left\ulcorner{ }^{\mathrm{PAEGNIUM}}{ }^{\urcorner}\right.$mit der Peitsche stürzen)

Paegnium (rasch ab in die Villa)

Toxilus (zum Aufseher, verstellt ihm den Weg) Halt!

5 Aufseher (perplex) Warum?

Toxilus Heut wird hier nicht geprügelt, denn heut bin ich \ulcorner\urcorner froh!

AufseHER Das ist $\left\ulcorner\operatorname{mir}^{\urcorner}\ulcorner\right.$ganz wurscht!

Toxilus Mir aber nicht!

AufseHER Das ist mir erst recht wurscht!

10 Toxilus (ruhig) Halt den Mund.

Aufseher (braust auf) Was erlaubst $\left.{ }^{\ulcorner} \mathrm{Du}\right\urcorner$ Dir --

Toxilus (unterbricht ihn donnernd) Wer ist da die oberste Instanz?! Du oder ich?! Wer?!

AufseHER $\ulcorner($ kleinlaut $)\urcorner$ Ich bin nicht taub.

15 Toxilus ( $\ulcorner$ wieder ruhig $\urcorner)\left\ulcorner\right.$ Also wer ${ }^{\urcorner}$hat hier zu befehlen?

Aufseher $\ulcorner$ Immer der, der fragt.

Toxilus $\ulcorner$ (grinst $)\urcorner{ }^{\urcorner}$Korrekt $\urcorner$, sehr ${ }^{\ulcorner}$korrekt $\urcorner$. Du kannst doch reiten?

AufsEHER ${ }^{\ulcorner}$Reiten? Natürlich kann ich reiten! Ich bin $\left\ulcorner\right.$ja ${ }^{\urcorner}$sogar gewissermassen auf dem Pferd geboren --

ToxiLus $\left\ulcorner(\text { fällt ihm ins Wort })^{\urcorner}\right.$Man merkts noch immer. Also höre: geh in den Stall und sattel $\|$ das schnellste Pferd.

Toxilus `Sattel zwei Pferde - (er blickt auf Matrosa) Drei Pferde!

Matrosa Ich kann nicht reiten!

25 Toxilus Egal!

Matrosa Ich brich mir noch den Hals!

Aufs Ihr zwei braucht drei Pferde?

${ }^{\ulcorner}$ToxiLus ${ }^{\urcorner}$Frag nicht, wenn ich befehle! $\left\ulcorner\right.$Sattel ${ }^{\urcorner}\left\ulcorner\right.$lieber, ${ }^{\urcorner}$sattel!

\begin{tabular}{|c|c|c|}
\hline 1 & $\lceil$ AUFSEH $\rceil$ & korrigiert aus: AUFSEh \\
\hline 1 & $\lceil$ PAEGNIUM $\urcorner]$ & korrigiert aus: PAEGnium \\
\hline 6 & \ulcorner\urcorner$]$ & [endlich] \\
\hline 6 & $\ulcorner$ froh! $\rceil]$ & froh[.]|!| \\
\hline 7 & $\ulcorner\operatorname{mir}\urcorner]$ & {$[\mathrm{mir}]$} \\
\hline 7 & \ulcorner\urcorner$]$ & [laber/] \\
\hline 11 & $\ulcorner\mathrm{Du}\urcorner]$ & $\mathrm{D}[\mathrm{i}]|\mathrm{u}|$ \\
\hline 14 & $\ulcorner($ kleinlaut $)\rceil]$ & {$[($ ruhig $)] \mid($ kleinlaut $) \mid$} \\
\hline 15 & $\lceil$ wieder ruhig $\rceil$ & [wieder] [leise] $\mid$ ruhig $\mid$ \\
\hline 15 & $\ulcorner$ Also wer $\urcorner]$ & \Also/ [Wer] |wer| \\
\hline 16 & $\lceil$ Immer $\rightarrow$ fragt. $\urcorner]$ & [Du.] |Immer $\rightarrow$ fragt.| \\
\hline 17 & $\ulcorner($ grinst $)\rceil]$ & $\backslash($ grinst $) /$ \\
\hline 17 & $\ulcorner$ Korrekt $\urcorner]$ & [Brav] |Korrekt| \\
\hline 17 & $\ulcorner$ korrekt $\urcorner]$ & [brav] |korrekt| \\
\hline 18 & \ulcorner\urcorner$]$ & {$[($ perplex $)]$} \\
\hline 18 & $\ulcorner\mathrm{ja}\urcorner]$ & lja/ \\
\hline 20 & $\ulcorner($ fällt $\rightarrow$ Wort $)\urcorner]$ & $\backslash($ fällt $\rightarrow$ Wort $) /$ \\
\hline 22 & \ulcorner\urcorner$]$ & [Warum?] \\
\hline $23-27$ & $\ulcorner$ Sattel $\rightarrow$ Pferde? $\urcorner]$ & ISattel $\rightarrow$ Pferde?/ \\
\hline 28 & $\lceil$ Toxilus $\urcorner]$ & eingefügt \\
\hline 28 & $\ulcorner$ Sattel $\urcorner]$ & korrigiert aus: Sattel, \\
\hline 28 & $\lceil$ lieber, $\urcorner]$ & \[lieb] |lieber,|/ \\
\hline
\end{tabular}


Aufs \ulcorner\urcorner (zuckt die Schultern $)\left\ulcorner\right.$ Von mir aus $\left\ulcorner\right.$ brechts Euch alle den Hals - ${ }^{\urcorner\urcorner}$

Matrosa (deutet plötzlich nach links) $\left\ulcorner\right.$ Dordalus! Dort kommt $\left\ulcorner\right.$ er! ${ }^{\prime}$

DIE DREI (blicken hin)

Aufs $\ulcorner$ Richtig!

$5\ulcorner$ Matrosa $\urcorner$ Unser aller $\ulcorner$ Händler.

$\left\ulcorner\right.$ ToxiLus ${ }^{\urcorner}$Ein $\ulcorner$Reptil.

Matrosa Auch ich war mal seine Ware. $\left\ulcorner\right.$ Aber wie ${ }^{\urcorner}$der einen lagert -- \ulcorner\urcorner Skandal!

\ulcorner\urcorner Aufseher Ein $\ulcorner$ schäbiger $\urcorner$ Geizhals! Wenn ich kein Sklave wäre, sondern ein freier Mann, dann tät ich dem Kerl was erzählen -- $\left.{ }^{\ulcorner}\right\urcorner$so! (er knallt mit der Peitsche)

Toxilus Knall hier nicht herum, sondern sattel lieber! Sattel, sattel! Aber dass Du mir die Pferde $\left\ulcorner\right.$ nicht $\mathrm{zu}^{\urcorner}$sehr schindest!

AufSEH $\ulcorner\text { (empört })^{\urcorner}$Ich? Ich sollt ein Tier misshandeln? Für was $\left\ulcorner\right.$hältst ${ }^{\urcorner}$Du mich?! (entrüstet $a b$ in den Hintergrund hinter die Villa)

15 Matrosa Toxilus! Im letzten Augenblick beschwör ich $\ulcorner$ Dich - $\urcorner$

Toxilus Beschwör mich nicht, sondern fahr ab! Oder bleib da, wie Du willst! Aber wenn Du mich verratest, dann häng ich Dich in das Meer hinein, mit dem Kopf nach unten, damit Dich die Polypen kitzeln!

Matrosa Nein, da tu ich nichtmehr mit! ( $a b$ in die Villa)

20 Dordalus (kommt von links mit zwei Gehilfen; er hält und sieht sich um) Ist das nicht Toxilus?

Toxilus (imitiert ihn) Ist das nicht Dordalus?

Dordalus Natürlich ist es Toxilus! Wie gehts-wie stehts, freches Haus! Na, was hab ich Dir gesagt vor acht Jahren? Du bringst es hier noch zuwas! Wer hat Dich hergebracht? Ich! Ich find schon immer die richtigen Stellen für die richtigen Sklaven!

Toxilus Ich bin Euch auch dankbar.

|| Dordalus Das hört man gern, denn Undank ist der Welten Lohn -- besonders von Euch Sklaven erntet man nichts als Undank, wo man sich Tag und Nacht abrak-

ÖLA 3/W $113-$ BS 58 b [1], Bl. $21 \mathrm{v}$

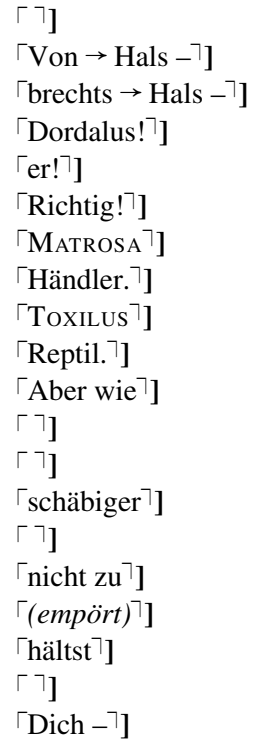

[Schön --]

IVon $\rightarrow$ Hals - I

[\{brechts $\}]$ brechts $\rightarrow$ Hals $-\mid$

Dordalus!/

[Dordalus[.]|!!] |er!|

Richtig[,]!! [er ists!]

IMatrosal

Händlerl./ [--]

[Toxilus] |Toxilus|

[eckelhaftes Untier.] |Reptil.|

[Wie] |Aber wie|

[ein]

gestrichen: UIII. Akt/

korrigiert aus: schäbbiger

[aber]

korrigiert aus: nichtbzu

[(empört)]

korrigiert aus: hältsts

[Toxilus Und Du geh]

[d]|D|ich[:] |- [nimm Vernunft an! Die Liebe ist allerdings wie der Vesuv da drüben, in einer Tur möcht sie ausbrechen, aber ein Sklave hat kein Krater zu sein -- spar Deine Lava und beherrsch Dich!] 
kert, um euch $\ulcorner$ ein $\urcorner$ gutes Haus zu verschaffen! Und dann verkauft man Euch noch unterm Preis, bloss damit Ihr es gut habt -- Dich auch. Dich hab ich auch viel zu billig verkauft, Du bereitest $\left\ulcorner\right.$ mir viel ${ }^{\urcorner}$Kummer! Mies wirds mir, wenn ich Dich seh -- also sehen wir was anderes: wo steckt denn die Hetäre, die ich mir da abholen soll? Lemniselenis heisst sie, die Schönste von Lemnos -- ist sie wirklich \ulcorner\urcorner hübsch?

Toxilus Herrlich! \ulcorner\urcorner

Dordalus $\ulcorner$ No! $\urcorner$ Sie stammt zwar nicht von mir, Dein Herr ist mir damals untreu geworden und hat sie bei Maximum in Herkulanum gekauft -- auch eine Firma!

$10 \quad$ Lauter Tineff!

Toxilus Sie ist aber wirklich schön --

Dordalus Dein Wort in Gottes Ohr! Mir gibt er sie jetzt in Kommission zum Verkauf -- auch ein Geschäft, nichts verdient man dabei, nur Müh und Plag und Aufregerei! Also zeig sie schon her! Wo steckt sie denn?

15 Toxilus Wenn ich das wüsst!

Aufseher (kommt zurück und hört das Folgende)

Dordalus Wie soll man das verstehen?

Toxilus Sie ist plötzlich verschwunden.

Dordalus Verschwunden? Du willst doch $\ulcorner$ damit $\urcorner$ nicht andeuten, dass sie -- gottbehüte!

Toxilus Ja.

Dordalus Sie ist geflohen?!

Toxilus Ihr sagt es.

Dordalus $\ulcorner$ Gott, Du bist gerecht! $\urcorner$ Na das sind ja nette Sachen, die Ihr da $\ulcorner$ treibt. $\urcorner$

25 Aufseher Wir?

DORDALus Ihr Sklaven seid immer nur „wir“. Wenn einer flieht, so haftet ihr alle! Alle, alle! Na in Euerer Haut möcht ich nicht stecken, wenn die ${ }^{\ulcorner}$Herrschaft retour ${ }^{\urcorner}$ -- wo er eh so jähzornig ist! Und der Herr Schwiegersohn erst! Na, Gott mit Euch, das werden Euere Buckel spüren! (ab mit seinen GEHIL nach links)

30 U AufseHER (fixiert Toxilus)

Toxilus (weicht seinen Blicken aus; nach einer Pause) Sind die Pferde gesattelt? AufseHER Nein.

ToxiLus Und warum nein?

AufseHER Weil ich nur nochmals fragen wollte, $\ulcorner$ welche $\urcorner$ Sättel ich nehmen soll, die gestickten oder -- Gut, dass ich gefragt hab! Oh Götter habt Dank! Das wär aber jetzt was gewesen, in was Du uns da hineingeritten hättest! Schämst Du Dich denn nicht?! Lässt die Hetär fliehen und denkst nicht an uns!

Toxilus Ich dachte nur an sie. ${ }^{\ulcorner}$Verzeih mir und hilf ${ }^{\urcorner}$mir --

$\begin{array}{ll}\ulcorner\text { ein }\urcorner \text { ] } & \text { korrigiert aus: einen } \\ \ulcorner\text { mir viel }\urcorner] & \text { korrigiert aus: mirbviel } \\ \ulcorner\urcorner] & {[\text { so] }} \\ \ulcorner\urcorner] & {[\text { Wirklich herrlich!] }} \\ \ulcorner\text { No! }\urcorner] & {[\text { Möglich.] |No!| }} \\ \ulcorner\text { damit }\urcorner] & \text { dalmit/ } \\ \ulcorner\text { Gott } \rightarrow \text { gerecht! }\urcorner] & \text { [Grosser Gott!] } \mid \text { Gott } \rightarrow \text { gerecht!| } \\ \ulcorner\text { treibt. }\urcorner] & \text { korrigiert aus: treibt } \\ \ulcorner\text { Herrschaft retour }\urcorner] & \text { korrigiert aus: Herrschaftvretur } \\ \ulcorner\text { welche }\urcorner] & \text { korrigiert aus: welches } \\ \ulcorner\text { Verzeih } \rightarrow \text { hilf }\urcorner] & \text { |Verzeih } \rightarrow \text { und/ [H]|h|ilf }\end{array}$


AUFSEH Ich kann mich beherrschen! Und überhaupt Dir soll ich helfen, wo Du mich immer $\left\ulcorner\right.$ anschnauzt ${ }^{\urcorner}$,Prügel nicht! Prügel $\left\ulcorner\right.$nicht! ${ }^{‘\urcorner}$ Das hab ich gern, so sehen sie aus, die Humanitätsapostel! -- (er knallt mit der Peitsche) $\ulcorner$ Jetzt bring ich Dich vor unser Gericht!

5 Toxilus Ich werd mich verantworten!

AufseHER Sie werden Dich verurteilen!

ToxiLus Ich nehme keine Strafe an!

(Vorhang) $)^{-1}$

\footnotetext{
$2 \quad\ulcorner$ anschnauzt $\urcorner] \quad$ ansc[ $]|h|$ nauzt

$2\lceil$ nicht! ‘ $] \quad$ nicht!‘ $\%$

3-8 $\quad\ulcorner$ Jetzt $\rightarrow$ Vorhang $)\rceil] \quad$ [Herbei-herbei! He, alle her! Alle, alle! Alle Sklaven herbei, alle!

Alle SKLAVEn (kommen von überall herbei; sie tragen noch ihre Masken)

AuFseHER] |Jetzt $\rightarrow$ Vorhang)|
} 
$\|$ Sklaven (ausser Toxilus und $\ulcorner\text { Matrosa, im Sprechchor) })^{\urcorner}$Hier tagt nun das Sklavengericht. ${ }^{\ulcorner}$Denn da ${ }^{\urcorner}$der Sklave ${ }^{\ulcorner}$keine Freiheit hat,,\ulcorner\urcorner$\left\ulcorner\right.$hat er $^{\ulcorner}$vor ${ }^{\ulcorner}$den ${ }^{\urcorner}$Freien ${ }^{\urcorner}$auch kein Recht. ${ }^{\urcorner\urcorner}$Denn die Macht und $\ulcorner$Gesetze $\urcorner$der Freien sind nicht $\ulcorner$die Gesetze der Sklaven..$\ulcorner\ulcorner$ Was $\urcorner$ für den Freien Recht, ist für den Sklaven Unrecht, und $\ulcorner$ umgekehrt $\urcorner$, aber das geht uns nichts an. ${ }^{\urcorner}$Die Gesetze der Freien sind niedergeschrieben, aber unsere sind ungeschrieben - ein jeder kennt sie dennoch. Denn wir kennen nur ein Gesetz: tue nichts, $\ulcorner$ was Sklaven schaden könnt!

Hier sind wir nun zusammen getreten, wie immer in tiefer Nacht, damits niemand weiss, denn wir dürfen nicht urteilen nach unserem Recht.

${ }_{10}\left\lceil\right.$ VorsitzendeR $\ulcorner\text { (erhebt sich })^{\urcorner}$Ich bin der Vorsitzende. $($setzt sich $\left.)\right\urcorner$

BeIsitzer Wir sind die Beisitzer.

$\ulcorner$ SKLAVE Ich führe das Protokoll.

AufseHER Ich bin der Ankläger.

\ulcorner\urcorner

$15\ulcorner$ Toxilus Und wer verteidigt mich?

Alle Du selbst! Nur Du selbst!?

Matrosa $\ulcorner$ (bei Seite $)\urcorner$ Ich tu nicht mit.

(Stille)

Vorsitzender (klopft) Der Ankläger hat das Wort!

20 Aufseher Hohes Gericht! Ihr wisst es ja eh schon alle, wie sich Euer Toxilus benommen hat - dieser Toxilus, der sich so gerne als Eueren Wohltäter aufspielt, $\ulcorner$ und derweil ist er nur ein sympathischer junger Mann! ${ }^{7}$

Fratzengalerie!

\begin{tabular}{ll}
\hline 1 & $\ulcorner$ Matros $a \rightarrow$ Sprechchor $)\urcorner]$ \\
$2-3$ & $\lceil$ Denn $\rightarrow$ Recht. $\urcorner]$
\end{tabular}

2-3 「Denn $\rightarrow$ Recht. $\urcorner]$

\begin{tabular}{|c|c|}
\hline 2 & $\ulcorner$ Denn da $\rceil$ \\
\hline 2 & $\ulcorner$ keine $\rightarrow$ hat,$\urcorner]$ \\
\hline 2 & \ulcorner\urcorner$]$ \\
\hline $2-3$ & $\ulcorner$ hat $\rightarrow$ Recht. $\urcorner]$ \\
\hline 2 & $\ulcorner$ vor $\rightarrow$ Freien $\urcorner]$ \\
\hline 2 & $\ulcorner\operatorname{den}\urcorner]$ \\
\hline 3 & $\ulcorner$ Gesetze $\urcorner]$ \\
\hline $3-4$ & $\ulcorner$ die $\rightarrow$ Sklaven. $\urcorner]$ \\
\hline $4-5$ & $\ulcorner$ Was $\rightarrow$ an. $\urcorner]$ \\
\hline 4 & $\ulcorner\mathrm{Was}\urcorner]$ \\
\hline $4-5$ & $\lceil$ umgekehrt $\urcorner]$ \\
\hline 7 & $\lceil$ was $\rightarrow$ könnt! $]$ \\
\hline 10 & $\ulcorner$ VORSITZENDER $\rightarrow$ sich $)\rceil]$ \\
\hline 10 & $\ulcorner($ erhebt sich $)\rceil]$ \\
\hline 12 & $\ulcorner$ SKLAVE $\rightarrow$ Protokoll. $\urcorner]$ \\
\hline 14 & \ulcorner\urcorner$]$ \\
\hline $15-16$ & $\lceil$ Toxilus $\rightarrow$ selbst! $]$ \\
\hline 17 & $\ulcorner($ bei Seite $)\rceil]$ \\
\hline $21-22$ & $\ulcorner$ und $\rightarrow$ Mann! $!]$ \\
\hline
\end{tabular}

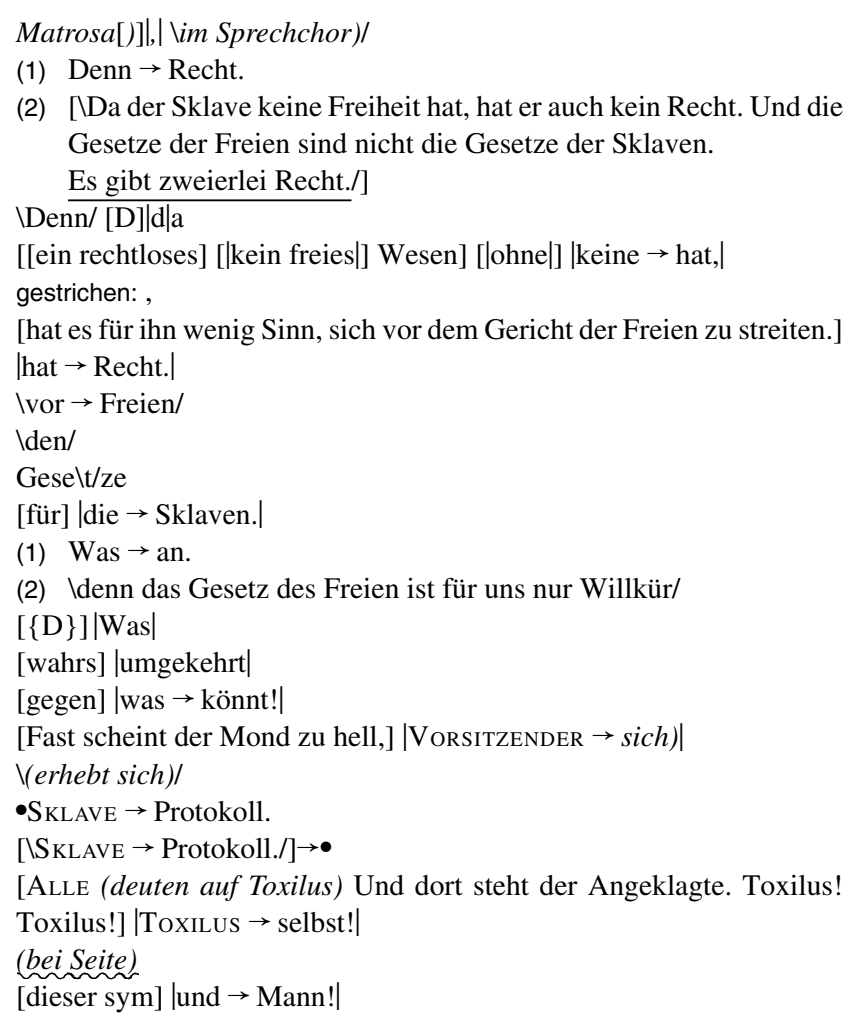


$\|$ V. Bild.

In den Kasematten des Zirkus. $\urcorner$

Von rechts führt eine $\ulcorner$ steile $\urcorner$ Treppe hinab. Im Hintergrund das Tor in die Arena. $\ulcorner$ Im Hintergrund eine Luke in der Wand. $\urcorner$ Oben eine Estrade, aus der man aus dem Zirkus

5 hinkommt. Man hört flotte Marschweisen, Gejohle und Beifall. Toxilus steht $\ulcorner$ in Ketten gelegt 7 , neben ihm ein Aufseher.

Aufseher Es wird noch einige Zeit dauern. Jetzt sind grad die Löwen dran. Dann kommt ein Wagenrennen, dann kommen wieder die Löwen und dann erst die Gladiatoren und $\mathrm{Du}$.

$\ulcorner$ (Beifall draussen $)\urcorner$

AufseHer (sieht $\ulcorner$ hinaus durch eine Luke) $\urcorner$ Bravo! Es steht 17:0 für die Löwen! Sie haben alle 17 zerrissen!

Toxilus Was haben denn die $\ulcorner 17\urcorner$ angestellt?

15 AufseHer Eigentlich nichts. Sie glauben an einen Gott, der gekreuzigt wurde. Ich weiss nicht, wie sie heissen. Mir scheint, Juden. Nein-nein, Christen heissen sie! Aber Juden und Christen - gehupft wie gesprungen! Gleiche Kappen, gleiche Brüder!

Toxilus Und warum muss ich eigentlich mit Gladiatoren kämpfen, warum lasst Ihr mich nicht gleich durch die Löwen zerreissen?

AufseHER $\left\ulcorner\right.$ Der ${ }^{\urcorner}$Löwentod ist \ulcorner\urcorner für Überzeugungstäter reserviert. ${ }^{\ulcorner}$Du aber bist ein gewöhnlicher Krimineller!

Toxilus $\ulcorner$ Und derweil hab $\urcorner$ ich $\ulcorner$ doch auch nur $\urcorner$ aus Überzeugung gestohlen! Aus Liebe -

Aufseher Kann ein jeder sagen! Gestohlen ist gestohlen! Und man stiehlt, um zu fressen! Ob aus Liebe oder nicht - was $\left\ulcorner\right.$ für ${ }^{\urcorner}$den Bauch bestimmt ist, ist kriminell!

GLADIATOREN (in Rüstungen gehen vorbei)

Aufseher Das waren die Gladiatoren.

Toxilus Martialisch.

30 A Aufseher Aber eigentlich gutmütig. Grosse Kinder. Nur eine rauhe Schale.

Toxilus Mit was soll ich eigentlich gegen die kämpfen?

AufseHer Du bekommst ein Schwert, allerdings nur ein kurzes.

Toxilus Aber da hab ich doch garkeine Aussicht, zu gewinnen!

AufseHER Natürlich nicht! $\ulcorner$ Das $\urcorner$ ist ja auch nicht der Zweck der Übung - übrigens: auch wenn Du mit voller Rüstung kämst, wärst Du gleich hin, diese Gladiatoren

\begin{tabular}{|c|c|c|}
\hline 2 & $\ulcorner$ In $\rightarrow$ Zirkus. $\urcorner]$ & $[$ Im Zirkus.] $\mid[1)].[\mid 2) \mid$.$] In \rightarrow$ Zirkus. $\mid$ \\
\hline 3 & $\ulcorner$ steile $\rceil$ & [tief $] \mid$ steile $\mid$ \\
\hline $3-4$ & $\ulcorner$ Im $\rightarrow$ Wand. $\urcorner]$ & Vm $\rightarrow$ Wand.I \\
\hline $5-6$ & $\lceil$ in $\rightarrow$ gelegt $\rceil$ & {$[g] \mid$ in $\rightarrow$ gelegt $\mid$} \\
\hline & $\ulcorner($ Beifall draussen $)\rceil]$ & (Beifall[)] $\mid$ draussen $) \mid$ \\
\hline & $\lceil$ hinaus $\rightarrow$ Luke $)\rceil]$ & hinaus[)] |durch eine Luke)| \\
\hline & $\ulcorner 17\urcorner]$ & $\backslash 17 /$ \\
\hline & $\ulcorner$ Der $\urcorner]$ & $\mathrm{D}[\mathrm{ie}]|\mathrm{er}|$ \\
\hline & \ulcorner\urcorner$]$ & [nur] \\
\hline $1-22$ & $\ulcorner\mathrm{Du} \rightarrow$ Krimineller! $]$ & [Ihr] |Du $\rightarrow$ Krimineller!| \\
\hline & $\ulcorner$ Und $\rightarrow$ hab $\urcorner$ & [Oho! Auch] |Und $\rightarrow$ hab $\mid$ \\
\hline & $\lceil$ doch $\rightarrow$ nur $\urcorner]$ & {$[\mathrm{hab}] \mid$ doch $\rightarrow$ nur $\mid$} \\
\hline & $\lceil$ für $\urcorner]$ & [für] |für| \\
\hline & $\ulcorner$ Das $\rceil]$ & [Aber] [d]|D|as \\
\hline
\end{tabular}


sind doch alles Beruf, alles Beruf - - was willst Du da als lumpiger Amateur? $(a b)$

Toxilus Oh Lemniselenis! $\ulcorner$ Wer als armer Bursche eindrang in die Pforten der Liebe (usw) $)^{\urcorner}$

5

Lem - Matrosa (erscheinen oben auf der Brüstung)

LEM Ich muss ihn sehen, ich muss ihn erreichen, ich muss ihn noch einmal sehen. Jetzt erst liebe ich ihn -

Matrosa Ach, Herrin, wie tollkühn seid 「Ihr?!

10 LEM Ich weiss nicht, wo er ist, aber meine Liebe begleitet ${ }^{\ulcorner}$ihn. $\urcorner$Ja, jetzt ja. Meine Liebe soll ihn schützen, ich werde für ihn beten $-\ulcorner\text { (sie stutzt })^{\urcorner}$Beten? Aber es gibt ja keine Götter mehr!

Matrosa Ich war gestern bei einem Gott. Tief unter der Erde.

LEM Man hört immer wieder von neuen Göttern, man weiss schon garnichtmehr was man glauben soll. $\ulcorner(a b$ mit MATRosa $)\urcorner$

$\circledast$

B AGNIO (kommt, begleitet vom Aufseher)

AufseHER Holla, Du kriegst einen Kollegen!

$20 \quad$ Bagnio Toxilus! ‘Was machst Du?!

ToxILUs Ich habs mir überlegt und wollte die 600 Silberlinge holen -

Bagnio Ach, Respekt!?

Toxilus Bagnio!

BAGNio Man $\left\lceil\right.$ hat ${ }^{\urcorner}$mein falsches Geld entdeckt. Man müsst eben Zeit haben, jetzt ist alles eins. - Die Gladiatoren. Ich kämpf überhaupt nicht. Ich lass mich gleich abstechen. Folge mir, es ist der beste Tod!

Toxilus Nein, ich werde kämpfen!

B AGNio Du wirst Dir doch nicht einbilden, dass Du siegst!

Toxilus $\ulcorner$ Nein. Ich werde sterben. Aber ich will mich wehren.?

$30\left\ulcorner\right.$ BAGNiO ${ }^{\urcorner}$Wozu?

Toxilus Ich werde nicht kapitulieren. Tief drinnen in der Brust sagt mir wer, dass ich recht habe. Recht, Recht, Recht! Und Recht ${ }^{\ulcorner}$soll ${ }^{n}$ niemals ohne Kampf untergehen!

Bagnio Du sprichst ergreifend.

(Lärm) Das war das Rennen. Gestern hab ich noch gesetzt. Ich hab zwar verloren, aber das Geld war eh nicht echt.

Toxilus Dann kommen wieder die Löwen.
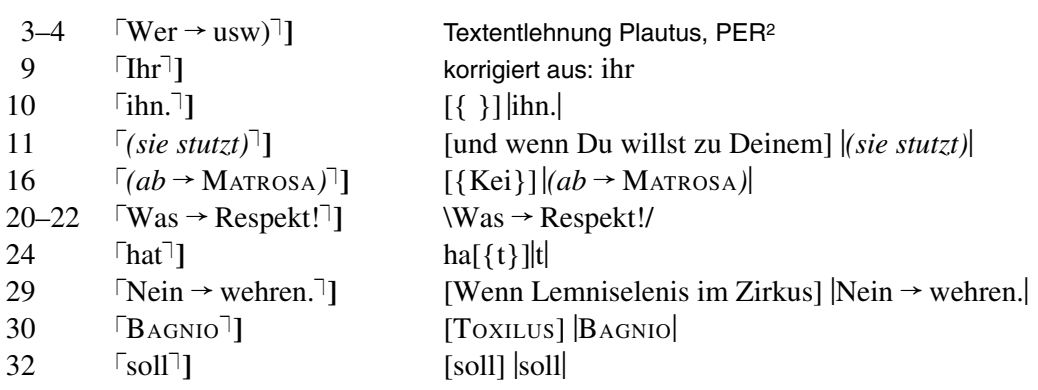
B AGNio Ich $\ulcorner$ kenn $\urcorner$ das Programm, ich bin hier Stammgast. Allerdings im Publikum. Es ist immer dasselbe. Was tätst Du jetzt, wenn Du frei wärst? Bereust Du Deine Tat?

Toxilus Wenn man mich nicht erwischt hätt, tät ichs nicht bereuen! Wenn ichs noch5 mal machen müsst, dann wüsst ich schon, was ich tät. (Die Kasse zuhaus)

$\ulcorner$ Toxilus Ich würde mich in der Nacht einschleichen.

Aufseher Die Gladiatoren! Der Erste raus! (Abschied)

BAGNio Wir sehen uns bald. Wir hören bald den Zerberus bellen. Fahr nicht allein über den Fluss!

10

B AGNio Jetzt bist Du frei! Und?

Toxilus Jetzt geh ich $\ulcorner$ stehlen? 


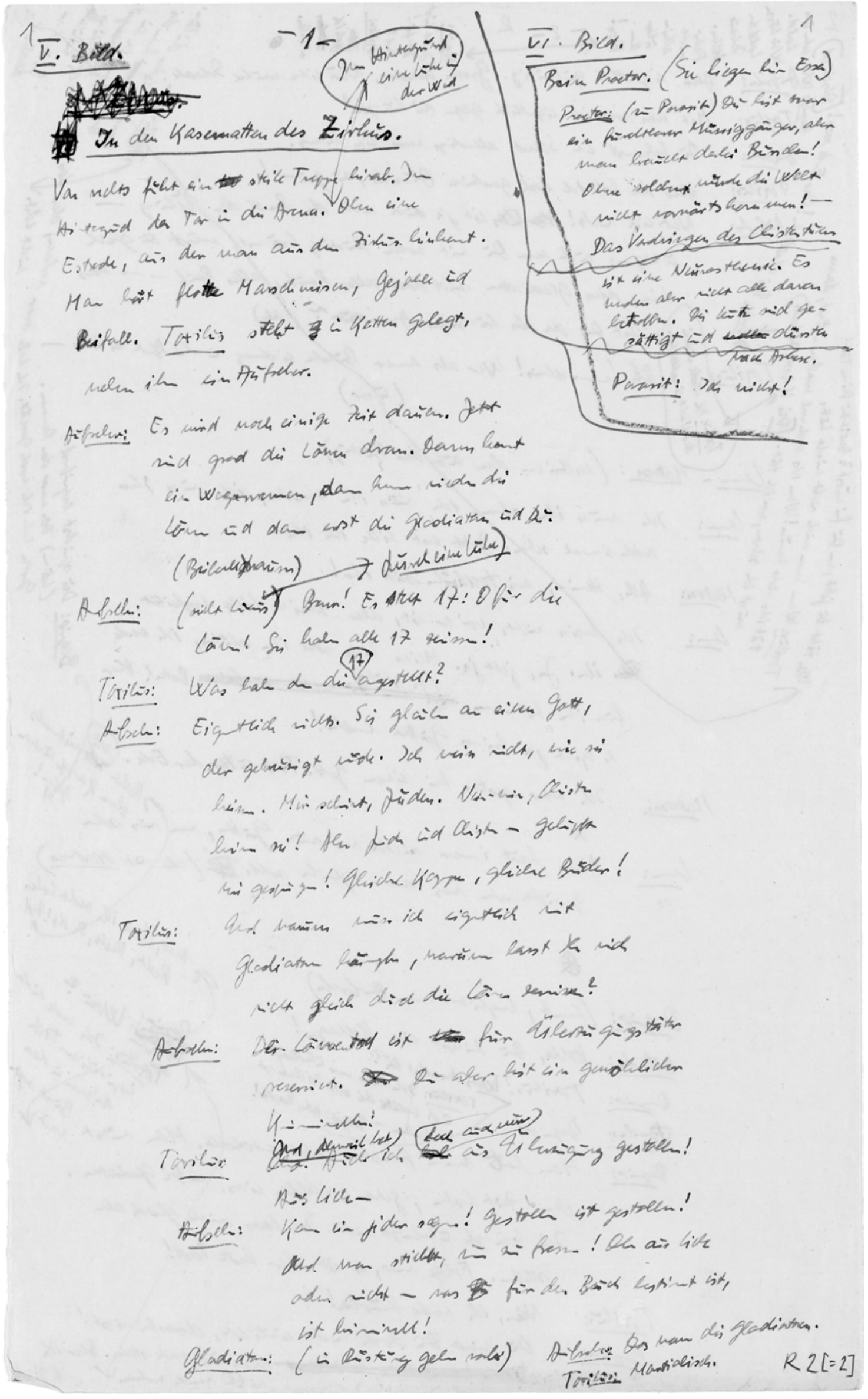




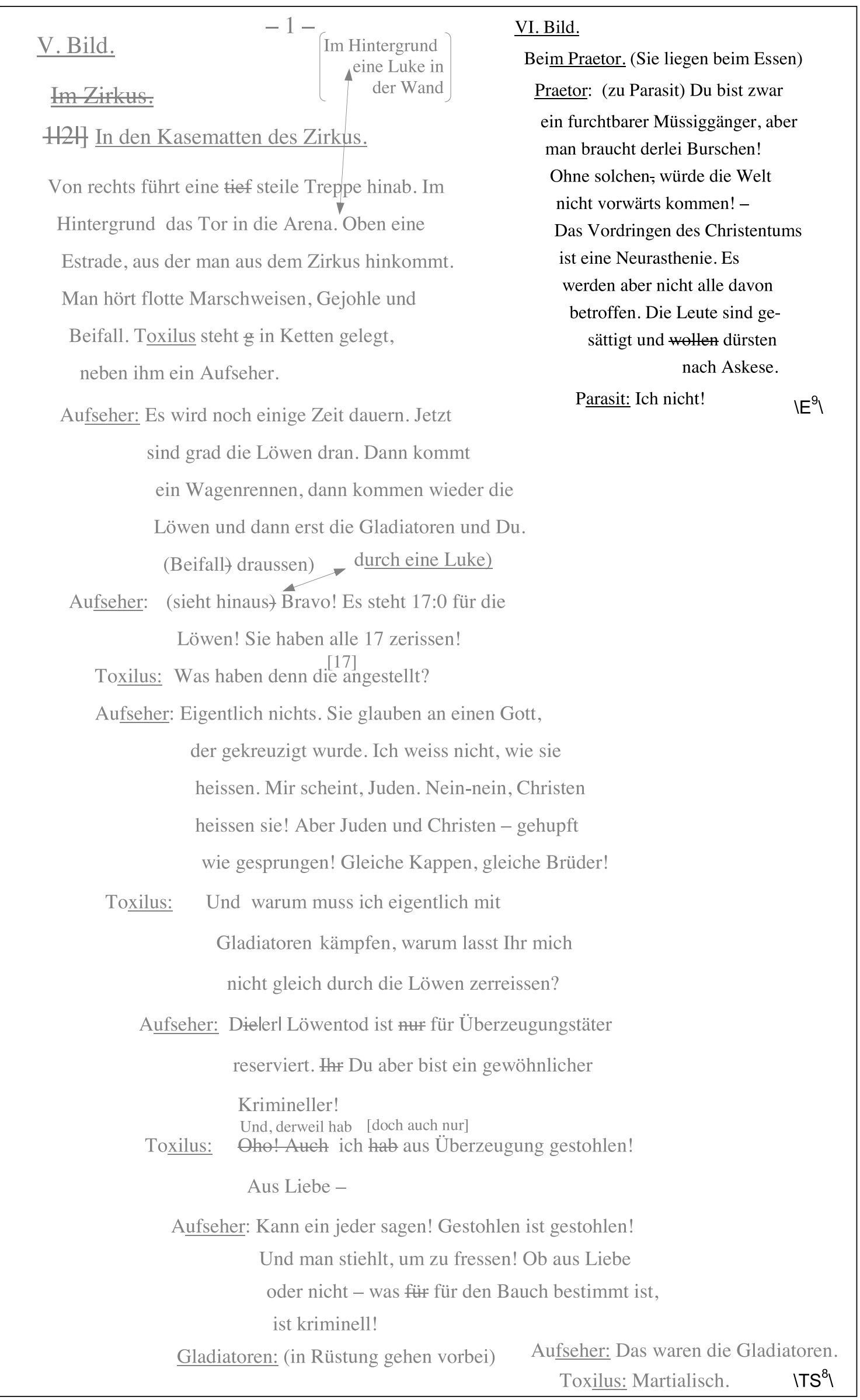




\section{Scush Bild. \\ Buim Proter.}

Lenumindenis: Fauzt or dem Praeter

Eis geseleschaft

Proetar: Wuncelar! Wum O-tanst, sorit is Qkinera Glicdem das Ineinanderglestan dur WCOten "isliaglas, es Mind Dich in teresrien: ich erlicus has Naclicer, dass 2) Oin cheralign Hern tot ibt. L.: Tor!!

Reactor: Ja. Eis Stä han ed ur.

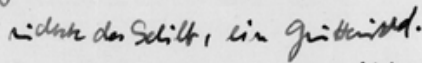
Es ging Entre wir Ma edMaso.

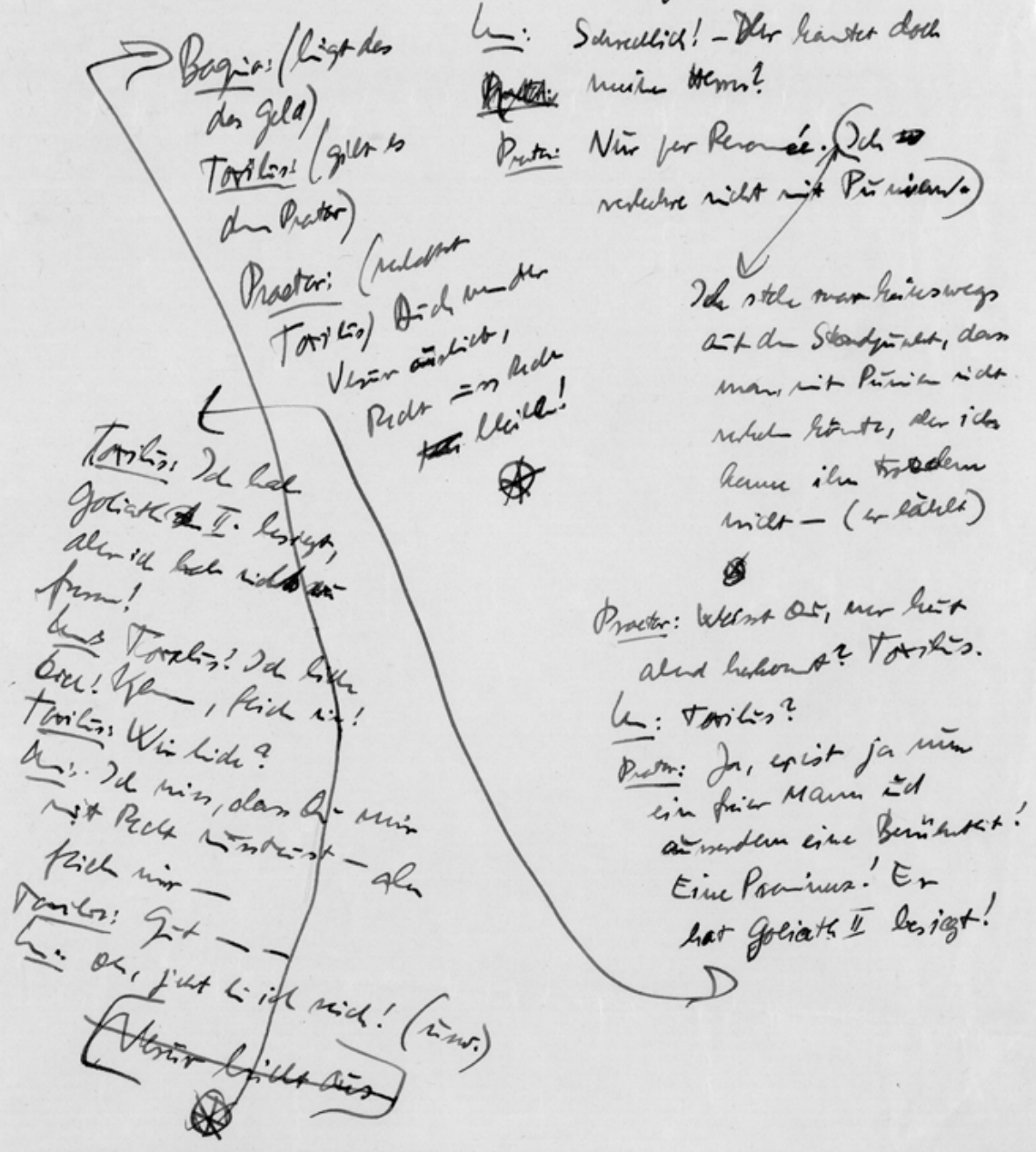




\section{Sechstes.Bild.}

Beim Praetor.

Lemniselenis: [tanzt vor dem Praetor]

\section{[Die Gesellschaft]}

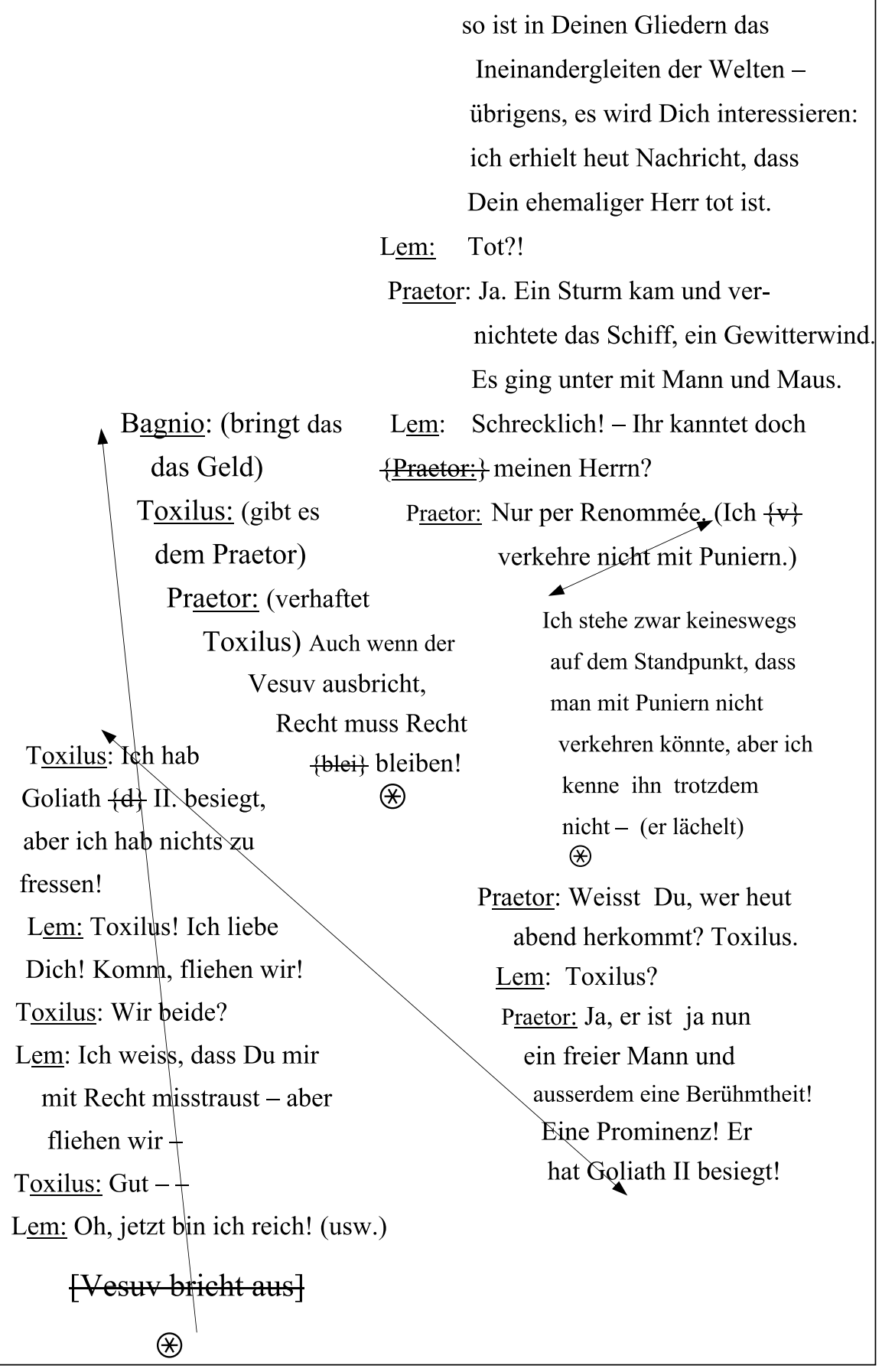




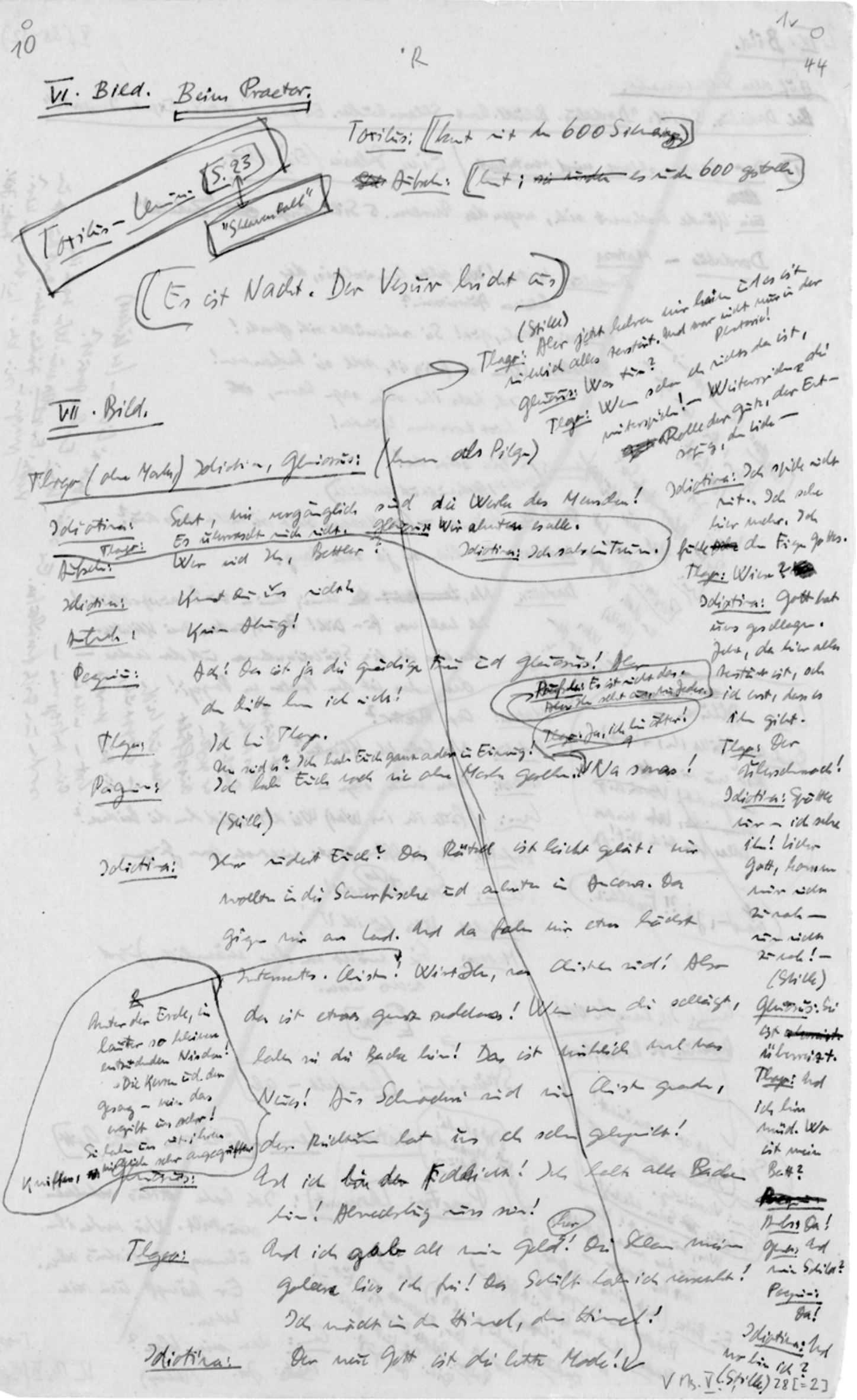


VI. Bild. Beim Praetor.

\section{[Toxilus $-\underline{\text { Lemnis. }}[\mathrm{S} .23]]$ \\ ["Sklavenball"]}

Toxilus: [kommt mit den 600 Silberlingen]

\{Sk1\} Aufseher: [kommt; sie wurden es wurden 600 gestohlen]

\section{[Es ist Nacht. Der Vesuv bricht aus]}

(Stille)

Thago: Aber jetzt kehren wir heim und es ist

VII. Bild. wirklich alles zerstört. Und zwar nicht nur in der Gloriosus: Was tun? Phantasie!

Thago: Wenn schon eh nichts da ist,

Thago (ohne Maske,) Idiotima, Gloriosus: (kommen als Pilger) weiterspielen! - \{w\}|Wleiterspielen, die

Idiotima: Seht, wie vergänglich sind die Werke des Menschen! \{Güte\} Rolle der Güte, der Ent-

Thago:

Es überrascht mich nicht. Gloriosus: Wir ahnten es alle.

Aufseher: Wer seid Ihr, Bettler?

Idiotima: Kennst Du uns nicht?

Aufseher: Keine Ahnung!

Paegnium: Ach den Dritten kenn ich nicht!

Thago: Ich bin Thago. sagung, der Liebe -

Idiotima: Ich spiele nicht mit.. Ich sehe Idiotima: Ich sahs im Traum. hier mehr. Ich fühle $\{$ sche\} den Finger Gottes. Thago: Wieso? \{\} Idiotima: Gott hat uns geschlagen. Jetzt, da hier alles

Paegnium: ITr seid es? Ich habe Euch ganz anders in Erinnerung!
Ich habe Euch noch nie ohne Maske gesehen! Na sowas! (Stille) zerstört ist, seh

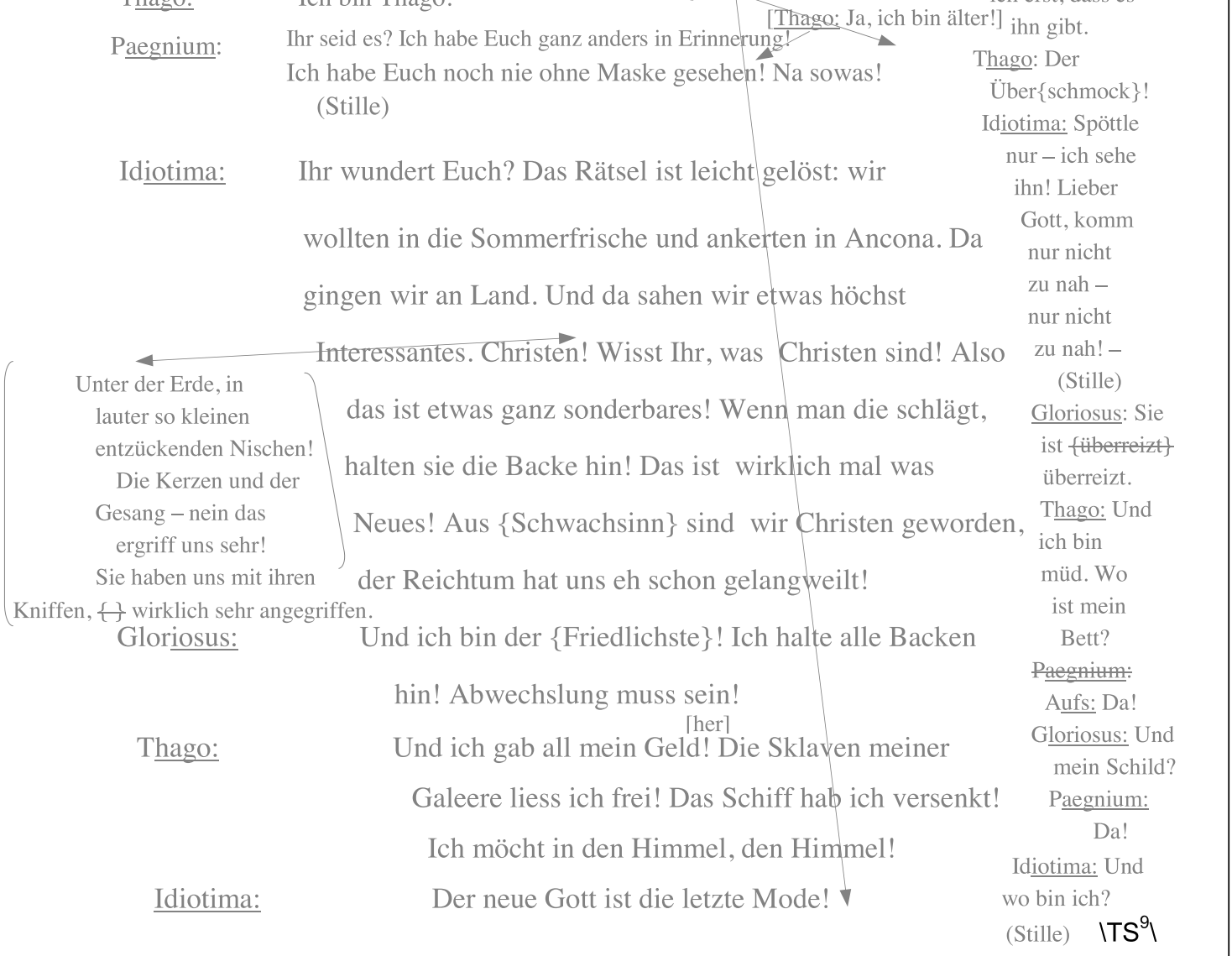


|| VII. Bild.

Thago (ohne $\ulcorner$ Maske), Idiotima, Gloriosus (kommen als Pilger)

Idiotima Seht, wie vergänglich sind die Werke des Menschen!

$5\ulcorner$ THAGO Es überrascht mich nicht.

Gloriosus Wir ahnten es alle.

IDIotima Ich sahs im Traum.

Aufseher Wer seid Ihr, Bettler?

IDIOTIMA Kennst Du uns nicht?

10 Aufseher Keine Ahnung!

$\left\ulcorner\right.$ PäGNIUM ${ }^{\circ}$ Ach! Das ist ja die gnädige Frau und Gloriosus! Aber den Dritten kenn ich nicht!

Thago Ich bin Thago.

PäGNIUM $\ulcorner$ Ihr seid es? Ich hab Euch ganz anders in Erinnerung! Ich habe Euch noch nie ohne Maske gesehen.

$\ulcorner$ THAGo Ja, ich bin älter!

Aufseher Es ist nicht das. Aber Ihr seht aus, wie Jeder.

$\left\ulcorner\right.$ PäGNIUM ${ }^{\top}$ Na sowas!

(Stille)

20 IDiotima Ihr wundert Euch? Das Rätsel ist leicht gelöst: wir sollten in die Sommerfrische und ankerten in Ancona. Da gingen wir an Land. Und da sahen wir etwas höchst Interessantes. Christen! `Unter der Erde, in lauter so kleinen entzückenden Nischen! Die Kerzen und der Gesang - nein das ergriff uns sehr! Sie haben uns mit ihren Kniffen, $\ulcorner$ wirklich $\urcorner$ sehr angegriffen. ${ }^{\urcorner}$Wisst Ihr, was Christen sind! Also das ist etwas ganz sonderbares! Wenn man die schlägt, halten sie die Backe hin! Das ist wirklich mal was Neues! Aus \{Schwachsinn $\}$ sind wir Christen geworden, der Reichtum hat uns eh schon gelangweilt!

GLORIOsus Und ich bin der \{Friedlichste\}! Ich halt alle Backen hin! Abwechslung muss sein!

Thago Und ich gab all mein Geld 'her`! Die Sklaven meiner Galeere liess ich frei! Das Schiff hab ich versenkt! Ich möcht in den Himmel, den Himmel!

IDiotima Der neue Gott ist die letzte Mode!

(Stille)

Thago Aber jetzt kehren wir heim und es ist wirklich alles zerstört. ‘Und zwar nicht nur in der Phantasie!

GLORIOSUS Was tun?

THAGO Wenn schon eh nichts da ist, weiterspielen! - $\ulcorner$ Weiterspielen $\urcorner$ die $\ulcorner$ Rolle der Güte $\urcorner$, der Entsagung, der Liebe -

\begin{tabular}{|c|c|c|}
\hline 3 & $\ulcorner$ Maske), $\urcorner]$ & korrigiert aus: Maske,) \\
\hline $5-7$ & $\lceil$ THAGO $\rightarrow$ Traum. $\urcorner]$ & $\backslash$ THAGO $\rightarrow$ Traum./ \\
\hline 11 & 「PÄGNIUM $\rceil]$ & korrigiert aus \\
\hline 4 & $\ulcorner\mathrm{Ihr} \rightarrow$ Erinnerung! $]$ & Erinnerung!/ \\
\hline $6-17$ & $\lceil$ THAGO $\rightarrow$ Jeder. $\urcorner]$ & ITHAGO $\rightarrow$ Jeder./ \\
\hline 8 & 「PÄGNIUM $\rceil]$ & \\
\hline $2-24$ & $\ulcorner$ Unter $\rightarrow$ angegriffen. $\urcorner]$ & IUnter $\rightarrow$ angegriffen./ \\
\hline 4 & $\left\ulcorner_{\text {wirl }}\right.$ & {$[\{\}$} \\
\hline 30 & $\lceil$ her $\urcorner]$ & Vher/ \\
\hline 34-35 & $\ulcorner$ Und $\rightarrow$ Phantasie. $\urcorner]$ & IUnd $\rightarrow$ Phantasie./ \\
\hline 37 & $\ulcorner$ Weiterspielen $\rceil$ & {$[\{w\}]|W|$ eiterspielen[,] } \\
\hline $37-38$ & $\ulcorner$ Rolle $\rightarrow$ Güte $\urcorner]$ & {$[\{$ Güte $\}] \mid$ Rolle $\rightarrow$ Güte $\mid$} \\
\hline
\end{tabular}


IDiotima Ich spiele nicht $\left\ulcorner\right.$ mit. ${ }^{\urcorner}$Ich sehe hier mehr. Ich fühle $\left.{ }^{\ulcorner}\right\urcorner$den Finger Gottes. Thago Wieso?

IDIOTIMA Gott hat uns geschlagen. Jetzt, da hier alles zerstört ist, seh ich erst, dass es ihn gibt.

5 Thago Der Über $\{$ schmock $\}$ !

IDiotima Spöttle nur - ich sehe ihn! Lieber Gott, komm nur nicht zu nah - nur nicht zu nah! -

(Stille)

GLORIOSUS Sie ist ${ }^{\text {überreizt. }}$

10 Thago Und ich bin müd. Wo ist mein Bett?

‘Aufseher Da!

GLORIOSUS Und mein Schild?

Paegnium Da!

IDiotima Und wo bin ich?

15 (Stille)

\Abbruch der Bearbeitung\

\begin{tabular}{rll}
\hline 1 & $\ulcorner$ mit. $\urcorner]$ & korrigiert aus: mit.. \\
1 & \ulcorner\urcorner$]$ & {$[\{$ scho $\}]$} \\
2 & \ulcorner\urcorner$]$ & {$[\{\}]$} \\
9 & $\ulcorner$ überreizt. $\urcorner]$ & [überreizt.] |überreizt.| \\
11 & $\ulcorner$ AufseHER Da! $\urcorner]$ & {$[$ PAEGNIUM] |AufseHER Da!| }
\end{tabular}


Strukturpläne in vier Bildern

ÖLA 3/W 125 - BS 58 f [1], Bl. 2v

1.) Voxder Villa.

IV $\mid \underline{V}$ MrR

$2 v$

2.) Va den $V_{i} U_{a}$.

3.) Vor Ner Villa, Eas Shearangenichy

4.) An̈f den Shavanmanlt.

Dordaciss - Marrosa.

Dedalusis Der Vesure hat gestean nimort.

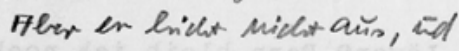

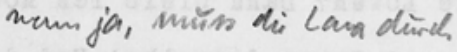

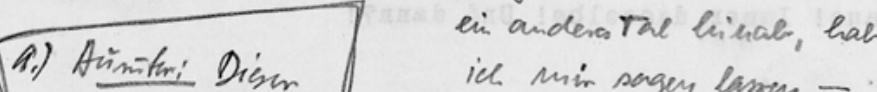

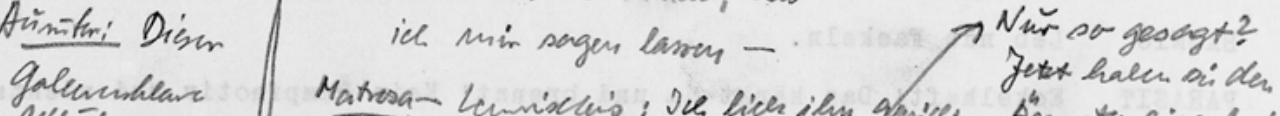

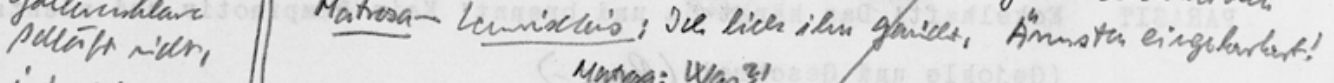
sote vider, en Marbas: Was?!

nidest Tog ind Nache!

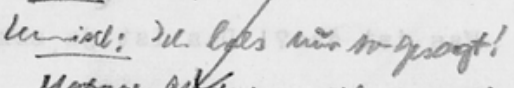

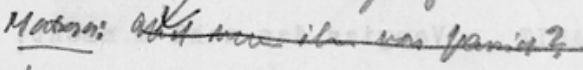

Uni Mus allem parsiot not uns!

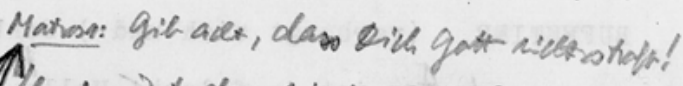

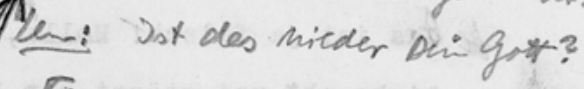

Pructor: [reanft Lemmiselenis]

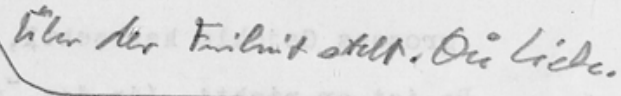

(4.) Bei Bagnio. Htohleg in Vesiñ

Bagnio / Parasit / Lemmisodenis / Totilis.

Pansit: Gestem hats arg gewachelt - was ist,

weun der Vesciv ainshicht?

Bagnia: Wir verhiecher ins ganz histors hin

ind dam geht alles i"hrs rino hiviney -

$x$

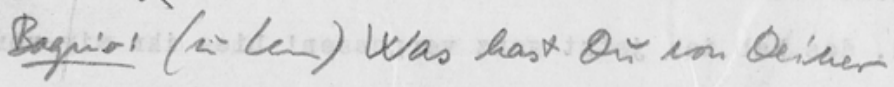

Frihix? Sits in cimen Höblel

Da ist \& hsser, wem On 2-Oordalis gehot!

Censides: Dri last nds.

Totilis: Aund iñusere lice?

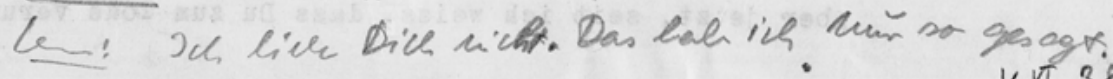

$v \sqrt{1}, 38[=4]$

438 
1.) Vor der Villa.

2.) Vor der Villa.

3.) Vor der Villa. [Das Sklavengericht]

4.) Auf dem Sklavenmarkt.

Dordalus - Matrosa.

Dordalus: Der Vesuv hat gestern rumort.

Aber er bricht nicht aus, und wenn ja, muss die Lava durch ein anderes Tal hinab, hab ich mir sagen lassen Nur so gesagt?

a.) Ausrufer: Dieser Galeerensklave schläft nicht, isst nicht, er rudert Tag und Nacht!

Matrosa- Lemniselenis : Ich liebe ihn garnicht. Ärmsten eingekerkert! Matrosa: Was?!

Lemnisel: Ich habs nur so gesagt!

Matrosa: Undwenn ihm was passiert?

Lem: Uns allen passiert was! was!

Matrosa: Gib acht, dass Dich Gott nicht straft! Lem: Ist das wieder Dein Gott?

[1.] Vor der Villa.

[2.] Vor der Villa

[Lemniselenis reitet fort]

[3.] Vor der Villa

[Das Sklavengericht]

Praetor: [kauft Lemniselenis]

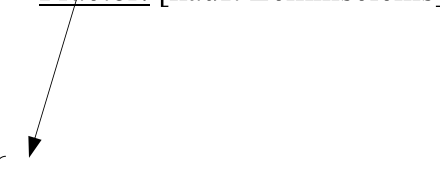

Matrosa: Es gibt etwas, das

über der Freiheit steht. Die Liebe.

$\mid E^{12} \backslash$

[4.] Bei Bagnio. [Höhleł im Vesuv]

Bagnio / Parasit / Lemniselenis / Toxilus.

Parasit: Gestern hats arg gewackelt - was ist, wenn der Vesuv ausbricht?

Bagnio: Wir verkriechen uns ganz hinten hin und dann geht alles über uns hinweg -

Bagnio: (zu Lem) Was hast Du von Deiner

Freiheit? \{W\} Sitzt in einer Höhle!

$\mathrm{Da}$ ist es besser, wenn Du zu Dordalus gehst!

Lemniselenis: Du hast recht.

Toxilus: Und unsere Liebe?

Lem: Ich liebe Dich nicht. Das hab ich nur so gesagt. 
Am nächsten Tage, wieder vor der Villa am Meer. Die Luxusgaleere ist fortgefahren, 5 nun liegt der Hafen still. Lemniselenis sitzt am Fusse der einen Säule und hält das Gesicht in den Händen verborgen. Matrosa sitzt neben ihr und strickt. Das Wetter ist noch immer schön.

Toxilus (kommt aus der Villa, erblickt Lemniselenis, hält und betrachtet sie; zu Matrosa) Was hat sie denn?

Matrosa Sie weint.

Toxilus Warum?

Matrosa Es ist ihr hier so gut gegangen und jetzt hat sie Angst vor der Zukunft.

Toxilus (grinst) Wie kann man nur!

15 Matrosa Speziell vor Dordalus zittert ihr Herzchen --

Toxilus Aber-aber! Dordalus in Pompeji ist zwar ein schleimiger Sklavenhändler, aber in dieser verdammten Branche gibts noch ganz andere Burschen -- da könnt ich erzählen!

Matros a (lacht) Ich auch!

20 Lemniselenis (sieht Toxilus zum ersten Male gross an) Ihr kennt Dordalus?

Toxilus Und ob! Er war es ja, der mich seinerzeit hierher verkauft hat.

LEMNiselenis „Verkauft“! Oh Götter, welch grausames Wort!

Matrosa ( $z u$ Lemniselenis) Lass Dich nicht so gehen!

LEMNISELENIS Ich gäb was drum, wenn ich nur nicht wieder auf den Sklavenmarkt

25 müsst -- (sie verbirgt wieder ihr Gesicht in den Händen)

Matrosa (fast entschuldigend $z u$ ToxiLus) Sie regt sich dabei immer so schrecklich auf.

Toxilus ( $z u$ Matrosa) Wie oft ist sie denn schon verkauft worden?

\| Matrosa Erst einmal. Aber sie hatte Pech. Die Firma Maximus in Herkulanum, die sie hierher verhandelt hat, hat sich richtig $\ulcorner$ schäbig $\urcorner$ benommen. Nichtmal eine eigene Kammer hatte das arme Mädel, musste in einem Raume hausen mit den letzten Galeerenruderern, diesem Abhub der Sklavenwelt! Schmutzig wie die Pest!

Toxilus Also beim Dordalus ist alles sauber, muss man ihm lassen. Peinlich sauber sogar! Adrett! Ich lag dort drei Wochen auf Lager, aber ich fand keine einzige Wanze.

Matrosa Das findet man allerdings selten, dass man keine findet!

LEMNISELENis (sieht Toxilus zum zweiten Male gross an) Ist er grob?

Toxilus (ein wenig verwirrt durch ihre Augen) Wer?

40 || Lemniselenis Dordalus.

Toxilus Keine Spur! Er ist ein subalternes Wesen.

LEMNISELENIS Wenigstens das. $\ulcorner\text { (sie starrt vor sich hin })^{\urcorner}$

$30 \quad\ulcorner$ schäbig $\urcorner]$

$42 \quad\ulcorner($ sie $\rightarrow$ hin $)\urcorner]$
Korrektur von fremder Hand: schäb[b]ig

V(sie [verbirgt wieder ihr Gesicht in den Händen)] |starrt $\rightarrow$ hin)|| 
ToxiLus Man kann mit ihm sogar reden und ich bin überzeugt, wenn Ihr artig zu ihm seid, verschafft er Euch \ulcorner\urcorner$\ulcorner$ einen $\urcorner$ bedeutend $\ulcorner$ besseren Posten! $\urcorner$ Keinen solchen $\ulcorner$ alten $\urcorner$ Kracher, wie meinen gnädigen Herrn, sondern einen eleganten, jungen -LEMNISELENIS (unterbricht ihn) Nur das nicht!

5 Toxilus (perplex) Was hör ich?

Matrosa ( $z u$ Toxilus) Sie möchte von der männlichen Jugend nichts wissen.

Toxilus (wie zuvor) Wieso warum denn nicht?

|| Lemniselenis Weil die jungen Herren nur an sich denken.

Toxilus So? Und an was denken denn noch die alten Herren, ausser an sich selbst?

LEMNISELENIS An den Tod. (sie lächelt kurz und verbirgt dann wieder ihr Gesicht in den Händen)

Toxilus (starrt sie an)

Matrosa ( $z u$ Toxilus) Wenns nach ihr ging, würde sie sich einen Herrn Gebieter aus dem Greisenasyl holen.

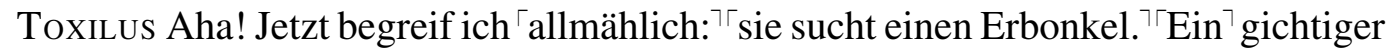
Greis, wacklig, zittrig, hirnrissig, der mit dem einem Haxen bereits durch die Unterwelt hatscht und von dem sich gar federleicht allerhand erben lässt -- schauschau! Eine geborene Krankenschwester!

LEMNISELENIS (sieht ihn $\ulcorner$ zum dritten Male $\urcorner$ gross an) Ihr versteht mich nur halb.

ToxiLus Kein Wunder! Denn jene Hälfte, dass Ihr nämlich von der männlichen Jugend überhaupt nichts wissen wollt -- diese Hälfte kapier ich allerdings überhaupt nicht!

LEMNISELENIS (erhebt sich) Diese Hälfte kann ich mir nicht leisten. (sie geht auf und $a b)$ Ihr dürft nicht annehmen, dass ich mit unerlaubten Mitteln, als da sind: böse Kräuter, Schlangengift, etcetera, das Ableben eines gebrechlichen Gebieters beschleunigen wollte. Ich würde auch nimmer ein massgebliches Wort in seinem Testament fälschen, aber ich tät ihm die Schrecken der Unterwelt ausmalen, und das fiele mir leicht, denn ich müsst ihm doch nur vom Schicksal der Sklaven auf der Oberwelt berichten. Die Haare würden ihm alle gen Himmel stehen und er würd mich vor lauter Grauen garantiert freikaufen, um nicht in der Unterwelt als Sklave verhandelt zu werden, als ein Ding mit menschlichen $\|$ Allüren -- Oh Götter, es fällt mir immer schwerer an Euere Güte zu glauben! Sagt mir: gibt es Euch denn überhaupt? Und wenn es Euch gibt, warum seid Ihr denn so böse zu mir? Wie gern würde ich gut sein --

Toxilus Das ist ein Traum.

Matrosa ( $z u$ Toxilus) Sie hat eine zarte Seele.

Toxilus ( $z u$ Matrosa) Was verstehst Du unter Seele?

LEMNISELENIS Was sich aus einem fortsehnt.

(Stille)

$\begin{array}{ll}\ulcorner\urcorner] & {[\backslash\{\text { noch }\} /]} \\ \ulcorner\text { einen }\urcorner] & \text { eineln/ } \\ \ulcorner\text { besseren Posten! }\urcorner & \text { bessereln/[Stelle noch als die da!] |Posten!| } \\ \ulcorner\text { alten }\urcorner] & {[\text { a } \mid \text { |allten }} \\ \ulcorner\text { allmählich: }:] & \text { allmählich[:[][|.|]|:| } \\ \ulcorner\text { sie } \rightarrow \text { Erbonkel. }\urcorner] & {[\text { lein Erbo/] [|da|] } \mid \text { sie } \rightarrow \text { Erbonkel.| }} \\ \ulcorner\text { Ein }\urcorner] & \text { korrigiert aus: ein } \\ \ulcorner\text { zum } \rightarrow \text { Male }\urcorner] & {[\text { plötzlich }] \mid \text { zum } \rightarrow \text { Male } \mid}\end{array}$


|| Matrosa ( $z u$ Toxilus) Sie hat nämlich nur einen Wunsch: keine Hetäre mehr sein zu müssen, heraus aus dieser Sklaverei -- endlich freigekauft zu werden! ( $z u$ LEM-

ÖLA 3/W $113-$ BS 58 b [2], BI. 36 NISELENIS) Nicht, Kindchen?

LEMNISELENIS (blickt vor sich hin; leise) Ja.

5 Toxilus Freigekauft? Ein grosses Wort!

Matrosa Fast zu gross -- (sie lächelt)

|| Toxilus (betrachtet schätzend Lemniselenis; $z u$ MAtrosa) Was würds denn kosten, wenn man sie freikaufen tät?

Matrosa Soviel ich weiss, $\left\ulcorner\right.$ zirka ${ }^{\urcorner}$sechshundert Silberlinge --

10 Toxilus Potz Pluto! Ein Vermögen!

LEMNISELENIS (horcht auf) Bin ichs nicht wert?

ToxiLus (grinst) Wahrscheinlich --

Lemniselenis (kurz) Danke.

(Stille)

15 Matrosa ( $z u$ Toxilus) Jetzt habt Ihr sie beleidigt. Macht es wieder gut.

$\|$ Toxilus ( $z u$ LemNiselenis) Es war nur ein $\ulcorner$ Scherz.

LEMNISELENIS (lächelt kalt) Lieb von Euch.

Toxilus (grinst) Ich tät Euch sogar freikaufen, wenn ich sechshundert Silberlinge hätt --

20 Lemniselenis (lacht kurz hellauf)

Toxilus Wer lacht da?

LEMNISELENIS Ich.

Matrosa ( $z u$ Toxilus) Ihr und sechshundert? Es ist alles möglich, aber das nicht! Toxilus Wer sagt das?

25 Matrosa Ich.

Toxilus Und ich sage: wenn ich will, leiht mir jederzeit jedermann sechshundert -Matrosa (fällt ihm ins Wort) Grössenwahn!

Toxilus Vergesst nur nicht, wer ich bin!

LEMNISELENIS Ein Sklave.

30 || Toxilus Gewiss! Jedoch während der Abwesenheit unserer Herrschaft wurde der Sklave Toxilus zum obersten Verwalter dieser Villa eingesetzt, verstanden?! Denn ich geniesse das restlose Vertrauen meines Herrn und könnte mir jederzeit auch sechstausend Silberlinge beschaffen, ich müsst nur was verkaufen, was nicht mir gehört oder irgendetwas unterschlagen, einen Wechsel fälschen oder

35 dergleichen!

Matrosa Ihr werdet Euch beherrschen!

Toxilus Ja.

Matrosa Na also!

Lemniselenis Schade. Denn der Mann, der mich freikaufen würde, der wäre der er-

40 ste und einzige Mann, den ich lieben könnte.

Toxilus (horcht auf)

Matrosa Alles Unsinn!

LEMNISELENIS Oho!

(Stille)

45 || Matrosa ( $z u$ Toxilus) Was starrt Ihr denn das Mädel so an?

$\begin{array}{rll}9 & \ulcorner\text { zirka }\urcorner & \text { zirk[a] }|\mathrm{a}| \\ 16 & \ulcorner\text { Scherz. }\urcorner & \text { [Witz.] } \mid \text { Scherz. }\end{array}$


Toxilus (einfach) Weil sie mir gefällt. Zu dumm, sie ist wirklich schön. Komisch, dass ich das erst jetzt bemerk --

Matrosa (erhebt sich; $z u$ Lemniselenis) $\ulcorner$ Komm $\urcorner$, Herrin, ziehen wir uns zurück -LEMNISELENIS (fällt ihr ins Wort) Nein.

5 Matrosa (unterdrückt, damit Toxilus nichts hört) Ich bitt Euch, macht keine Dummheiten, Ihr seid eine brave Hetär und jener ist ein Sklave! Das schickt sich nicht, der Kaiser hats verboten! Verdreht ihm nicht den Kopf!

LEMNISELENIS Ich verdreh ihn aber, verdreh ihn --

Matrosa (fällt ihr barsch ins Wort) Schluss! Kommt!

LEMNiselenis (herrscht sie an) Wer hat hier zu befehlen?! Du bist meine Sklavin, merkt Euch das endlich, Gnädigste!

Matrosa Die Sklavin einer Hetäre ist wie die Mutter einer freien Frau: ein schützender Geist.

Lemniselenis Behalt Deinen Schutz! Jetzt werd ich frei! ( $z u$ Toxilus) Also Ihr seid nun hier der Herr?

Toxilus (starrt sie noch immer an) Ja.

LEMNISELENIS Und alles muss Euch gehorchen?

Toxilus Alles.

LEMNISELENIS Ich auch?

20 Toxilus (stutzt) Hm. Eigentlich --

LEMNISELENIS Nun? Ja oder nein?

Toxilus (lächelt etwas verlegen) Nach den Gesetzen der Logik eigentlich ja --

Lemniselenis (fällt ihm ins Wort) Dann befehlt doch. Befehlt!

(Stille)

Toxilus (etwas verwirrt) Später! Sagt mal: kommt Ihr nicht aus Aegypten?

Lemniselenis Mein Vater ist Aegypter.

Toxilus Ich hörs an Euerem Akzent.

Lemniselenis Meine Wiege stand auf Lemnos, von wo die schönen Frauen stammen. Meine Mutter war Griechin. Aus Koroneia.

30 Toxilus Interessant!

Lemniselenis Arme Mama! Sie lebte nur kurz, mein Papa ass ihr alles weg.

Toxilus (perplex) Ass ihr weg?

$\|\ulcorner$ Lemniselenis Papa ist nämlich ein Parasit, ein Vielfrass, wie alle meine Vorfahren väterlicherseits. ${ }^{\ulcorner}$Nicht nur meine Mama, auch meine Freiheit wurde ein Opfer seiner Gier: er verschacherte mich als Sklavenkind für ein opulentes Menu.

ToxiLus Ein Unhold!

Lemniselenis Er konnt den Fasanen, Muränen und Hummern nicht $\ulcorner$ widerstehen? Die geschlachteten Tiere haben ihn überwältigt, sie wohnen in ihm und sitzen auf seinem Willen -- er kennt nur den Bauch, sonst nichts.

Lemniselenis (seufzt) Ja, meine Kindheit war traurig. Ewiger Zwist der Eltern, zerrüttete Familienverhältnisse -- (sie verbirgt wieder ihr Gesicht in den Händen) Matrosa (bei Seite) Was das Mädel aufführt!

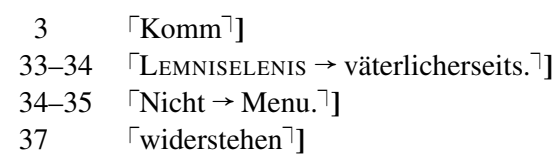

$\operatorname{Komm}[\mathrm{t}]$

Textentlehnung Plautus, PER ${ }^{5}$

Textentlehnung Plautus, $\mathrm{PER}^{13}$

korrigiert aus: wiederstehen 
Toxilus ( $z u$ Lemniselenis; ehrlich) Wie leid Ihr mir tut --

LEMNISELENIS (sieht ihn zum vierten Male gross an) Wirklich?

Toxilus Ja. Wenn ich Euch neben mir betrachte, gehts ja sogar mir noch besser: Als dreijähriger Knirps geriet ich in die Sklaverei, bei Babylon wurd ich gefangen -5 || Lemniselenis Ach, Ihr seid ein Perser?

Toxilus Keine Ahnung! Ob Perser, Grieche, Inder, Aegypter -- was weiss ich, woher ich stamm!

Lemniselenis Schad! Denn Perser sind interessant. Perser sind alle dunkel und ich bin blond.

10 Toxilus (lächelt) Wenn Ihr es wollt, dann werd ich ein Perser --

Lemniselenis (klatscht in die Hände) Fein!

Matrosa Wie man freiwillig ein Perser sein möcht, das geht über meinen Horizont.

Toxilus Warum?

Matrosa Weil alle Perser böse Menschen sind.

15 || Lemniselenis (lacht) Böse Menschen gibts überall!

(Stille)

Toxilus (tritt ganz dicht an Lemniselenis heran) Ihr sagtet zuvor, der Mann, der Euch die Freiheit brächte, dieser Mann wäre der einzige -- (er stockt)

|| LEMNisELENis Und Ihr sagtet zuvor, Ihr könntet Euch jederzeit auch sechstausend

$20 \quad$ Silberlinge beschaffen --

Toxilus Ja.

LEMNISELENIS (sieht ihn zum fünften Male gross an) Man liebt nur einmal im Leben.

Matrosa (hat gehorcht) Ich möcht nicht wissen, wie oft Ihr noch lieben werdet mit Eueren lumpigen achtzehn Jahren!

LEMNISELENIS (herrscht MATROSA an) Schweig! (sie wendet sich wieder Toxilus zu und lächelt melancholisch) Ich lebe nicht lang.

Toxilus (innig) Sei so gut --

LEMNISELENIS Wer hilft mir?

|| Toxilus (zuckt plötzlich zusammen) Au! (er fasst sich ans Herz und windet sich et30 was)

LEMNISELENIS (erschrickt) Was ist? Was habt Ihr?

Toxilus (leise) Mir scheint, ich bin verwundet -- so ein stechender Schmerz --

LEMNisELENIS Tuts weh?

Toxilus (lächelt) Nein.

35 (Die Luft klingt)

|| Lemniselenis (blickt empor und ruft) Amor, Amor! -- Dort fliegt er, dort!

Matrosa (blickt auch empor) Na servus!

LEMNISELENIS (überglücklich) Oh, jetzt fürcht ich nichtsmehr! Amor hat geholfen!

(Man hört von links Peitschengeknalle)

40 || DIE DREI (schrecken etwas zusammen und blicken nach links)

PAEgnium (läuft von links herbei, verfolgt von dem AufSEHER, der mit seiner Peitsche knallt)

$\ulcorner$ Aufseher (ausser Atem) Lausbub, elender! Ich soll ein Peitschenkuli sein?! Das wagst Du?! Mir, dem älteren Mann?!

45 PAEgniUm (frech) Du bist ein Sklav, genau wie ich!

43-44 「AUfSEHER $\rightarrow$ Mann?! $]$ Textentlehnung Plautus, PER ${ }^{10}$

45-445,4 「PAEGNIUM $\rightarrow$ Freund! $]$ Textentlehnung Plautus, PER ${ }^{11}$ 
Aufseher So? Na pass nur gut auf, was ich Dir geben werde!

Paegnium Nichts! Du hast ja nichts!

|| Aufseher Mich sollen doch alle Götter strafen --

PAEGNium (fällt ihm ins Wort) Das wünsch ich Dir auch als guter Freund!

5 Aufseher Jetzt steht die Welt nimmer lang! (er $\ulcorner$ stürz $t\urcorner$ sich mit seiner Peitsche auf Paegnium)

PAEgniUm (entkommt ihm jedoch in die Villa)

AufseHER (will ihm nach)

ToxiLus (vertritt ihm den Weg) Halt!

10 Aufseher (perplex) Warum?

Toxilus Heut wird hier nicht geprügelt, mein Freund, denn heute bin ich froh.

Aufseher Das ist mir ganz wurscht!

Toxilus Mir aber nicht!

Aufsener Das ist mir erst recht wurscht!

15 Toxilus (ruhig) Halt den Mund.

Aufseher (braust auf) Was erlaubst Du Dir --

Toxilus (unterbricht ihn donnernd) Wer ist hier die oberste Instanz?! Du oder ich?! Wer?!

AufseHER (wieder ruhig) Ich bin nicht taub.

20 Toxilus (auch wieder ruhig) Wer hat hier zu befehlen?

Aufseher Immer der, der fragt.

Toxilus Korrekt, sehr korrekt. Du kannst doch reiten?

AufseHER Reiten? Natürlich kann ich reiten! Ich bin ja sogar gewissermassen auf dem Pferd geboren.

Toxilus Man merkts noch immer. Höre: geh in den Stall und sattle die ${ }^{\ulcorner}$zwei $^{\urcorner}$schnellsten Stuten, das heisst -- (er wirft einen Blick auf Matrosa) drei Stuten, drei!

Aufseher (deutet auf Matrosa und ToxiLus) Ihr zwei braucht drei $\ulcorner$ Stuten?

Toxilus Frag nicht, sondern gehorche! Sattle-sattle!

Matrosa (deutet plötzlich nach links) Dordalus! Dort kommt er!

30 LeMNiselenis Oh! (sie schmiegt sich unwillkürlich an Toxilus)

DIE VIER (blicken nach links)

AufseHER Richtig! Unser aller Händler -- ein Reptil. Wenn ich nur $\ulcorner$ einmal $\urcorner$ frei wär, dann tät ich dem Kerl was erzählen -- so! (er knallt mit der Peitsche)

|| Toxilus (zum Aufsener) Erzähl uns da nichts, sondern sattle lieber! Marsch in den

35 Stall! Aber dass Du mir die Viecher nicht zu sehr schindest!

AufseHER (empört) Ich sollt ein Tier misshandeln?! Für was hältst Du mich?! (entrüstet $a b$ in den Hintergrund)

Matrosa (ängstlich) Toxilus, was habt Ihr vor?

ToxiLus Später! (er redet leise auf LEMNISELENIS ein)

40 Matrosa (horcht, hört aber nichts)

LEMNISELENIS (lauschte aufmerksam, gibt nun ToxiLus einen flüchtigen Kuss auf die Wange; leise) Wiedersehen -- (rasch ab in die Villa)

Matrosa (sieht ihr nach; sehr besorgt) Wohin? 
Toxilus Kannst Du reiten?

Matrosa Ich? Gottbehüte nein!

Toxilus Dann bleibst Du zurück.

Matrosa (entsetzt) Ihr werdet doch nicht fliehen?!

5 Toxilus Erraten.

Matrosa Verblendet, verblendet! Ihr endet noch am Galgen -- und das arme Mädel!

Toxilus (herrscht sie an) Prophezei hier nicht herum und mach mich nervös! Sonst häng ich Dich ins Meer hinein, mit dem Kopf nach unten, damit Dich die Polypen kitzeln!

10 Matrosa Nein, da tu ich nichtmehr mit! Wo ist der Stall?!

ToxiLus Sag ich nicht. Still!

|| Dordalus (kommt mit ZWEI GeHILFEn von links; er sieht aus, wie ein melancholischer Librettist; er hält und sieht sich um) Da wären wir. Säulen, als wärs ein Tempel des Jupiter, derweil ist es nur der ländliche Lustsitz eines alten Wucherers, Erpressers, Wechsel- und Kontofälschers, Witwen- und Waisengeldbehälters. Das lebt sich, diese Herren Punier -- (er erblickt ToxiLus) Ist das nicht Toxilus?

ToxILus (imitiert ihn) Ist das nicht Dordalus?

Dordalus (lächelt) Immer noch frech und frech! No wie gehts-wie stehts, Herr Baron? Was hat Dir der alte Dordalus gesagt vor acht Jahren? Lass Dich hierherverkaufen, hat er gesagt. No hab ich erraten? Ich find schon immer die passende Stell für das passende Material, ich hab einen Riecher.

Toxilus Ich bin Euch auch dankbar.

Dordalus Ein seltenes Wort! Denn besonders von Euch Sklavengesindel erntet man nichts als Undank, wo man sich Tag und Nacht abrackert, um Euch an ein solides Haus verkaufen zu können. Und dann verkauft man Euch noch mit Verlust, bloss damit Ihr es gut habt, man lebt ja schon nur für seine Herren Sklaven! Dich hab ich auch viel zu billig abgegeben, mies wirds mir, wenn ich Dich seh. Also sehen wir das Andere, diese Hetär, die ich mir da abholen soll. Lemniselenis heisst sie, damit man sich die Zung bricht, wenn man sie ruft -- lauter Rache!

Toxilus Sie ist die Schönste von Lemnos.

Dordalus Dein Wort in Gottes Ohr! Möglich ist alles! Sie stammt zwar vom Maximus in Herkulanum -- auch eine Firma! Lauter Tineff! Und ich soll sie jetzt da in Kommission verkaufen -- auch ein Geschäft, nichts verdient man dabei, nur Müh und Plag und Aufregerei! Und am End zahlt man wieder drauf! Also zeig sie schon her, führ sie vor, Deine Schönste aus Lesbos!

Toxilus Lemnos!

Dordalus Von mir aus! Also los-los! Wo steckt das Objekt?

Toxilus Wenn ich es wüsste!

40 Dordalus Was heisst das? Wie soll einer das verstehen?

Toxilus Sie ist plötzlich verschwunden.

(Stille)

Dordalus Du willst doch damit nicht andeuten, dass sie -- grosser Gott!

Toxilus Ja.

45

Dordalus (entsetzt) Geflohen?!

$\|$ Toxilus Ihr sagt es.

Dordalus Gott Du bist gerecht! Was Ihr da für Geschichten treibt! 
DoRdalus Sklaven gibts nur in der Mehrzahl, wenn einer was angestellt hat -- ist einer unverschämt, werden alle verprügelt, flieht einer, werden alle eingesperrt. Grosse Neuigkeit für Euch, was? Weil Ihr gar so geistreich glotzt!

Matrosa Wir haben diese Neuigkeit nur vergessen gehabt -- momentan.

5 Dordalus Die Hauptsach ist, Ihr erinnert Euch wieder! So wenig, wie ein Sklave ein Privatleben führen darf, so wenig darf er sich der Verantwortung an den Taten seiner Kollegen entziehen. Alle büssen immer für einen -- und in Euerer Haut möcht ich nicht stecken, wenn dann die Herrschaft aus der Sommerfrisch kommt -- wo der Herr Präsident eh so jähzornig sind! Und gar erst der Herr Schwiegersohn! $\mathrm{Na}$, Euere Buckel werdens spüren! Lebet wohl! (ab mit seinen GeHILFEN nach links)

Matrosa (fixiert Toxilus) Habt Ihr das gehört?

Toxilus Ja. Das hab ich allerdings vergessen, dass alle hier darunter leiden werden. Matrosa Was tun?

Toxilus Da sie am Papier bereits geflohen ist, soll sie auch in der Praxis fliehen. Es bleibt dabei.

Matrosa Schämst Du Dich denn nicht alle diese unschuldigen Menschen hineinzureiten?

Toxilus Nein. Denn ich möchte, dass sie frei wird. Das ist mehr $\left\ulcorner\right.$ wert. Wir ${ }^{\urcorner}$reiten jetzt fort -- ich bringe sie in Sicherheit.

Matrosa Und dann ist sie frei? (höhnisch)

Toxilus Nein. Dann treib ich morgen das Geld auf. Richt es ihr aus, sie sitzt im Keller --

Matrosa Einen solchen Unsinn richte $\ulcorner$ ich $\urcorner$ nicht aus! Das Mädel bleibt da!

Toxilus Weib, bring mich nicht zur Raserei!

|| Aufseher (kommt rasch aus dem Hintergrund) He, Toxilus! Ist das wahr, dass die Hetär wegreiten darf?!

ToxiLus Wer sagt das?

30 Aufseher Sie selber hats zu mir gesagt! Grad zuvor, Du hättest es ihr erlaubt --

Matrosa Sie ist fortgeritten?!

$\ulcorner$ AufseHER $\urcorner\ulcorner$ Ja. In $\urcorner$ Galopp.

Toxilus ALLEIN?!

AufseHer Natürlich! Mit wem denn?!

35 Matrosa Um Gottes Willen! Jetzt ists zu spät!

AUfSEHER (horcht auf)

Toxilus Wie konnt sie auch nur ohne mir wegreiten, ich hab doch gesagt sie soll auf mich warten! Wer löst mir das Rätsel?

Matrosa Ich. Sie wollte Euch los werden!

40 Toxilus Das ist nicht wahr, das ist eine niederträchtige Lüge!

Matrosa Ach, Ihr seid ja von Amor ganz verrückt gemacht?

Aufseher $\ulcorner$ Amor?! Ist $\urcorner$ sie geflohen?!

$19\lceil$ wert. Wir $\urcorner$

$24\ulcorner\mathrm{ich}\urcorner]$

26\lceil\urcorner$]$

$32\lceil$ AUFSEHER $\urcorner]$

$32\lceil\mathrm{Ja} . \mathrm{In}\urcorner]$

$42\ulcorner$ Amor?! Ist $\urcorner]$ korrigiert aus: wert.Wir

korrigiert aus: ihr

gestrichen: Aufseher He, Toxilus!

korrigiert aus: AUFSE ER

korrigiert aus: Ja. In

korrigiert aus: Amor?! Ist 
Matrosa Ja.

Aufseher ( $z u$ Toxilus) Und Du hast das arrangiert?! $\ulcorner$ Du?! $\urcorner$ Na wart, dich $\ulcorner$ krieg ich $\urcorner$ noch!

Toxilus Wenn ich nur wüsst, wo sie hingeritten ist, damit ich ihr nachkann!

5 Aufseher Du wirst hier garnirgends nach! Jetzt bring ich Dich vor unser Gericht! Dort verantworte Dich! Sie werden Dich verurteilen!

Toxilus Ich nehme keine Strafe an! 


\section{|| DRITTES BILD}

Wieder vor der Villa am Meer. Es ist Nacht geworden und der Mond scheint hell. Alle SklaVen und Sklavinnen, noch mit ihren Masken, sind versammelt, denn es 5 tagt das Sklavengericht. Auf einer provisorisch errichteten Erhöhung sitzt der VoRSITZENDE, neben ihm ZWEI BeIsitzer. Der Aufseher fungiert als Ankläger. Toxilus steht vor seinen Richtern. Matrosa hockt wieder etwas abseits auf den Stufen der Villa, verfolgt jedoch mit regem Interesse die Verhandlung.

10「AUfSeher .......

VORSITZENDER Toxilus, trete vor!

$\ulcorner$ LEMNISELENIS $\urcorner$

Toxilus (tritt vor)

VoRsitz Du hast die Anklage gehört, die jener vorgebracht hat. Es wird Dir zur Last gelegt, dass Du Deine Pflichten gegenüber Deinen Mitsklaven in einer durchaus egoistischen, herrischen Weise verletzt hast. Du hast nicht an uns gedacht, hast nicht daran gedacht, dass immer alle büssen müssen für $\left\ulcorner\right.$ einen. Bekennst ${ }^{\urcorner} \mathrm{Du}$ Dich schuldig?

Toxilus Nein. Ich sehe keine Schuld. Denn ich wollte einen Sklaven freikaufen, und für den Freikauf eines Sklaven kann ein jeder von uns etwas abkriegen --

Vorsitz Das ist schon richtig. Aber Du hast ihn aus herrischen Motiven freikaufen wollen, $\left.{ }^{\ulcorner}\right\urcorner$rein willkürlich. Wenn Du schon einem was gutes tust, dann hättest Du Dir den aussuchen müssen, der es am meisten braucht!

SkLAVIN Kauf eine arme Sklavin frei! Keine Reiche!

Toxilus Oh Schwester! Was weisst Du von der reichen Sklaven Leid? ---- ihr ${ }^{\ulcorner}$Herz liegt ${ }^{\urcorner}$auf Stein.

(Murren)

Vorsitz (klopft mit einem Hammer) Ruhe! Also Du bekennst Dich nicht schuldig?

30 || Toxilus Nein. Und ausserdem lehne ich Euer Gericht ab, ich will vor ein ordentliches Gericht gestellt werden --

Vorsitz Toxilus! Du weisst, warum wir hier richten! Du weisst, dass ein Sklave vor einem ordentlichem Gerichte nie Recht bekommt! Du willst hier gegen uns reden, gegen unser Recht! Schäm Dich, Toxilus!

Toxilus Ich schäme mich nicht! Aber Ihr macht es genau so, wie die Anderen mit ihrem Gericht! Auch Ihr wollt mich verurteilen, weil $\left\ulcorner\right.$ ich ${ }^{\urcorner} \operatorname{mir}^{\ulcorner}$erlaubt $^{\urcorner}$habe, mal an mich zu denken, und nur an mich!

VoRsitz Nur an Dich? Erkläre Dich!

$\ulcorner$ ToxILus Ich bin verliebt! Ich liebe Lemniselenis --

\begin{tabular}{|c|c|c|}
\hline 10 & $\ulcorner$ AufSEHER ....... $]$ & \AufseHER ......./ \\
\hline 12 & $\ulcorner$ LEMNISELENIS $\urcorner]$ & /LEMNISELENIS/ \\
\hline 17 & $\lceil$ einen. Bekennst $\urcorner]$ & korrigiert aus: einen.Bekennst \\
\hline 22 & \ulcorner\urcorner$]$ & [weil Du Dich interessierst,] \\
\hline $26-27$ & $\ulcorner$ Herz liegt $\urcorner]$ & korrigiert aus: Herznliegt \\
\hline 36 & $\ulcorner\mathrm{ich}\urcorner]$ & korrigiert aus: Ihr \\
\hline 36 & $\ulcorner$ erlaubt $\urcorner]$ & korrigiert aus: erla bt \\
\hline $39-450,4$ & $\lceil$ Toxilus $\rightarrow$ usw) $\urcorner]$ & Textentlehnung Plautus, $\mathrm{PER}^{2}$ und $\mathrm{PER}^{3}$ \\
\hline
\end{tabular}


Vorsitz Ja, lieben $\ulcorner$ denn $\urcorner\ulcorner$ Sklaven $\urcorner$ auch?

Toxilus Was soll ich tun? Den Göttern trotzen? Bin ich ein Titane? Wer als armer Mann in die Pforten der Liebe eingedrungen ist, (usw) $)^{\urcorner}$

ToxiLus Nehmt mal Euere Masken ab, Euere Masken, voller Sorgen und Grauen, was steckt dahinter?! Seht Euch mal an! Hättet Ihr es nicht auch getan: Hand aufs Herz!

VoRsitz (erhebt sich und nimmt die Maske ab, alle auch) Höre das Urteil: $`$ Wir alle --(usw) $)^{\top}$

Toxilus ( $($ Verteidigungsrede $\urcorner)$ Ihr habt alle mir gedankt -- lasst mich auch mal Euch danken!

15

Vorsitz Das ist alles recht schön und gut. Aber Gesetz muss Gesetz bleiben, es gibt keine Ausnahmen. Du wirst verurteilt.

Toxilus Aber, wenn es auch Gesetz ist, so muss es eben geändert werden! Es muss doch ein jeder Sklave das Recht haben zu lieben, das Naturrecht, -- so denkt doch mal, denkt!

$\ulcorner$ SKLAVEN Wir denken (usw) $\urcorner$

$\ulcorner($ Stille $)$

Matrosa Habt Ihr gehört, dass es einen neuen Gott geben soll?

Vorsitz Ich verkünde das Urteil: Toxilus, Du wirst ${ }^{\ulcorner}$in den leeren Brunnen gesperrt, bis unsere Herrschaft kommt, damit die unseren guten Willen sieht. ${ }^{\urcorner}$Fasst ihn! Toxilus (zieht ein Schwert unter seinem Mantel hervor) Zurück! Jetzt verkünde ich Euch das Urteil: Ihr seid eine blöde Bagage, Ihr seid es wert, dass Ihr Sklaven seid, denn Ihr könnt nicht denken! Niedrig seid Ihr, usw!

\begin{tabular}{|c|c|c|}
\hline 1 & $\ulcorner$ denn $\urcorner]$ & korrigiert aus: den \\
\hline 1 & $\lceil$ Sklaven $\rceil$ & korrigiert aus: SKlaven \\
\hline $10-11$ & $\ulcorner$ Wir $\rightarrow$ usw $)\urcorner]$ & vgl. $\mathrm{K}^{4} / \mathrm{TS}^{2} / \mathrm{A}^{3} / \mathrm{BS} 30$ a, BI. $34 \mathrm{f}$. \\
\hline 13 & $\ulcorner$ Verteidigungsrede $\urcorner]$ & korrigiert aus: verteidingsrede \\
\hline 21 & $\lceil$ SKLAVEN $\rightarrow$ usw) $\urcorner]$ & vgl. $\mathrm{K}^{4} / \mathrm{TS}^{2} / \mathrm{A}^{3} / \mathrm{BS} 30$ a, Bl. 39 \\
\hline $22-30$ & $\ulcorner($ Stille $\rightarrow$ Vorhang $)\urcorner]$ & $\backslash($ Stille $\rightarrow$ Vorhang $) /$ \\
\hline $25-26$ & $\ulcorner$ in $\rightarrow$ sieht. $\urcorner]$ & [zum Tode verurteilt.] lin $\rightarrow$ sieht.| \\
\hline
\end{tabular}





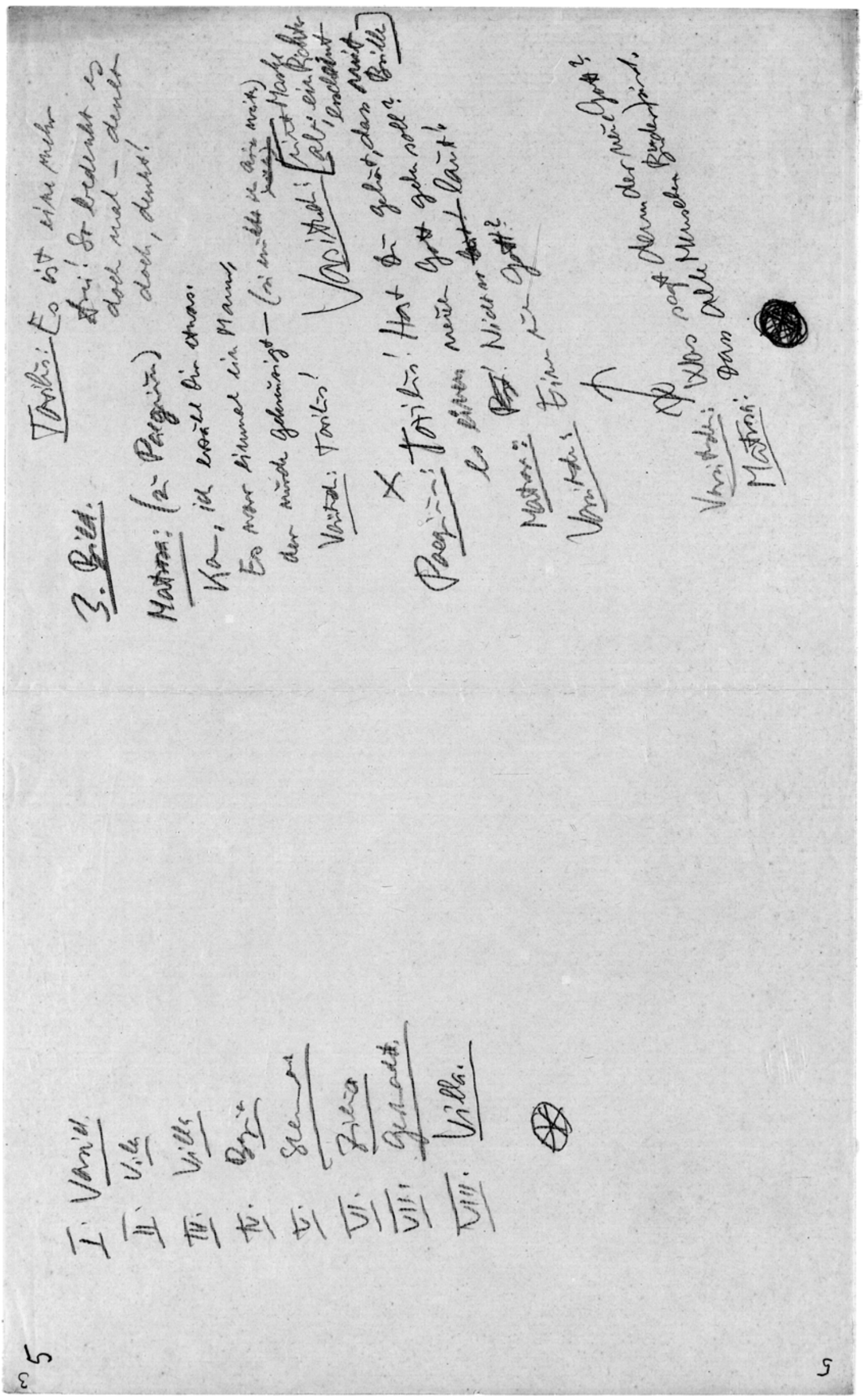




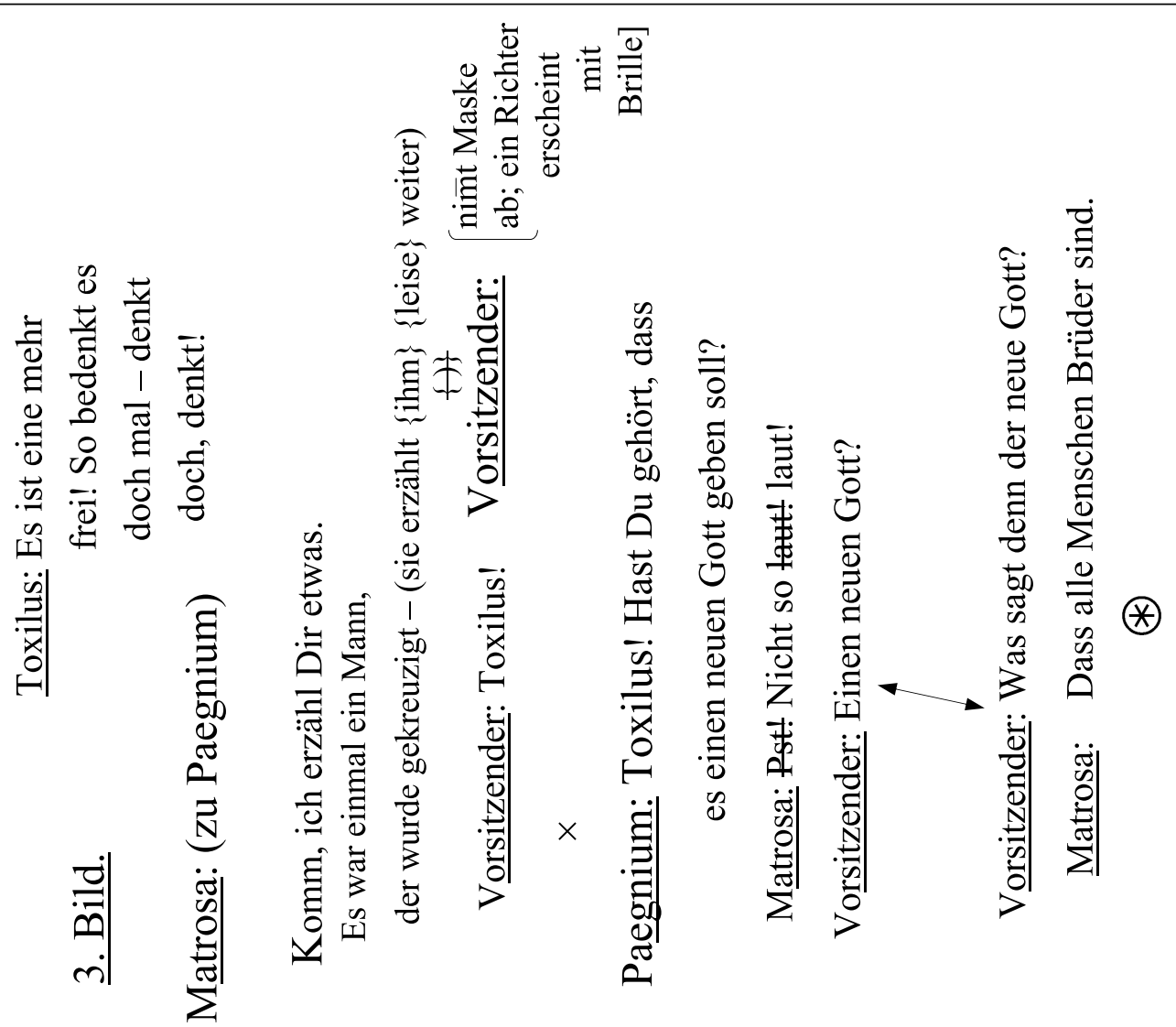

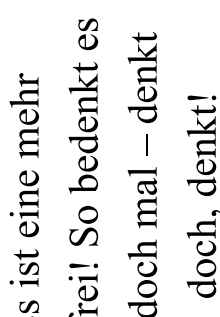

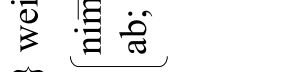

กั่ 乌 : 表 丞 寻

ำ 
